\title{
Dinámicas productivas en torno al cambio de uso del suelo y sus repercusiones en la Reserva de Biósfera Maya (RBM) en Petén, Guatemala
}

Aldo Rodas

Iliana Monterroso

Dietmar Stoian 
Working Paper 1

\section{Dinámicas productivas en torno al cambio de uso del suelo y sus repercusiones en la Reserva de Biósfera Maya (RBM) en Petén, Guatemala}

Aldo Rodas

Iliana Monterroso

Dietmar Stoian 
Working Paper 1

\section{(C) 2021 CIFOR-ICRAF}

El contenido de esta publicación se encuentra bajo una licencia Creative Commons Attribution 4.0

International (CC BY 4.0), http://creativecommons.org/licenses/by/4.0/

DOI: $10.17528 /$ cifor/008390

Rodas, A., Monterroso, I. y Stoian, D. 2021. Dinámicas productivas en torno al cambio de uso del suelo y sus repercusiones en la Reserva de Biósfera Maya (RBM) en Petén, Guatemala. Working Paper 1. Bogor, Indonesia: Centro para la Investigación Forestal Internacional (CIFOR); y Nairobi, Kenia: Centro Internacional de Investigación Agroforestal (ICRAF).

\section{CIFOR}

JI. CIFOR, Situ Gede

Bogor Barat 16115

Indonesia

$T+62$ (251) 8622-622

$F+62$ (251) 8622-100

E cifor@cgiar.org

\section{ICRAF}

United Nations Avenue, Gigiri

PO Box 30677, Nairobi, 00100

Kenya

$\mathrm{T}+254207224000$

$\mathrm{F}+254-20-7224001$

E worldagroforestry@cgiar.org

\section{cifor-icraf.org}

Quisiéramos agradecer a todos los socios financieros que apoyaron esta investigación a través de sus contribuciones al Fondo de CGIAR. Para ver la lista de donantes del Fondo, visite: http://www.cgiar.org/about-us/our-funders/

Cualquier opinión vertida en este documento es de los autores. No refleja necesariamente las opiniones de CIFOR-ICRAF, de las instituciones para las que los autores trabajan o de los financiadores. 


\section{Indice}

Agradecimientos $\quad$ vi

Resumen $\quad$ vii

Introducción viii

1 Reseña de la historia reciente de Petén (1990 - 2021) 1

1.1 Algunos indicadores de los cambios en Petén 8

2 Principales cambios económico-productivos en Petén 11

2.1 Industria forestal 11

2.2 Industria de turismo 18

$\begin{array}{ll}2.3 \text { Industria de fruticultura } & 19\end{array}$

2.4 Industria de granos básicos $\quad 20$

2.5 Industria ganadera 20

2.6 Industria de palma africana 22

2.7 Impactos de las dinámicas económicas sobre los bosques 24

3 La inversión pública en Petén 31

3.1 Inversión por tipo de fondo $\quad 31$

3.2 Inversión por sector 34

4 Discusión: Implicaciones para la gestión de recursos y la RBM 36

5 Conclusiones $\quad 40$

$\begin{array}{ll}\text { Bibliografía } & 41\end{array}$ 


\section{Lista de figuras y cuadros}

\section{Figuras}

1. Línea de tiempo (1990-2021) visualización de los cambios más importantes a nivel del departamento de Petén

2. Población estimada basada en número de estudiantes $2000-2009$

3. Dinámica de crecimiento poblacional $2002-2018$ por municipio. 9

4. Dinámica de crecimiento de la red de carreteras en Petén 2000 - 2020

5. Ubicación de Areas Protegidas de Petén, RBM y Sistema de Areas Protegidas del Sur de Petén 12

6. Distribución de ingresos a nivel de nueve Empresas Forestales Comunitarias EFC que manejan concesiones comunitarias

7. Distribución del ingreso obtenido en las EFC, a nivel de empleo y a nivel de repartición de dividendo

8. Area y monto relacionado con la implementación de programas de incentivos forestales en Petén (1998-2020)

9. Ubicación de áreas bajo programas de incentivos forestales (2021)

10. Area y monto de inversión de incentivos forestales PINFOR-PROBOSQUE

11. Mapa de adjudicación de concesiones industriales del FYDEP (1980) y actual zonificación de las áreas protegida de Petén (1990)

12. Distribución de ganaderos y ganadería de Petén fuera de areas protegidas 2021

13. Dinámica de crecimiento del cultivo de palma africana en Petén 2000 - 2020 en la región sur de Petén

14. Dinámica de la adquisición de fincas por parte de las empresas palmeras en la región sur de Petén (2017-2019)

15. Cobertura forestal de Petén 2000 - 2016

16. Área de pérdida de bosque y crecimiento agropecuario en el período 2000-2016

17. Análisis de cambios a nivel de cuadrantes

18. Cuadrante 1 principales cambios de uso de la tierra 2000-2020

19. Cuadrante 2 principales cambios de uso de la tierra $2000-2020$

20. Cuadrante 3 principales cambios de uso de la tierra 2000-2020

21. Cuadrante 4 principales cambios de uso de la tierra 2000-2020

22. Cuadrante 5 principales cambios de uso de la tierra 2000-2020

23. Incremento de la red de carreteras dentro del PNLT Parque Nacional Laguna de Tigre (2000-2020)

24. Inversión en el periodo 2005-2019 a través del aporte a consejos de desarrollo 32

25. Inversión en el periodo 2009-2020 a través del FONPETROL 33

26. Inversión en el periodo 2005-2020 a través del Consejo de Desarrollo de Petén (tres fuentes) 33

27. Sectores de inversión de CODEDE (tres fuentes) para el periodo 2005-2019 34

28. Inversión municipal en relación con el número de habitantes 35

29. Análisis de la inversión pública con distintos Fondos del CODEDE (tres fuentes) de Petén, distribución a municipios

30. Continuidad del proceso catastral del FYDEP en regiones prioritarias de Petén

31. Continuidad del proceso catastral del FYDEP e INTA y culminación por parte del RIC en la ZAM-RBM 


\section{Cuadros}

1. Petén principales acontecimientos y cambios sociales $(1990-1999)$

2. Petén principales acontecimientos y cambios sociales (2000-2021) 4

3. Dinámica de crecimiento del sistema de caminos (asfalto y terracería) en el periodo 2000 - 2020 de Petén $\quad 10$

4. Dinámica de la venta de madera en distintos períodos de tiempo 18

5. Dinámica de crecimiento en ganadería para el periodo 2000 - 2020 de Petén 21

6. Distribución de plantaciones de palma africada en municipios de Petén 23

7. Cobertura forestal de Petén (2000 - 2016) 25

8. Parámetros de origen (2000-2003) y situación actual (2016-2020) para los principales usos de la tierra en Petén $\quad 26$

9. Resumen de los valores brutos anuales (US\$) generados por las principales industrias del Petén, 2010-2020 $\quad 31$

10. Inversión pública en función del tipo de aporte 31

11. Análisis comparativo para diferentes parámetros estudiados y su relación con los cambios ocurridos en el periodo $2000-2020$ 


\section{Agradecimientos}

Este trabajo se llevó a cabo en el marco de los programas de investigación de CGIAR sobre Políticas, Instituciones y Mercados (PIM), dirigido por el Instituto Internacional de Investigaciones sobre Políticas Alimentarias (IFPRI), y sobre Bosques, Árboles y Agroforestería (FTA), dirigido por CIFOR. Este documento de trabajo no ha seguido el procedimiento estándar de revisión por pares del IFPRI. Las opiniones aquí expresadas corresponden a los autores y no reflejan necesariamente las opiniones de CIFOR, PIM, IFPRI, CGIAR o los patrocinadores financieros. Agradecemos la colaboración de los técnicos del Centro de Monitoreo y Evaluación de CONAP que dirigieron el ánalisis de información geográfica bajo la dirección de Julian Zetina, y al Ing. Wyllsson Martínez e Inga. Ana Castellanos del Instituto Nacional de Bosques (INAB) por su apoyo en proporcionar y colaborar con el análisis de información sobre incentivos forestales. Los datos sobre los aportes al Consejo de Desarrollo fueron aportados por SEGEPLAN a través del Ing. Gerson Tillit. 


\section{Resumen}

Este documento de trabajo busca aportar información socio-ambiental que permita contribuir a papel cambiante de los bosques en la historia reciente de Petén. Analiza las dinámicas de cambio de uso de suelo que muestran diferencias a nivel de los espacios de la región, especialmente durante los últimos 20 años que lleva establecida la Reserva de Biósfera Maya en Petén, Guatemala. Tiene como objetivo comprender los factores que han incidido en las dinámicas diferenciadas de uso de suelo en Petén, enfocándose en analizar los principales cambios económico-productivos a nivel de 1 departamento de Petén que implican trayectorias diferentes de uso de la tierra, así como sus implicaciones para la gestión de los recursos naturales a nivel de la RBM. Partiendo de una combinación de métodos cualitativos y cuantitativos y análisis de información geográfica busca aportar datos e información a los diversos procesos sobre la toma de decisiones en materia de recursos naturales. Los resultados apuntan a cambios en las trayectorias de política que tienen impactos en la percepción de los bosques, el uso de la tierra y la relación entre las poblaciones locales y los recursos naturales.

El documento está organizado en cuatro secciones. Inicia con una breve reseña histórica del departamento, haciendo énfasis en la etapa reciente (1990-2021). La segunda sección presenta los principales cambios económicos relacionados con sectores productivos que tienen un impacto en los cambios de uso de la tierra. Se enfoca en las actividades económico-productivas priorizadas en el eje de desarrollo económico territorial planteados en el Plan de Desarrollo Integrado de Petén 2032 enfocándose en las principales industrias de la región. La tercera sección se enfoca en analizar la inversión pública en el departamento. Finalmente, partiendo de los resultados presentados, el documento presenta una discusión y conclusiones en relación a las implicaciones en la gestión de la RBM.

Los resultados muestran como intervenciones de política pública influyen en trayectorias diferentes de uso de la tierra con implicaciones diversas para la gestión de recursos y específicamente a nivel de la RBM. Analizando acontecimientos claves, los cambios en las intervenciones del Estado y las respuestas de los actores en el territorio generan trayectorias diferentes con implicaciones para la gestión de los recursos y el manejo de la RBM. El análisis de estas trayectorias evidencia algunos de los desafíos de articular las necesidades de desarrollo con la gestión de recursos - con implicaciones para el uso de la tierra diferentes. Este estudio apunta a la necesidad de profundizar en estos hallazgos para promover alternativas de desarrollo que concilien las necesidades de desarrollo con la conservación - de manera que articule la participación de las comunidades, la generación de oportunidades que incorporen de manera más clara el rol de la gestión de recursos a escala regional. 


\section{Introducción}

A nivel mundial, se estima que las comunidades locales y los Pueblos Indígenas poseen hasta el 65\% de la tierra disponible bajo tenencia consuetudinaria, pero solo el $18 \%$ de esta tierra ha sido reconocida formalmente como propiedad o designada para su uso (RRI 2015). En 2020, al menos el 31\% de la superficie terrestre (571 Mha) estaba bajo algún tipo de régimen de tenencia colectiva, la mayoría bajo propiedad de los Pueblos Indígenas, comunidades locales y afrodescendientes, ya sea de propiedad y gestión consuetudinaria o designadas para su uso, mientras que 137 Mha permanecen legalmente sin reconocer (RRI 2020). En términos de tierras forestales, en 2017, casi el 29,9\% de los bosques en América Latina estaban bajo algún tipo de régimen de tenencia colectiva bajo propiedad de las comunidades, y otro 6,3\% de la superficie había sido designado para su uso (RRI 2020). El $59 \%$ restante es propiedad del Estado o está administrado por él (RRI 2020).

Durante décadas América Latina ha sido testigo de amplias reformas políticas que redefinieron los derechos de tenencia sobre los recursos naturales como resultado de los cambios en la normativa sobre quién gobierna la apropiación y el uso de los bosques y las tierras (Larson et al. 2010; Monterroso et al. 2019). Estas reformas son el resultado de las luchas sociales, pero también de cambios en políticas de gobierno que promovieron el reconocimiento de derechos sobre las tierras y los bosques (Roldán, 2004). De hecho, en la región, una porción importante de la tierra se encuentra bajo régimen de tenencia colectiva de comunidades locales y/o Pueblos Indígenas incluyendo México (52\%), Perú (35\%), Colombia (34\%), Brasil (23\%) y Nicaragua (28\%) (IBC 2016; Larson et al. 2016; Herrera 2017).

A nivel de Centroamérica los mecanismos utilizados por los Estados varían, en casos como Honduras y Nicaragua (Larson et al. 2015; Sylvander 2021; Herlily and Tappan 2019), donde se han reconocido territorios de Pueblos Indígenas. En Guatemala, el reconocimiento de derechos ha estado marcado por el surgimiento de esquemas que permitan la coadministración de los bosques. La Reserva de la Biosfera Maya (RBM) en Petén, Guatemala, es un ejemplo destacado de devolución exitosa de los derechos sobre los bosques a las comunidades locales. La RBM tiene un enorme valor ambiental y cultural de importancia global. Resguarda una amplia diversidad de ecosistemas naturales, algunos de ellos únicos e íntegros, así como de especies vegetales y animales, tales como mamíferos, reptiles, aves residentes y migratorias, anfibios y peces endémicos (CONAP 2015). Asimismo, la RBM alberga sitios arqueológicos de renombre mundial que se benefician de una cobertura forestal intacta en sus alrededores.

Desde 1990, bajo la supervisión del Consejo Nacional de Áreas Protegidas (CONAP), la RBM constituye la mayor área protegida (2,1 millones de hectáreas) del país y los mayores bosques tropicales de Centroamérica. La RBM se encuentra ubicada en el departamento de Petén, el cual abarca el 40\% de la superficie territorial de Guatemala. Mas del 70\% de la extensión del departamento se encuentra bajo algún tipo de régimen de conservación. Sin embargo, a pesar de la porción importante del territorio que se encuentra bajo conservación desde entonces, la historia de Petén ha estado marcada por intervenciones del Estado, especialmente desde mediados de 1950, para promover la integración de los bosques a la economía y promover el desarrollo bajo un fuerte énfasis agropecuario. Estos cambios en las dinámicas de cambio de uso de suelo muestran diferencias a nivel de los espacios de la región, especialmente durante los últimos 20 años que lleva de establecida la RBM. Para comprender mejor los factores que han incidido en esta dinámica tan diferenciada en Petén, este estudio brinda un análisis reciente desde el punto de vista del cambio de uso de suelo vinculado a actividades económico-productivas - en algunos casos ligados a intervenciones del Estado, a partir de tres preguntas clave: 
1. ¿Cuáles son los principales cambios económico-productivos a nivel de Petén?

2. ¿Qué intervenciones de actores gubernamentales y/o privados explican las diferentes trayectorias de uso de la tierra en Petén?

3. ¿Qué implicaciones tienen estos hallazgos en la gestión de los recursos naturales y específicamente a nivel de la RBM?

En esta investigación utilizamos una combinación de métodos cualitativos y cuantitativos. A nivel de las herramientas utilizadas, se combinó la revisión de literatura, entrevistas a informantes clave incluyendo representantes de organismos gubernamentales, $\mathrm{ONG}$, investigadores, organizaciones comunitarias y empresas del sector privado, visitas de campo, grupos de discusión y la experiencia de trabajo combinada de los autores en la región.

Además, se revisaron datos cuantitativos de fuentes oficiales y herramientas de información geográfica ${ }^{1}$ para presentar los resultados de forma visual. El análisis se enfoca en acontecimientos recientes (19902021) y busca aportar datos e información a los diversos procesos sobre la toma de decisiones en materia de recursos naturales. Los resultados apuntan a cambios en las trayectorias de política que tienen impactos en la percepción de los bosques, el uso de la tierra y la relación entre las poblaciones locales y los recursos naturales. Este documento busca aportar información socio-ambiental que permita contribuir el papel cambiante de los bosques en la historia reciente de Petén.

El documento está organizado en cuatro secciones. Inicia con una breve reseña histórica del departamento, haciendo énfasis en la etapa reciente (1990-2021). La segunda sección presenta los principales cambios económicos relacionados con sectores productivos que tienen un impacto en los cambios de uso de tierra. Se enfoca en las actividades económico-productivas específicamente a partir de industrias que dependen del uso de la tierra y los recursos, las cuales fueron priorizadas en el eje de desarrollo económico territorial planteados en el Plan de Desarrollo Integrado de Petén 2032 (SEGEPLAN, 2013). La tercera sección se enfoca en analizar la inversión pública en el departamento. Finalmente, partiendo de los resultados presentados, el documento presenta una discusión y conclusiones en relación a las implicaciones en la gestión de la RBM.

1 El análisis de información geográfica fue liderado por técnicos del Centro de Monitoreo del CONAP. Los datos utilizados son oficiales y fueron elaborados bajo la dirección de Julian Zetina del Centro de Monitoreo y Evaluación de CONAP, con excepción de la información de incentivos forestales (los cuales fueron proporcionados y trabajados en conjunto con el Ing. Wyllsson Martínez e Inga. Ana Castellanos del Instituto Nacional de INAB). La información de aportes al Consejo de Desarrollo que fueron aportados por SEGEPLAN a través del Ing. Gerson Tillit. 



\section{Reseña de la historia reciente de Petén (1990 - 2021)}

Para ilustrar la perspectiva del Estado, identificamos políticas, regulaciones y planes cuya implementación en combinación con acontecimientos específicos reflejan cambios en la visión sobre los bosques. El texto prioriza acontecimientos que inciden en cambios en las dinámicas de uso del suelo como por ejemplo la ampliación de la red de carreteras y los cambios en los principales sistemas productivos. Parte de esta discusión se basa en el análisis de tres períodos históricos (siguiendo a Monterroso et al. 2018) que reflejan un giro importante en la perspectiva que el Estado tiene sobre los bosques y la gestión de los recursos forestales:

1. Petén antes de la RBM: La integración de los bosques a la economía nacional - (1959-1988);

2. La creación de la RBM: Los bosques como un espacio de protección $(1989-2000)$ y

3. Los desafíos por consolidar la RBM: Reconsiderando el papel de los bosques como oportunidad de crecimiento económico (2000 - actualidad).

Una síntesis de los principales procesos se muestra en la Figura 1, al final de esta sección. El primer período, desde los años 60 hasta finales de los 80 , fue una etapa de colonización, en la que los bosques se consideraban principalmente una fuente de materias primas para la economía extractiva. En este período la colonización de los bosques fue la principal política de desarrollo con el objetivo de incrementar la productividad y asegurar la integración económica y política de la región (Melville y Melville 1971). Las políticas implementadas durante este período se centraron en promover el desarrollo agrario a través de la colonización de los bosques - para superar el aislamiento de las tierras forestales, percibidas como un obstáculo para el desarrollo y promover la extracción de recursos de alto valor comercial - madera, chicle y petróleo-. La implementación de estas políticas estuvo a cargo de la Empresa de Fomento y Desarrollo Económico de Petén (FYDEP), una entidad que dependía de la presidencia y estuvo liderada principalmente por personal militar (Casasola 1968; Pellecer 2010), operó durante casi tres décadas (1959-1986). Como resultado de estas políticas, se incrementa el número de personas que llegan a Petén en busca de tierra. La tasa de inmigración alcanzó su nivel más alto en 1970 y comienza a estabilizarse recién hasta 1990s (Grandia et al. 2001; Carr 2008). De los acontecimientos más importantes de este período, en 1970 se habilita la carretera de terracería de Santa Elena a, Poptún; en 1981 se inaugura el Aeropuerto Mundo Maya; en 1985 se aprueba la nueva Constitución Política de Guatemala, y se asigna un artículo al departamento de Petén (Artículo15 transitorio), declarando de emergencia nacional la inclusión del departamento de Petén a la economía nacional.

Este estudio se concentra en particular en datos desde el segundo período, desde principios hasta finales de los años 90, dado que marca una nueva forma de ver los bosques como un recurso natural a proteger. Este período está marcado por la creación de la RBM (1990) un ejemplo del giro en las políticas del Estado en torno al departamento. El interés internacional sobre la protección y conservación ambiental coincide con la negociación de los Acuerdos de Paz y el retorno a elecciones democráticas. Una reforma constitucional en 1985 establece las bases para la regulación y la institucionalidad ambiental en el país. En 1989 se crea el Consejo Nacional de Áreas Protegidas, CONAP ente rector del Sistema Guatemalteco de Áreas Protegidas SIGAP. Esto incluye el área que ocupaba la antigua reserva forestal del FYDEP. Cuatro complejos de Áreas Protegidas, se establecen en el sur de Petén en 1995 (411 mil hectáreas).

En el norte de la región, el establecimiento de la RBM conlleva la rezonificación, dividiendo el área en tres zonas de manejo, bajo objetivos de conservación. Dichas zonas son, de acuerdo a su Plan Maestro (CONAP, 2001): 
1. Zonas núcleo $(36 \%, 767,000 \mathrm{ha})$, integrada por parques nacionales y biotopos protegidos, son áreas silvestres y arqueológicas protegidas, donde no se permite asentamientos humanos, ni extracción de recursos para mantener los procesos naturales.

2. Zona de usos múltiple, ZUM (40\%, 848,440 ha) permite a grupos organizados el acceso y uso de los recursos bajo sistemas de aprovechamiento sostenible.

3. Zona de amortiguamiento, $(24 \%, 497,500$ ha.). Esta franja, situada al sur de la reserva, es un área en donde se permite actividades agrícolas, pecuarias y extractivas bajo esquemas de ordenamiento territorial, prácticas sostenibles y asentamientos humanos.

El establecimiento de la RBM es uno de los cambios más significativos en la visión del Estado sobre los bosques.

La implementación de esta política de conservación a nivel regional se consolida en el Plan de Desarrollo Integral de Petén (1992), uno de los primeros instrumentos de ordenamiento y planificación del territorio a nivel del país (UNEPET y APESA, 1992). A pesar de este cambio drástico, en el sur de Petén las políticas de desarrollo agrario mantienen la trayectoria iniciada durante el período anterior, promoviendo la expansión de la ganadería y la agricultura (Clark, 2000). Mientras que el interés por continuar la actividad de extracción petrolera en el norte, dentro de una zona de alta prioridad para la conservación, Laguna del Tigre, evidencia las contradicciones entre el nuevo planteamiento de conservación y la falta de un consenso sobre como manejar los recursos estratégicos de la región. Durante esta etapa, y en respuesta a lo que originalmente se concebía como una protección total, las protestas sociales condujeron a acuerdos entre el CONAP, por un lado, y las comunidades locales, las empresas madereras y los promotores turísticos, por otro, que condujeron a un punto intermedio, es decir, la conservación de los bosques a través de la gestión sostenible de los recursos. Una síntesis de los principales acontecimientos y cambios sociales y económicos se presenta en el Cuadro 1.

Cuadro 1. Petén principales acontecimientos y cambios sociales (1990 - 1999)

\begin{tabular}{|c|c|c|}
\hline Año & Acontecimiento & Cambios sociales y económicos en la región de Petén \\
\hline 1990 & $\begin{array}{l}\text { Se crea la Reserva de la Biosfera } \\
\text { Maya (Decreto 5-90). }\end{array}$ & $\begin{array}{l}\text { La RBM tiene un área de } 21,602 \mathrm{~km}^{2}(60.24 \% \text { de Petén }) \\
\text { dividida en tres zonas de manejo. El área protegida ocupa el } \\
\text { espacio que anteriormente fue destinado a una reserva forestal } \\
\text { por parte del FYDEP. }\end{array}$ \\
\hline 1992 & $\begin{array}{l}\text { Se actualiza el Plan de Desarrollo } \\
\text { Integrado (PDI) a través de la } \\
\text { cooperación internacional de } \\
\text { Alemania (GTZ). }\end{array}$ & $\begin{array}{l}\text { El PDI de Petén da seguimiento a una planificación anterior } \\
\text { (la del FYDEP) que propone una reserva forestal a norte del } \\
\text { paralelo } 17.10 \text { y al sur la parte designada a ser colonizada y } \\
\text { para agricultura/ganadería. }\end{array}$ \\
\hline 1994 & $\begin{array}{l}\text { Se otorga la primera concesión } \\
\text { forestal comunitaria (San Miguel La } \\
\text { Palotada), con un área de } 7,039 \mathrm{Ha} \\
\text { en acompañamiento del CATIE. }\end{array}$ & $\begin{array}{l}\text { Con esta primera concesión forestal se inicia un proceso ante } \\
\text { CONAP, mediante el cual la Zona de Usos Múltiples (ZUM) es } \\
\text { propuesta para un manejo forestal sostenible. Posterior a San } \\
\text { Miguel llega La Pasadita (en 1997) con un área mayor sobre la } \\
\text { misma ruta a Carmelita e Impulsores Suchitecos en } 1998 \text { del } \\
\text { lado de Melchor de Mencos. }\end{array}$ \\
\hline 1994 & $\begin{array}{l}\text { Se crea el Viceministerio Encargado } \\
\text { de Asuntos de Petén del MAGA } \\
\text { (Acuerdo Gubernativo 316-94). }\end{array}$ & $\begin{array}{l}\text { Esta iniciativa refleja una decisión del Estado de organizar } \\
\text { su Ministerio de Agricultura y Ganadería a través de } 3 \\
\text { viceministerios temáticos y uno territorial, el Viceministerio } \\
\text { de Asuntos Específicos de Petén. Se justifica por ser el } \\
\text { departamento más grande, con amplias zonas fronterizas } \\
\text { con México y Belice, así como el crecimiento en temas de } \\
\text { ganadería, agricultura de granos básicos y recursos naturales. }\end{array}$ \\
\hline 1995 & $\begin{array}{l}\text { Se establece el Sistema de Áreas } \\
\text { Protegidas del Sur de Petén } \\
\text { (Decreto 64-95). }\end{array}$ & $\begin{array}{l}\text { La Ley de Áreas Protegidas del Sur de Petén, se integran por } \\
\text { cuatro Complejos en el sur del departamento. }\end{array}$ \\
\hline 1996 & Se firma el Acuerdo de paz. & $\begin{array}{l}\text { Se consolida la ampliación del área asignada para el } \\
\text { otorgamiento de concesiones comunitarias en la ZUM. }\end{array}$ \\
\hline
\end{tabular}




\begin{tabular}{|c|c|c|}
\hline Año & Acontecimiento & Cambios sociales y económicos en la región de Petén \\
\hline 1997 & $\begin{array}{l}\text { Inicia el programa de Incentivos } \\
\text { Forestales de Guatemala (PINFOR) } \\
\text { administrado por el INAB y Petén } \\
\text { como departamento se constituye } \\
\text { en una sola región (VIII) de la } \\
\text { institución. }\end{array}$ & $\begin{array}{l}\text { El Instituto Nacional de Bosque (INAB) posterior a DIGEBOS } \\
\text { y precedido por INAFOR - se plantea como la entidad de } \\
\text { gobierno posterior a FYDEP en la gestión de bosques y en } \\
\text { particular de aspectos maderables). INAB inicia en Petén con } \\
\text { cuatro subregiones, constituyéndose en una región de amplia } \\
\text { cobertura para el tema de reforestaciones. Posteriormente } \\
\text { empresas reforestadoras llegan a Petén con la finalidad } \\
\text { de aprovechar dos aspectos: la disponibilidad de tierra ya } \\
\text { legalizada (con títulos de propiedad) y la opción que ofrece la } \\
\text { recepción de incentivos forestales por el INAB. }\end{array}$ \\
\hline 1998 & $\begin{array}{l}\text { Se establece la Unidad Técnica } \\
\text { Jurídica UTJ - PROTIERRA y el } \\
\text { primer proyecto piloto de catastro } \\
\text { a nivel nacional en el Municipio de } \\
\text { San Francisco. }\end{array}$ & $\begin{array}{l}\text { Se inicia un proceso de catastro en el municipio de San } \\
\text { Francisco, que posteriormente traerá un seguimiento de la } \\
\text { legalización de tierras del resto de Petén. Este es el primer } \\
\text { proyecto de catastro a nivel nacional. Otros proyectos de } \\
\text { catastro y legalización de tierra continúan en los municipios } \\
\text { de La Libertad y Sayaxché. A nivel de la RBM, la legalización } \\
\text { de tierras se da en la Zona de Amortiguamiento (ZAM), } \\
\text { exceptuando la ZUM y los PN de la RBM. La UTJ Protierra, } \\
\text { da seguimiento a la antigua asignación de tierras por parte del } \\
\text { FYDEP. }\end{array}$ \\
\hline 1998 & $\begin{array}{l}\text { La concesión forestal comunitaria } \\
\text { de Impulsores Suchitecos logra } \\
\text { obtener la Certificación Forestal del } \\
\text { FSC }(01 / 12 / 1998) \text { y posteriormente } \\
\text { todas las otras concesiones la } \\
\text { obtienen. }\end{array}$ & $\begin{array}{l}\text { Manteniendo las clausulas establecidas en los contratos de } \\
\text { obtener la certificación en los tres primeros años después } \\
\text { de la firma, las demás concesiones otorgadas obtienen la } \\
\text { certificación forestal del Forest Stewardship Council (FSC). }\end{array}$ \\
\hline 1998 & $\begin{array}{l}\text { Temporada de incendios más } \\
\text { drástica en la RBM y plaga de } \\
\text { gorgojo del pino ataca los bosques } \\
\text { de Poptún. }\end{array}$ & $\begin{array}{l}\text { Se pide ayuda internacional para mitigar los incendios, se } \\
\text { cierra el aeropuerto internacional Mundo Maya por el humo } \\
\text { generado y los fuegos se apagan finalmente con la llegada de } \\
\text { las lluvias. Paralelamente, en el sur, los pinares de Poptún se } \\
\text { ven muy afectados por la plaga del Gorgojo del Pino. }\end{array}$ \\
\hline 1999 & $\begin{array}{l}\text { Inicia el cultivo de Palma Africana } \\
\text { en Petén. }\end{array}$ & $\begin{array}{l}\text { Se establecen las primeras áreas de cultivo de palma africana } \\
\text { en el municipio de Sayaxché. Este cultivo } 20 \text { años después } \\
\text { representara una cobertura de } 68,740.18 \text { Ha en Sayaxché y } \\
78,921.02 \text { Ha en todo Petén (llegando a San Luis, Poptún, El } \\
\text { Chal, San Francisco y San Andrés) }{ }^{2} \text {. }\end{array}$ \\
\hline 2000 & $\begin{array}{l}\text { Inauguración de la carretera } \\
\text { asfaltada Petén - Guatemala ( } 7 \text { de } \\
\text { Enero })^{3}\end{array}$ & $\begin{array}{l}\text { Propiciando un amplio incremento poblacional en Petén, } \\
\text { aumentó el flujo comercial entre Petén y el resto del país. Entre } \\
\text { este año y el año } 2010 \text { se incrementan en } 509 \mathrm{~km} \text { asfaltados en } \\
\text { Petén (rutas hacia Melchor, el Naranjo Frontera y Sayaxché). } \\
\text { Petén pasa de tener } 366,735 \text { habitantes en } 2002 \text { a } 545,600 \text { en } \\
2018 \text { (con lo que crece en un } 149 \% \text { en un periodo de } 16 \text { años). }\end{array}$ \\
\hline
\end{tabular}

Un tercer período se caracteriza por el renovado interés en promover el desarrollo a partir de actividades que promuevan el crecimiento económico y la inversión público-privada en la RBM (Ver Cuadro 2). Prevalece la visión de conservación, y se consolida la implementación de políticas y planes que promueven el petróleo y turismo. Se estima que entre 1990 y el año 2,000 cerca de 150 millones de dólares son invertidos por USAID y otros donantes para operativizar el manejo de la RBM (Gnych et al. 2021). Estas concesiones tienen como antecedente un proceso de manejo forestal establecido en las cooperativas del Usumacinta, donde ya había iniciado el aprovechamiento forestal bajo planificación (Monterroso 2015).

2 https://www.grepalma.org/wp-content/uploads/2020/04/Anuario_estadistico_2018_2019.pdf

3 https://culturapeteneraymas.wordpress.com/2011/08/07/antecedentes-historicos-de-la-carretera-flores-poptun-guatemala/ 
La revisión de la política sobre concesiones y la continuidad del apoyo al sistema, permite avances importantes en las actividades de manejo forestal en la ZUM. Los documentos de planificación elaborados durante este período evidencian esfuerzos por articular las acciones de conservación con propuestas de desarrollo económico (SEGEPLAN 2013; CONAP 2015). A nivel social, conflictos en torno a la compatibilidad de modelos propuestos evidencia las contradicciones por articular una visión que concilie los diversos intereses a nivel territorial. A pesar de que se logra estabilizar las tasas de pérdida de bosque en algunas zonas de manejo, el escaso financiamiento asignado al CONAP pone en duda la prioridad que el Estado otorga a las áreas protegidas (Bovarnick et al. 2010). Además, dificulta los esfuerzos de control y vigilancia que no logran articular el apoyo de comunidades locales. En algunas zonas, la pérdida de gobernabilidad evidencia los fuertes desafíos para asegurar la presencia del Estado y el cumplimiento de los objetivos de conservación en regiones aisladas de la RBM (Sesnie et al. 2017).

Cuadro 2. Petén principales acontecimientos y cambios sociales (2000-2021)

\begin{tabular}{|c|c|c|}
\hline Año & Acontecimiento & Cambios sociales y económicos en la región de Petén \\
\hline 2001 & $\begin{array}{l}\text { Declaratoria de Petén como } \\
\text { área libre del Mosca del } \\
\text { Mediterráneo. }\end{array}$ & $\begin{array}{l}\text { Casi todo Petén es declarado como área libre de la Mosca del } \\
\text { Mediterráneo, con lo cual se abre un amplio espacio de oportunidad } \\
\text { para el fomento de la fruticultura. Esto da pie al establecimiento de la } \\
\text { misión China-Taiwán en la región de La Libertad y el impulso de un } \\
\text { cultivo de papaya, que se convertiría en un referente a nivel de la región. }\end{array}$ \\
\hline 2002 & $\begin{array}{l}\text { Declaratoria de Zona } \\
\text { Arqueológica Especial Cuenca } \\
\text { Mirador (Acuerdo gubernativo } \\
\text { 129-2002) }\end{array}$ & $\begin{array}{l}\text { Este acuerdo declara el manejo de una zona especial en el borde de El } \\
\text { Mirador, ampliando el área a zonas que se encuentran bajo contrato de } \\
\text { concesión, pero es derogado en } 2005 \text {. }\end{array}$ \\
\hline 2002 & $\begin{array}{l}\text { Se consolida la firma de } \\
\text { contratos de concesión forestal } \\
\text { a comunidades e industria. }\end{array}$ & $\begin{array}{l}\text { Un total de } 12 \text { concesiones comunitarias y dos industriales fueron } \\
\text { otorgadas en la ZUM, dejando áreas sin otorgar: tres corredores } \\
\text { biológicos, una zona entre El Mirador y concesión La Gloria } \\
\text { (denominada Lechugal), y el triángulo Candelaria (ubicado entre } \\
\text { la concesión Paxbán y el PNLT). Otras zonas de la ZUM como el } \\
\text { triángulo Candelaria son afectadas por ocupaciones ilegales (incluida } \\
\text { la denominada Laguna Larga donde se implementa una orden de } \\
\text { desalojo con fuertes conflictos sociales). }\end{array}$ \\
\hline 2004 & $\begin{array}{l}\text { Se amplía el catastro en el } \\
\text { departamento de Petén, a través } \\
\text { de UTJ CATASTRO. }\end{array}$ & $\begin{array}{l}\text { Con financiamiento del Proyecto de Administración de Tierras PAT } \\
\text { financiado por Banco Mundial (en dos fases) (las zonas de Mopán, y } \\
\text { San Luis). Se realizaron readecuaciones de catastros digitales (CATIE, } \\
\text { CARE y ALBORA). }\end{array}$ \\
\hline 2006 & $\begin{array}{l}\text { Se inaugura el Rastro Ganadero } \\
\text { de La Libertad (el mayor y más } \\
\text { moderno de Centro América })^{4}\end{array}$ & $\begin{array}{l}\text { Establecido en el municipio de La Libertad, cuenta con una inversión } \\
\text { mayor a } 17 \text { millones de quetzales (más de USD2 millones). Se } \\
\text { establece como respuesta al amplio crecimiento de la ganadería en } \\
\text { el departamento de Petén (la cual en su mayoría vino de la costa sur } \\
\text { del país, derivado del desplazamiento de la actividad por el valor de } \\
\text { las tierras, los procesos de legalización y la ampliación de cultivos } \\
\text { de caña, y palma africana). El rastro cuenta con amplia capacidad y } \\
\text { tecnología, pero su funcionamiento es costoso y requiere de una gran } \\
\text { cantidad de animales sacrificados por día, para lograr su rentabilidad. } \\
\text { Petén paso de tener } 315,819 \text { cabezas de ganado en } 2003 \text { a } 1,031,292 \\
\text { en } 2014 \text { y se estima que para el año } 2021 \text { habrán } 1,536,714 \text {. }\end{array}$ \\
\hline
\end{tabular}

4 https://www.engormix.com/MA-porcicultura/noticias/guatemala-inauguran-rastro-libertad-t11744/p0.htm 


\begin{tabular}{|c|c|c|}
\hline Año & Acontecimiento & Cambios sociales y económicos en la región de Petén \\
\hline 2008 & $\begin{array}{l}\text { Se inaugura el Centro de } \\
\text { Mejoramiento Genético de } \\
\text { Ganado de La Libertad }\end{array}$ & $\begin{array}{l}\text { El centro de mejoramiento genético de ganado se establece también } \\
\text { como respuesta al amplio crecimiento de la ganadería en Petén, } \\
\text { intentando mejorar las razas de ganado (especialmente engorde y } \\
\text { crianza) mediante generación de semen de razas especializadas. } \\
\text { Se queda a cargo del MAGA y es puesto a funcionar por medio } \\
\text { de sementales importados y adquiridos a través de la cooperación } \\
\text { internacional (EEUU). Su funcionamiento no crea el impacto que se } \\
\text { esperaba, contando con poco interés del sector ganadero y con poca } \\
\text { capacidad del MAGA para mantenerlo activo. }\end{array}$ \\
\hline 2008 & $\begin{array}{l}\text { Se aprueba Ley de } \\
\text { FONPETROL (Decreto } \\
\text { 71-2008) que permite a las } \\
\text { Municipalidades recibir un } \\
\text { porcentaje por la extracción de } \\
\text { hidrocarburos }^{6} \text {. }\end{array}$ & $\begin{array}{l}\text { Este fondo viene a dinamizar la inversión por parte de municipalidades } \\
\text { de Petén. Desde el año } 2009 \text { al año } 2020 \text { FONPETROL ha generado } \\
\text { Q. 921,685,258.31(más de USD } 122 \text { millones) en regalías. }\end{array}$ \\
\hline 2008 & $\begin{array}{l}\text { Se concluye carretera asfaltada } \\
\text { hacia el naranjo frontera y } \\
\text { aduana el Ceibo, en los bordes } \\
\text { del Parque Nacional Laguna de } \\
\text { Tigre. }\end{array}$ & $\begin{array}{l}\text { Clave por el acceso rápido y seguro hacia los Estados del Sur de } \\
\text { México. Esta ruta no se ha logrado potenciar desde el punto de vista } \\
\text { comercial o turístico, sin embargo, desarrolla un papel importante } \\
\text { para la conexión fronteriza y facilitar las actividades de extracción de } \\
\text { petróleo del Pozo Xan. }\end{array}$ \\
\hline 2008 & $\begin{array}{l}\text { Desalojos en parques } \\
\text { nacionales. }\end{array}$ & $\begin{array}{l}\text { Se registran varios desalojos en comunidades ubicadas en diversas } \\
\text { zonas de la RBM, especialmente en ubicaciones cercanas a los } \\
\text { parques de Sierra de Lacandon (comunidades Arroyo Macabilero, } \\
\text { Pollo Solo y Nueva Esperanza) }\end{array}$ \\
\hline 2008 & $\begin{array}{l}\text { Lanzamiento del Proyecto } 4 \\
\text { Balám. }\end{array}$ & $\begin{array}{l}\text { El gobierno de Álvaro Colom lanza el proyecto } 4 \text { Balam que propone } \\
\text { la creación de un proyecto arqueológico }{ }^{7} \text {, dicho proyecto no logra } \\
\text { realizarse. }\end{array}$ \\
\hline 2009 & $\begin{array}{l}\text { Se cancela la concesión forestal } \\
\text { de San Miguel La Palotada y } \\
\text { se suspende el Plan de Manejo } \\
\text { de concesión La Pasadita. } \\
\text { Resolución No. 05/08/2009 y } \\
\text { Resolución 01/02/2009. }\end{array}$ & $\begin{array}{l}\text { En el año 2009, CONAP cancela el derecho de Concesión Forestal a } \\
\text { San Miguel y suspende el plan de manejo de La Pasadita, por perder } \\
\text { su certificación y otras irregularidades. }\end{array}$ \\
\hline 2010 & $\begin{array}{l}\text { Propuesta de iniciativa de } \\
\text { ley No. } 4234 \text { de } 2010 \text { para } \\
\text { declarar Cuenca Mirador (no se } \\
\text { aprueba). }\end{array}$ & $\begin{array}{l}\text { En una segunda oleada de presión por parte del proyecto Cuenca } \\
\text { Mirador, respaldado por fundaciones privadas. }\end{array}$ \\
\hline 2011 & $\begin{array}{l}\text { Municipios del departamento } \\
\text { empiezan a recibir regalías } \\
\text { atrasadas desde el año } 2008 \text { de } \\
\text { FONPETROL }\end{array}$ & $\begin{array}{l}\text { Producto de la explotación petrolera y junto a la ampliación del } \\
\text { contrato de concesión para la explotación petrolera por } 20 \text { años más, } \\
\text { la municipalidades reciben Q. } 267,961,684.41 \text {, un aporte record de } \\
\text { FONPETROL. }\end{array}$ \\
\hline 2011 & $\begin{array}{l}\text { Se crea el Municipio de Las } \\
\text { Cruces (Decreto 32-2011). }\end{array}$ & $\begin{array}{l}\text { Petén llega a tener } 13 \text { municipios. El área de Las Cruces se deriva del } \\
\text { municipio de La Libertad }\end{array}$ \\
\hline 2012 & $\begin{array}{l}\text { Un gran año para el sector } \\
\text { Turismo en Petén. }\end{array}$ & $\begin{array}{l}\text { La celebración del } 13 \text { Baktun trae consigo un buen año para el sector } \\
\text { turismo, que recibe amplia visitación, por toda la publicidad dada } \\
\text { a esta fecha. En este año se da un amplio auge a El Mirador, como } \\
\text { destino turístico. }\end{array}$ \\
\hline
\end{tabular}

5 https://www.engormix.com/MA-porcicultura/noticias/guatemala-inauguran-rastro-libertad-t11744/p0.htm\#: :text=El\%20 rastro\%20de\%201a\%20Libertad\%2C\%20Pet $\% \mathrm{C} 3 \% \mathrm{~A} 9 \mathrm{n} \% 2 \mathrm{C} \% 20 \mathrm{es} \% 20$ considerado $\% 20$ como $\% 20 \mathrm{el}, \mathrm{de} \% 2017 \% 20$ millones\%20de\%20quetzales

6 https://www.elconfidencial.com/mercados/2008-11-18/congreso-de-guatemala-aprueba-ley-que-crea-fondo-conganancias-de-petroleras_942917/

7 https://www.skyscrapercity.com/threads/4-balam-el-parque-arqueológico-mas-grande-de-guatemala.1185801/ 


\begin{tabular}{|c|c|c|}
\hline Año & Acontecimiento & Cambios sociales y económicos en la región de Petén \\
\hline 2012 & $\begin{array}{l}\text { Inauguración de centro de } \\
\text { capacitación técnica INTECAP } \\
\text { en Petén. }\end{array}$ & $\begin{array}{l}\text { Ampliación de oferta de carreras técnicas a la población petenera. Este } \\
\text { centro se establece en la carretera que conduce de San Benito a San } \\
\text { Francisco. }\end{array}$ \\
\hline 2012 & Actualización del PDI de Petén. & $\begin{array}{l}\text { En seguimiento al primer PDI (1992) la Secretaría de Planificación } \\
\text { y Programación de la Presidencia SEGEPLAN elabora entre el año } \\
2012 \text { y } 2013 \text { el Diagnóstico y el Plan de Desarrollo Integrado de } \\
\text { Petén, herramienta para la gestión y planificación del desarrollo del } \\
\text { departamento. }\end{array}$ \\
\hline 2013 & $\begin{array}{l}\text { FUNDESA - Plan de turismo } \\
\text { en Cuenca Mirador y otros } \\
\text { sitios. }\end{array}$ & $\begin{array}{l}\text { Derivado de la propuesta de Ley } 4234 \text { (2010) para declarar Cuenca } \\
\text { Mirador, se hace gestión para crear el Plan de turismo en la cuenca El } \\
\text { Mirador. }\end{array}$ \\
\hline 2014 & $\begin{array}{l}\text { Se crea el Municipio de El Chal } \\
\text { (Decreto 5-2014). }\end{array}$ & $\begin{array}{l}\text { Petén llega a tener } 14 \text { municipios. El área de El Chal se deriva del } \\
\text { municipio de Dolores. }\end{array}$ \\
\hline 2015 & $\begin{array}{l}\text { Se aprueba la ley } \\
\text { PROBOSQUE (Decreto } \\
\text { 2-2015). }\end{array}$ & $\begin{array}{l}\text { La Ley de Fomento al Establecimiento, Recuperación, Restauración, } \\
\text { Manejo, Producción y Protección de Bosques en Guatemala -también } \\
\text { denominada PROBOSQUE continúa el programa de incentivos } \\
\text { forestales en Petén, con montos más altos para la protección de } \\
\text { bosques, mecanismos que permiten acceder a los incentivos bajo } \\
\text { tierras en posesión, se agregan sistemas agroforestales y otras } \\
\text { modalidades de incentivo (como restauración). }\end{array}$ \\
\hline 2015 & Desalojo de UM La Colorada. & $\begin{array}{l}\text { Posterior a un proceso de cancelación de la concesión forestal } \\
\text { comunitaria La Colorada (que operó del año } 2000 \text { al 2013) se procedió } \\
\text { a desarrollar el desalojo de la comunidad, requiriendo la presencia } \\
\text { permanente del CONAP y el Ejército para resguardar el área. }\end{array}$ \\
\hline 2019 & $\begin{array}{l}\text { En Estados Unidos, se presenta } \\
\text { al senado la propuesta de Ley } \\
\text { S3131. }\end{array}$ & $\begin{array}{l}\text { Propuesta de Ley para la creación de la Alianza de Seguridad y } \\
\text { Conservación Maya de la Cuenca Mirador-Calakmul (Guatemala y } \\
\text { México), con una asignación presupuestaria de USD62 millones de } \\
\text { dólares generando un gran debate en Guatemala. }\end{array}$ \\
\hline 2019 & Proyecto Playa Mundo Maya. & $\begin{array}{l}\text { Empresa Grupo Puntacana y Municipalidad de Flores inician } \\
\text { conversación para un proyecto turístico de gran magnitud }{ }^{8} \text {. }\end{array}$ \\
\hline 2020 & $\begin{array}{l}\text { Pandemia COVID-19 impacta } \\
\text { Petén. }\end{array}$ & $\begin{array}{l}\text { Amplia incertidumbre en el sector productivo de Petén, baja } \\
\text { considerablemente (casi a cero) el turismo en el departamento, por las } \\
\text { medidas de restricción establecidas. }\end{array}$ \\
\hline 2020 & $\begin{array}{l}\text { Aprobación de la prórroga de } \\
\text { los primeros dos contratos de } \\
\text { concesión. }\end{array}$ & $\begin{array}{l}\text { Tras la aprobación de las Normas para el otorgamiento de concesiones } \\
\text { (Resolución 01-19-2019) oficialmente se otorga la renovación por } \\
25 \text { años más a las primeras dos concesiones: Carmelita e Impulsores } \\
\text { Suchitecos }\end{array}$ \\
\hline 2021 & $\begin{array}{l}\text { Oficialmente se otorga la } \\
\text { renovación por } 25 \text { años más a } \\
\text { otras concesiones (AFISAP y } \\
\text { SC Laborantes del Bosque) y } \\
\text { se otorgan nuevas concesiones } \\
\text { en otras dos áreas de la ZUM. }\end{array}$ & $\begin{array}{l}\text { Oficialmente se otorga la renovación por } 25 \text { años más a otras } \\
\text { concesiones: Arbol Verde, AFISAP y SC Laborantes del Bosque. } \\
\text { Paralelamente se concesionan la unidad de Manejo San Bartolo } \\
\text { a SC Amigos del Bosque (Melchor de Mencos) y se concesiona } \\
\text { nuevamente la UM La Colorada (unida a otro espacio dentro de la } \\
\text { ZUM llamada el Molino) a la Asociación Selva Maya del Norte (San } \\
\text { Andrés). }{ }^{10}\end{array}$ \\
\hline
\end{tabular}

Como un ejemplo de los impactos que estos acontecimientos han tenido en los cambios de uso de suelo y las dinámicas espaciales a nivel del departamento de Petén, la Figura 1, muestra una línea de tiempo los principales sucesos dentro de la RBM y dentro de Petén incluyendo una secuencia de mapas relacionados a población, cobertura forestal, carreteras y ampliación de cultivos palma africana.

$8 \mathrm{https}$ //elperiodico.com.gt/noticias/economia/2019/12/18/grupo-puntacana-se-interesa-en-concesion-de-aeropuertomundo-maya/

9 https://acofop.org/victoria-historica-para-el-modelo-forestal-comunitario/

10 https:/conap.gob.gt/prorroga-de-25-anos-a-las-concesiones-forestales-comunitarias-en-la-rbm/ 


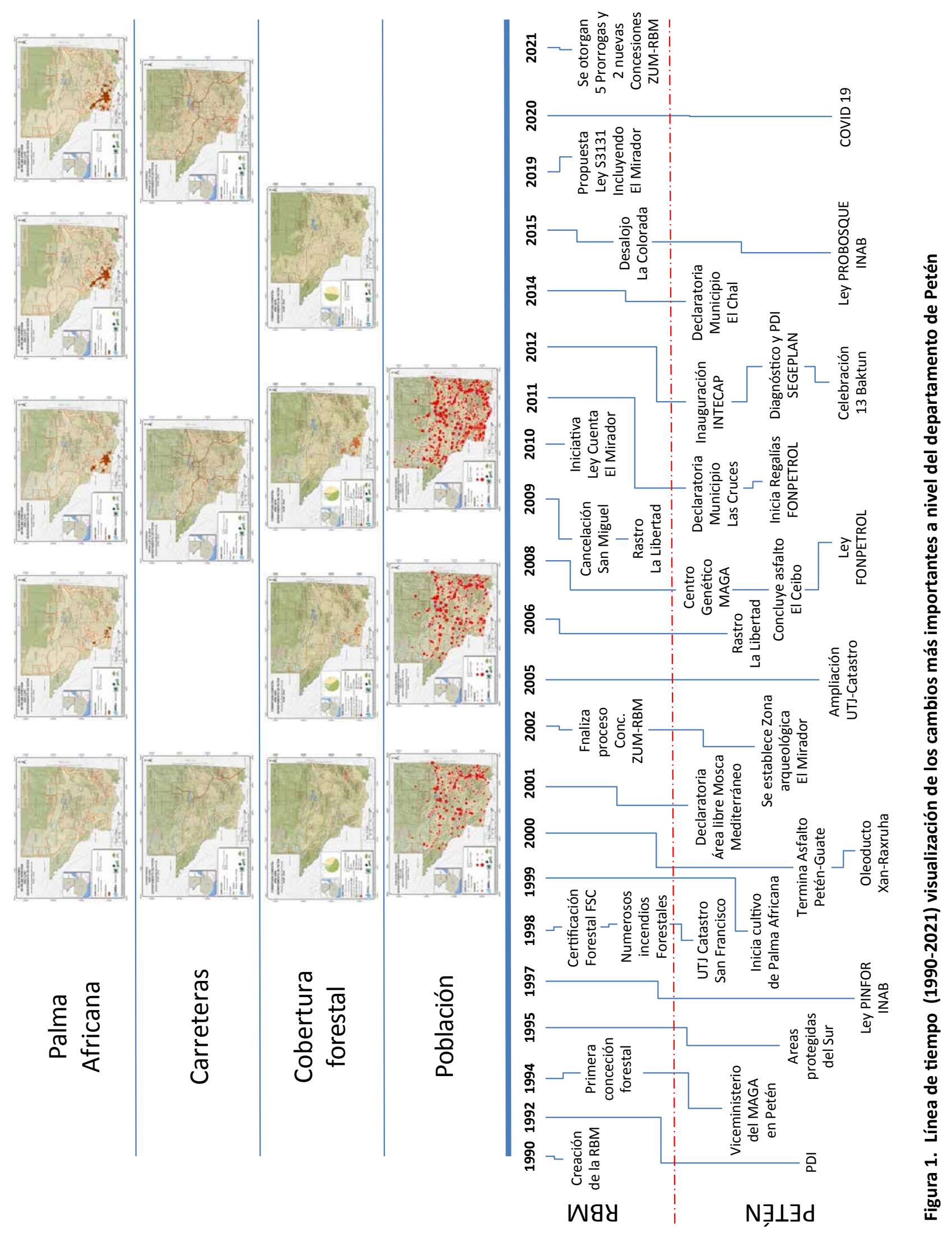




\subsection{Algunos indicadores de los cambios en Petén}

\subsubsection{Dinámicas demográficas de Petén}

Si bien el departamento de Petén permaneció durante mucho tiempo siendo la región con la más baja tasa de crecimiento poblacional (Schwartz, 1990). La Figura 2 muestra que la población del territorio se ha duplicado entre el 2002 al 2018 (crecimiento del 48\%, según datos del censo), pasando de tener 224,884 habitantes en 1994 a 366,735 en el año 2002 y a 545,600 en el 2018, con lo cual su población creció en 2.43 individuos en un periodo de 24 años $^{11}$ (INE 2002; INE 2018).

La población se encuentra dispersa, generando grandes retos para asegurar la provisión de servicios básicos, como la salud y la educación, así como la prestación de servicios públicos como agua y drenajes. La mayor parte de la población de Petén se concentra en el Sur, en particular en los municipios de Sayaxché, Poptún, San Luis, La Libertad y el área central de San Benito, Santa Elena y Flores. Dada la existencia de la RBM en la zona norte, la población es mucho más escasa, con la excepción de los Parques Nacionales Laguna de Tigre y Sierra de Lacandón, donde los centros poblados se han extendido especialmente en los últimos 10 años.
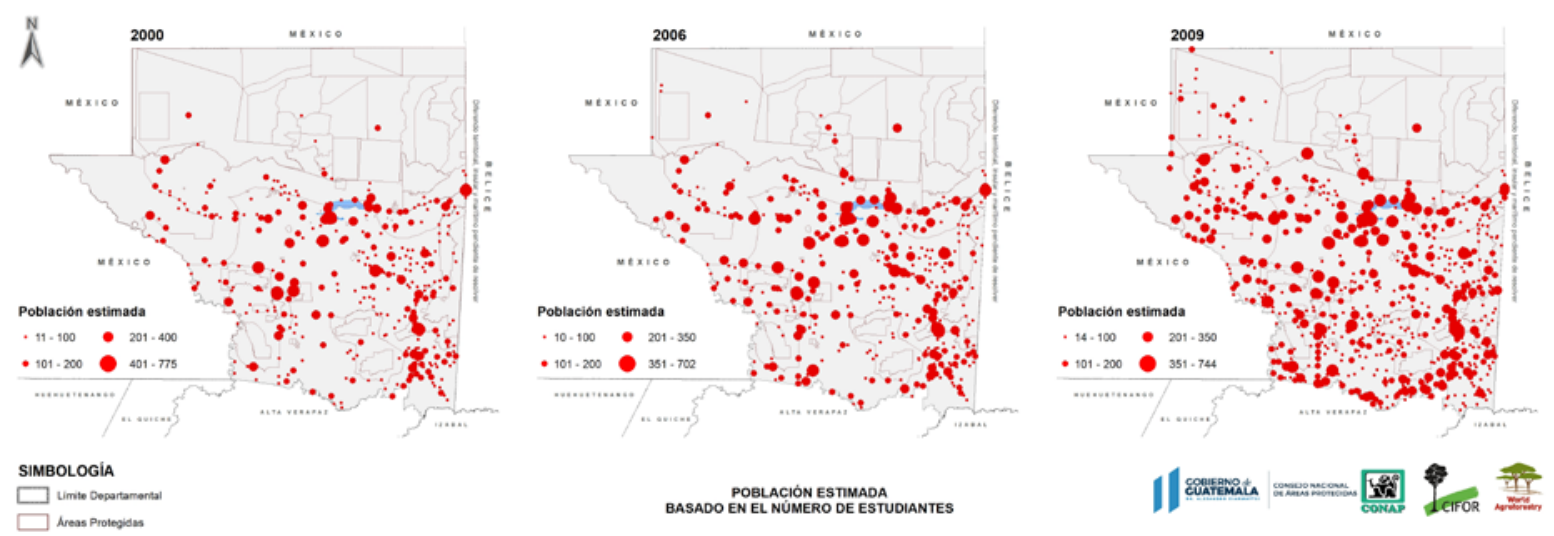

Figura 2. Población estimada basada en número de estudiantes 2000 - 2009

El mayor crecimiento poblacional de Petén para este periodo se dio en el municipio de Sayaxché que pasó de tener 55,578 habitantes a 93,414 (crecimiento de 2,365 habitantes/año), el aumento de población podría estar relacionado con la inmigración generada en parte por el trabajo vinculado al trabajo con la palma africana, que de acuerdo a GREPALMA (2019) genera unos 13 mil empleos directos.

El municipio con el menor crecimiento lo representa La Libertad y el único municipio que reporta un decrecimiento es Dolores (-5,484 en el periodo reportado), dada la creación del nuevo municipio de El Chal.

11 https://censopoblacion.gt/archivos/resultados_censo2018.pdf 


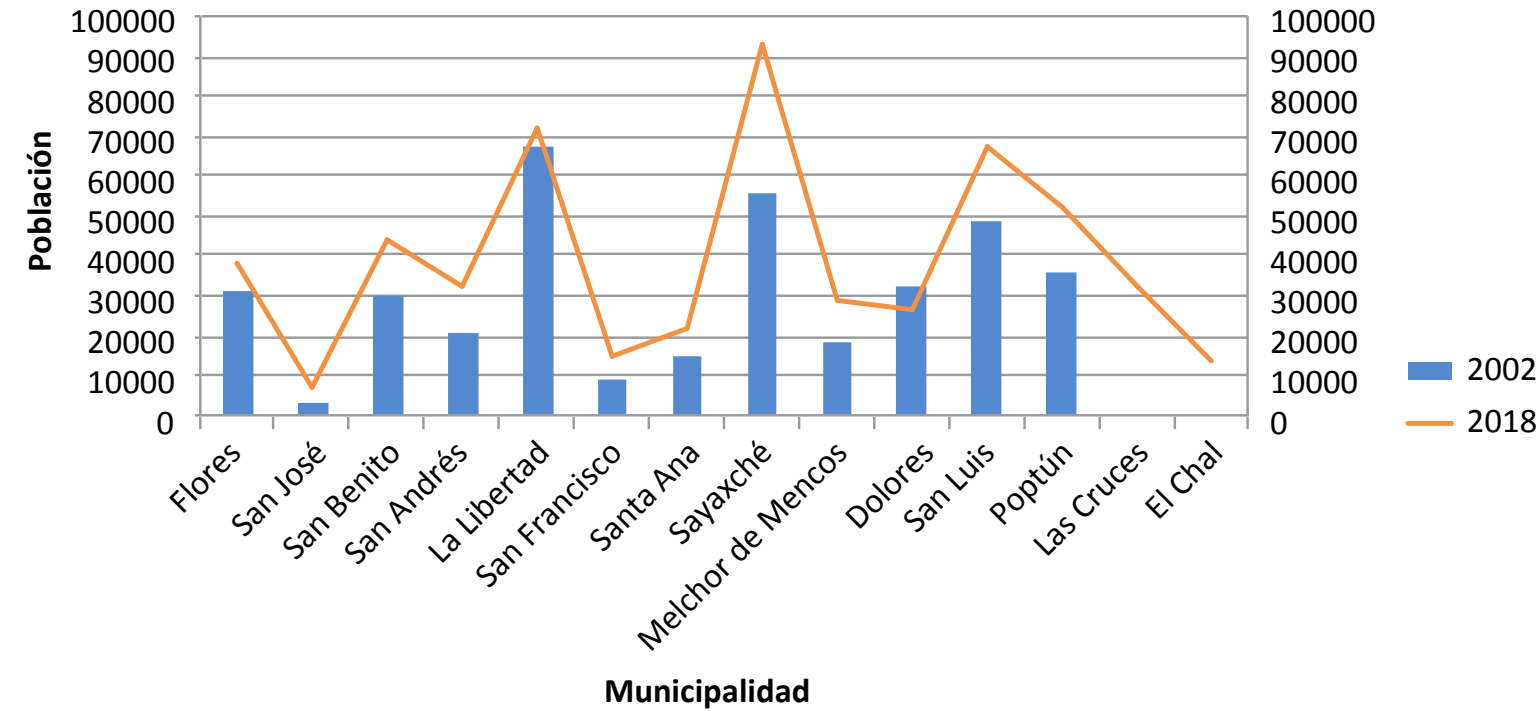

Figura 3. Dinámica de crecimiento poblacional 2002 - 2018 por municipio Datos Censo Nacional de Población, 2002 y 2018 (INE, 2002; INE, 2018)

La población de Petén es joven y rural, en 2018 el 60\% de la población se reportaba en áreas rurales y más del $74 \%$ son menores a los 35 años. Se caracterizan también por ser poblaciones empobrecidas, que sufren diversas privaciones (MIDES, 2018). De acuerdo a la última Encuesta de Condiciones de Vida el $60 \%$ de la población se encuentra bajo niveles de pobreza y $20 \%$ bajo pobreza extrema. En el sur de Petén, en los municipios de Sayaxché y San Luis, menos del 25\% de la población cuenta con acceso a agua entubada. Esta situación coincide con que ambos municipios se concentra la mayor proporción de población indígena (alrededor del 35\%). En ese sentido, las mejoras en el acceso a servicios básicos de agua, electricidad y drenajes, reportadas por el INE están limitadas a las zonas urbanas (INE, 2014). Por un lado, el analfabetismo ha disminuido en 18 puntos porcentuales por encima del nivel nacional. También ha aumentado, en dos años, el número promedio de años de estudio; sin embargo, el índice de escolaridad sigue siendo uno de los más bajos de todo el país.

\subsubsection{Carreteras}

Otro indicador que permite entender los cambios a nivel del uso del suelo y los cambios en las dinámicas poblacionales es el incremento en la red de carreteras (Ver Figura 4).
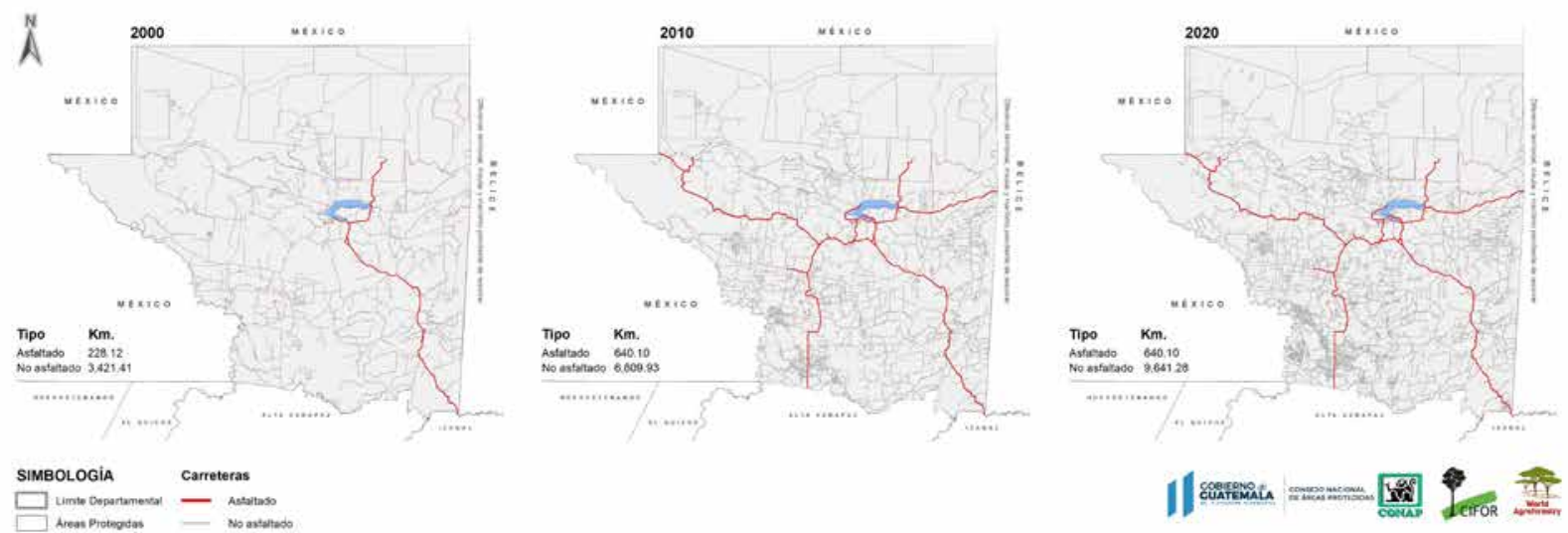

Figura 4. Dinámica de crecimiento de la red de carreteras en Petén 2000 - 2020 
La inversión de carreteras en Petén inicia desde el tiempo del FYDEP tiempo durante el cual se inició con la construcción de caminos madereros y rutas para la exploración petrolera (FYDEP, 1971). Los esfuerzos conjuntos del FYDEP, cuerpo de ingenieros del Ejército de Guatemala, COVIAL y Municipalidades de forma acumulada hasta el año 2000 se refleja con 4,662 km en su mayoría caminos de tipo terracería, en un periodo de 40 años (1960 a 2000) según se puede ver en el Cuadro 3.

Cuadro 3. Dinámica de crecimiento del sistema de caminos (asfalto y terracería) en el periodo 2000 - 2020 de Petén

\begin{tabular}{llcccccc}
\hline \multicolumn{2}{l}{ Asfalto } & \multicolumn{5}{c}{ Terracería - Sendero - Trocopás } \\
\hline No & Año & Km & Incremento & No & Año & Km & Incremento \\
\hline 1 & 2000 & 229 & $\mathbf{0}$ & 1 & 2000 & 4662 & $\mathbf{0}$ \\
\hline 2 & $2001-2010$ & 738 & $\mathbf{5 0 9}$ & 2 & $2001-2010$ & 8283 & $\mathbf{3 6 2 1}$ \\
\hline 3 & $2011-2020$ & 742 & $\mathbf{4}$ & 3 & $2011-2020$ & 11265 & $\mathbf{2 9 8 3}$ \\
\hline
\end{tabular}

El más amplio crecimiento en la red de carreteras de asfalto se dio entre el 2001 - 2010, cuando creció en $509 \mathrm{~km}$ de asfalto (rutas: Flores-Melchor de Mencos, Flores-El Ceibo y Flores-Sayaxché). Pero el dato relevante está en la ampliación de red de carreteras de terracería, que se incrementó en ese mismo periodo en 3,621 Km y siguió creciendo en el siguiente periodo (2011-2020) con 2,983 Km. Esto implica que en Petén se dio un crecimiento de 2.42 unidades en su red de carreteras de terracería en un periodo de 20 años. Este crecimiento se observa más marcado fuera de las áreas protegidas, especialmente en zonas con requerimiento de una red vial adecuada, circundantes a actividades productivas dedicadas a la palma africana, la papaya y la teca. 


\section{Principales cambios económico- productivos en Petén}

La descripción de los principales cambios económicos descritos en esta sección se basa en uno de los ejes propuestos por el Plan de Desarrollo Integrado de Petén 2032: el eje de desarrollo económico territorial (SEGEPLAN, 2013a: 46-48; 80-114). Parte del análisis de los cambios en las principales industrias de la región, tales como la industria maderera y la de productos no maderables (ej. xate, chicle, pimienta gorda), la agroindustria, la industria bovina, la de los granos básicos, y la industria de petroleo (Fonpetrol) ${ }^{12}$. Los otros ejes propuestos en el Plan de Desarrollo son: desarrollo de capacidades, gestión ambiental, seguridad y gobernabilidad, articulación territorial. En esta sección nos referimos a las principales industrias identificadas en el plan (Ibid, 2013a: 90-114) para identificar dinámicas productivas que permiten entender los cambios a nivel del uso de recursos. El análisis no es exhaustivo, dado que un análisis profundo de las industrias principales requeriría el análisis de las cadenas asociadas y, por ende, implicaría un esfuerzo que va más allá de los objetivos de este estudio; sin embargo, permite ilustrar cambios en el tiempo y el espacio a diferentes escalas en relación a las industrias principales.

\subsection{Industria forestal}

\subsubsection{Manejo forestal comunitario: Empresas forestales comunitarias}

En 1994, el Gobierno de Guatemala promovió un enfoque innovador para la gestión de la RBM: se otorgaron concesiones forestales de dos tipos, industriales y comunitarias (Ver Figura 5). Parte del proceso incluía firmar contratos por un ciclo de 25 años, con posibilidad de prórroga. Los contratos de concesión se otorgaron con la condición de obtener la certificación forestal del Forest Stewardship Council (FSC) en los tres años siguientes a la firma del contrato de concesión. Entre 1994 y 2002, se otorgaron 12 concesiones forestales comunitarias a comunidades residentes y no residentes en la Zona de Uso Múltiple (ZUM) de la reserva en una superficie cercana a las 400.000 ha (Radachowsky et al. 2012; Hodgon et al. 2015) ${ }^{13}$. Cada concesión es operada por una empresa forestal comunitaria (EFC) responsable de la gestión sostenible del bosque y de la distribución de los beneficios resultantes entre los miembros (Butler, 2021). A diferencia de sus contrapartes industriales, los contratos de las EFC permitían el manejo de productos forestales maderables y no maderables.

Este proceso de devolución de los derechos proporcionó incentivos para la gestión forestal comunitaria a largo plazo, generando ingresos, empleo y nuevas formas de inversión tanto a nivel de la empresa comunitaria como de los hogares (Stoian et al. 2018). Las concesiones forestales comunitarias han demostrado ser un modelo exitoso para combinar los objetivos de sostenibilidad con mecanismos que mejoran la calidad de vida y promueven el desarrollo local, contribuyendo especialmente a la consecución de diversos Objetivos de Desarrollo Sostenible (ODS) (Stoian et al. 2019).

La gestión forestal sostenible en la ZUM, tal y como demuestra la certificación independiente de terceros, ha conseguido reducir considerablemente las tasas de deforestación en la ZUM $(0,4 \%$ anual durante el periodo 2000-2013) (Hodgdon et al. 2015). La deforestación en las concesiones activas se ha registrado cerca de cero, en comparación con las zonas núcleo y de amortiguación de la RBM, donde las tasas de

12 Este último se describe en la siguiente sección.

13 Además se firmaron dos contratos con empresas bajo la figura de concesión forestal industrial, por la misma duración, limitada al manejo forestal maderable. 


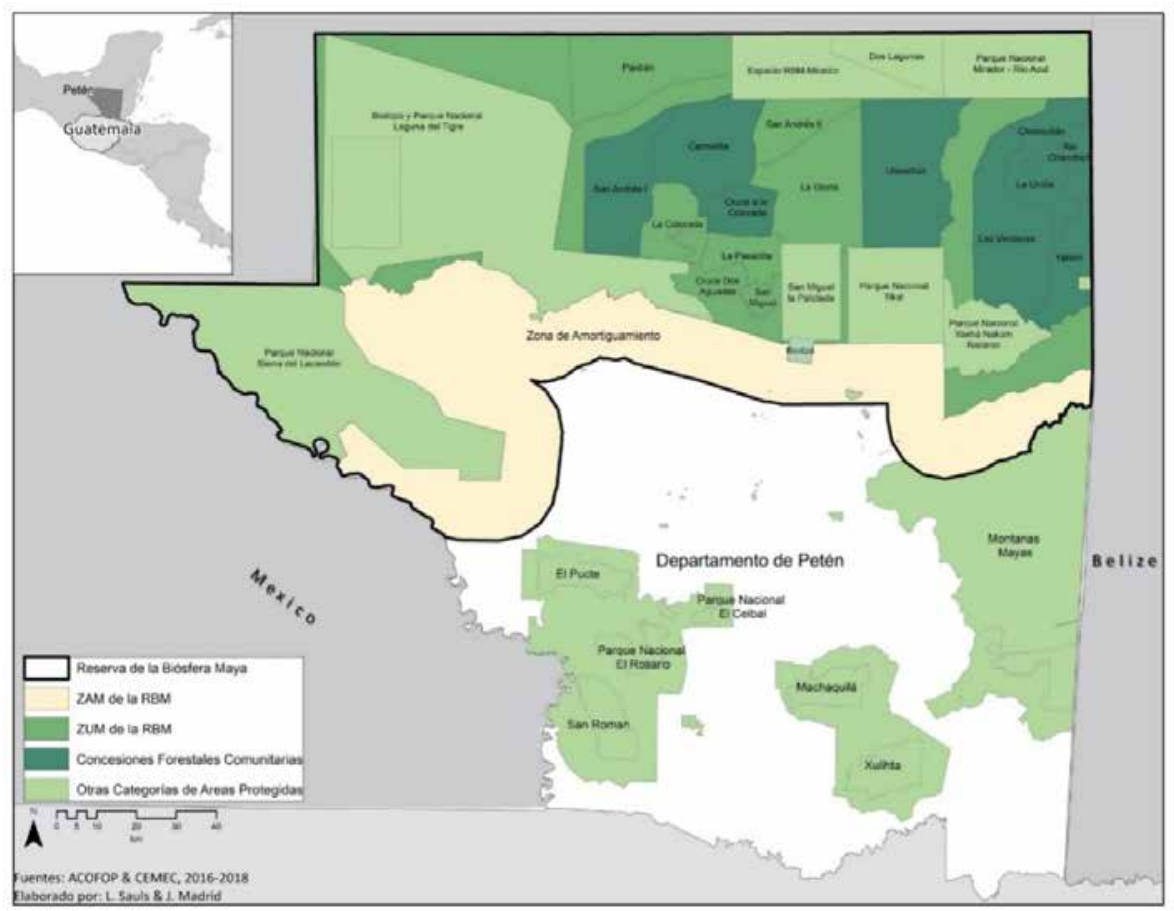

Figura 5. Ubicación de Areas Protegidas de Petén, RBM y Sistema de Areas Protegidas del Sur de Petén Fuente: Monterroso et al. 2018:11

deforestación durante el mismo período fueron del 1,0\% y el 5,5\% anual, respectivamente. Además, la EFC invierte alrededor de 500.000 USD cada año para organizar patrullajes contra los incendios forestales y proteger los límites del bosque de actividades ilícitas (Monterroso et al. 2018). Esto permite garantizar la conservación de los bosques, y contribuir al desarrollo socioeconómico de las comunidades que gestionan los bosques. Esto se refleja en el aumento de los ingresos, las inversiones, los ahorros, la capitalización de las empresas comunitarias y la creación de activos tanto a nivel familiar como empresarial (Bocci et al. 2018). Las cadenas de valor madereras generan más de USD5M anualmente y representan un promedio del $40 \%$ de los ingresos familiares permitiendo invertir en salud y educación, manteniendo a muchos de sus miembros fuera de la pobreza (Stoian et al. 2018) (Ver Figura 6).

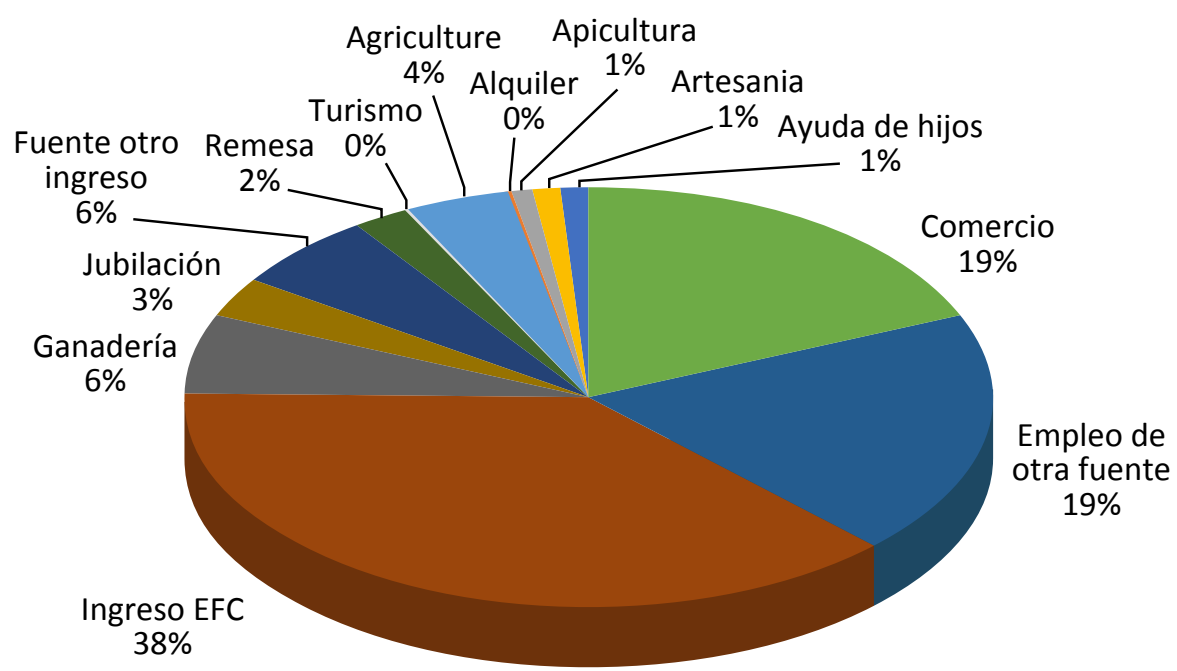

Figura 6. Distribución de ingresos a nivel de nueve Empresas Forestales Comunitarias EFC que manejan concesiones forestales comunitarias

Fuente: Stoian et al. (2018) 
Las empresas forestales comunitarias han ayudado a resolver retos sociales, económicos y de gobernanza que han representado desafíos más grandes en algunas áreas de protección estricta (Divine et al. 2020). Además, consiguieron reforzar la gobernanza contra las actividades ilícitas proporcionando ingresos y empleo para evitar el desplazamiento de las personas. El proceso de movilización y organización de base comunitaria se logró consolidar a través creación de organizaciones de nivel secundario -como la Asociación Forestal Comunitaria de Petén (ACOFOP)-, han sido capaces de fortalecer las estrategias de acción colectiva para resistir las presiones actuales y construir la gobernanza a lo largo del tiempo (Millner et al. 2020; Paudel et al. 2013). A pesar de cumplir con el doble objetivo de la conservación de los bosques y el desarrollo de los medios de vida, "el acuerdo que ha llevado a esta historia de éxito está bajo amenaza", como se informó recientemente en un artículo de la BBC (https://www.bbc.com/news/ world-latin-america-49753886). A tan solo dos años de la renovación del primer contrato de concesión, existen incertidumbres sobre el proceso de renovación que van desde propuestas para poner la ZUM bajo protección total, en combinación con el desarrollo del turismo, hasta aquellas que buscan ampliar la ganadería, la exploración petrolera y otras actividades que socavarían los esfuerzos de conservación del bosque a través de la gestión forestal sostenible por parte de las comunidades. Entre 2019 y 2021, se ha logrado la aprobación de la prórroga de cinco de nueve contratos activos además del otorgamiento de dos zonas de manejo en áreas que aún no habían sido concesionadas incluyendo el corredor Este de San Bartolo a la organización Amigos del Bosques y una nueva unidad de manejo denominada La ColoradaEl Molino a la Sociedad Civil Selva Maya del Norte. Estas dos organizaciones llevaban más de 10 años en proceso de solicitud de contrato.

El ingreso forestal, a nivel de estas empresas forestales comunitarias, proviene de dos fuentes principales, la generación de empleo directo y la repartición de dividendos (Ver Stoian et al. 2018 para más detalle) las cuales generan inversiones importantes a nivel de hogar y de las comunidades cuyos miembros forman parte de las EFC (Ver Figura 7), la cual muestra inversiones especialmente en educación y salud; así como inversiones en el hogar que buscan mejorar las condiciones de vida de los asociados.

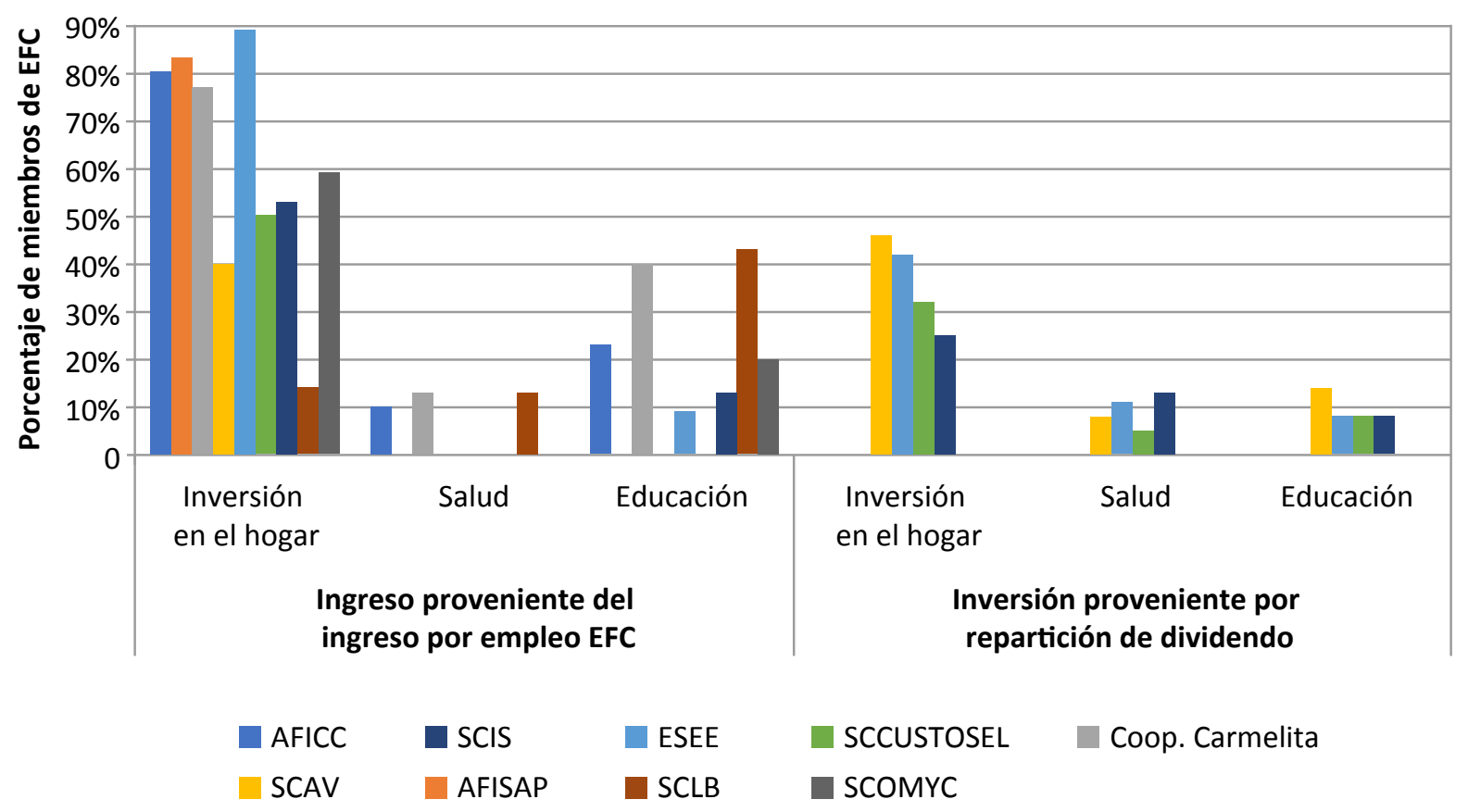

Figura 7. Distribución del ingreso obtenido en las EFC, a nivel de empleo y a nivel de repartición de dividendo Fuente: Stoian et al. 2018 


\subsubsection{Programa de incentivos forestales}

El programa de incentivos forestales dio inicio en Petén en 1997 y los primeros proyectos se pagaron en 1998 (Figura 8). El programa de incentivos forestales PINFOR operó entre 1997 al 2016 y evolucionó del 2017 en adelante en PROBOSQUE, además paralelamente se estableció otro programa dedicado a pequeños poseedores, el Programa de Incentivos Forestales para poseedores de pequeñas extensiones de tierra de vocación forestal o agroforestal (PINPEP) que inició en el año 2012. La Figura 9 refleja la distribución espacial acumulada de las tres iniciativas en Petén.

Los incentivos operan fuera de área protegida y dentro de las zonas de amortiguamiento de éstas. El área de menor incidencia de incentivos se da en Sayaxché, mientras San Luis cuenta con la mayor incidencia de incentivos en la modalidad PINPEP. En Petén se ha establecido un total de 8,883 proyectos de incentivos, de los cuales 4,453 proyectos se han hecho en lotes con título de propiedad (PINFORPROBOSQUE) y 4,430 proyectos se han hecho en lotes sin título de propiedad (PINPEP). Además, se han invertido un total de Q. 739,776,832.48 en el periodo 1998-2021 (US\$ 98,636,911) en fincas privadas y Q. 213,150,610.25 (US\$ 28,420,081.37) bajo proyectos PINPEP.

\section{MONTO (Q.)}
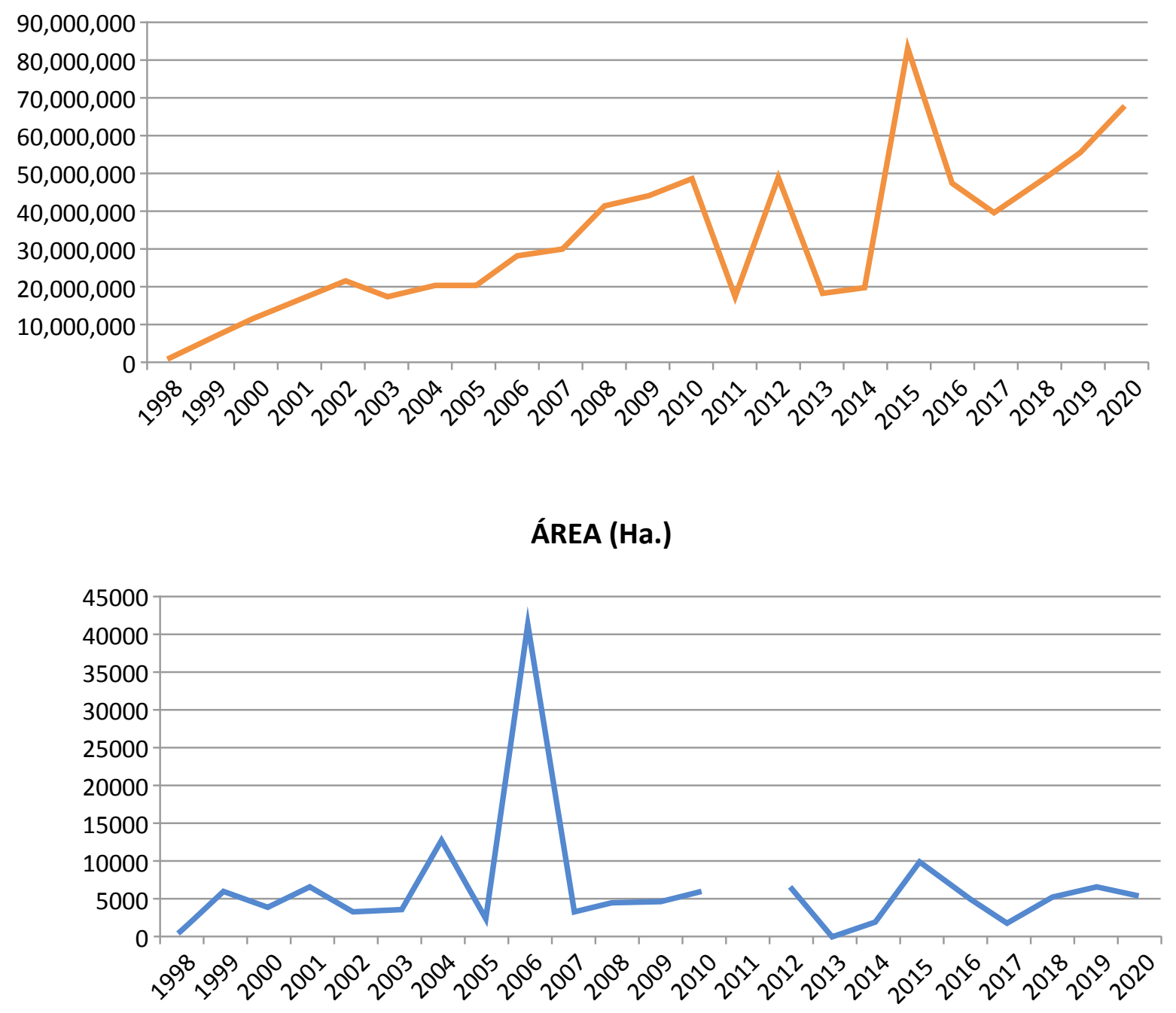

Figura 8. Area y monto relacionado con la implementación de programas de incentivos forestales en Petén (1998-2020) 


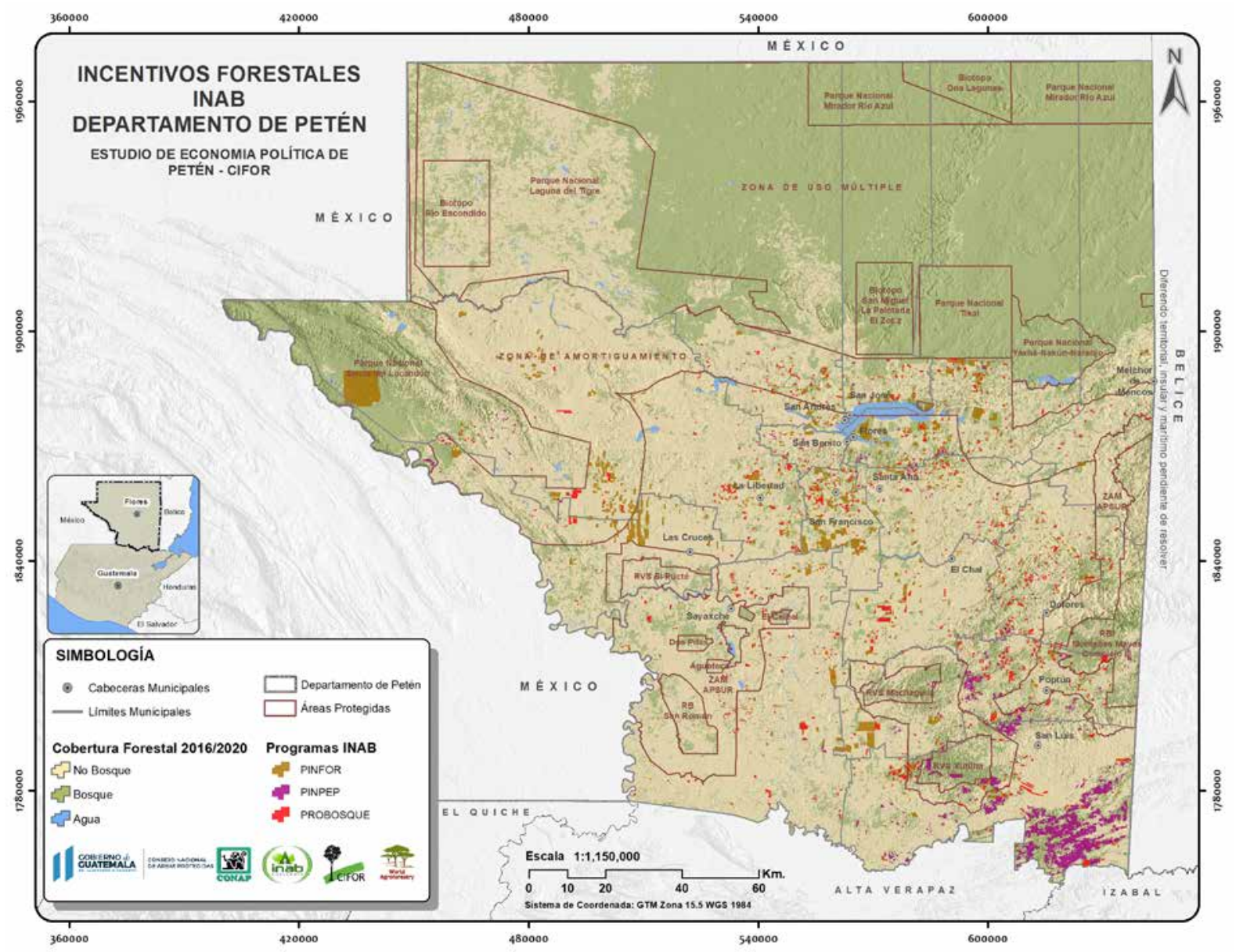

Figura 9. Ubicación de áreas bajo programas de incentivos forestales (2021)

Para el año 2000 se habían establecido 5,865 Ha bajo incentivos y para el año 2020 habían llegado a 158,396 (un incremento de 152,531 Ha en el periodo estudiado). Para PINFOR-PROBOSQUE el año con mayor área de establecimiento fue el año 2006 cuando se establecieron 40,582 Ha. Con respecto al pago de incentivos fue el año 2015 cuando se desembolsaron Q, 83,357,601.

Para PINFOR-PROBOSQUE la modalidad de incentivo que más número de proyecto ha presentado es manejo de bosque natural de protección, mientras restauración y sistemas agroforestales son los menos solicitados. En cuanto a los montos pagados, son los proyectos de reforestación los que más recurso han recibido (Q. 419,091,897), seguidos por los proyectos de protección (Q. 307,432,448.4) en el periodo estudiado.

A nivel de síntesis, los incentivos bajo las modalidades PINFOR-PROBOSQUE asignaron entre 1998 y el 2020 un promedio de US\$ 4.48 millones/año (Figura 10). Mientras que la modalidad PINPEP ha aportado US\$ 28.4 millones en el periodo 2013-2020 (US\$ 3.6 millones/año). En total el Incentivo Forestal PROBOSQUE y PINPEP han estado pagando un promedio anual de US\$ 8.1 millones/año). PINFOR-PROBOSQUE han establecido 4,453 proyectos en el periodo 1998-2020 bajo distintas modalidades (202 proyectos anuales) estableciendo un área de 137,466.28 $\mathrm{Ha}(6,248.47 \mathrm{Ha} /$ año). Mientras que PINPEP han establecido 4,430 proyectos en el periodo 2013-2020 bajo distintas modalidades (554 proyectos anuales) estableciendo un área de 20,929.34 Ha (2,616 Ha/año). 


\section{No. de Proyectos}

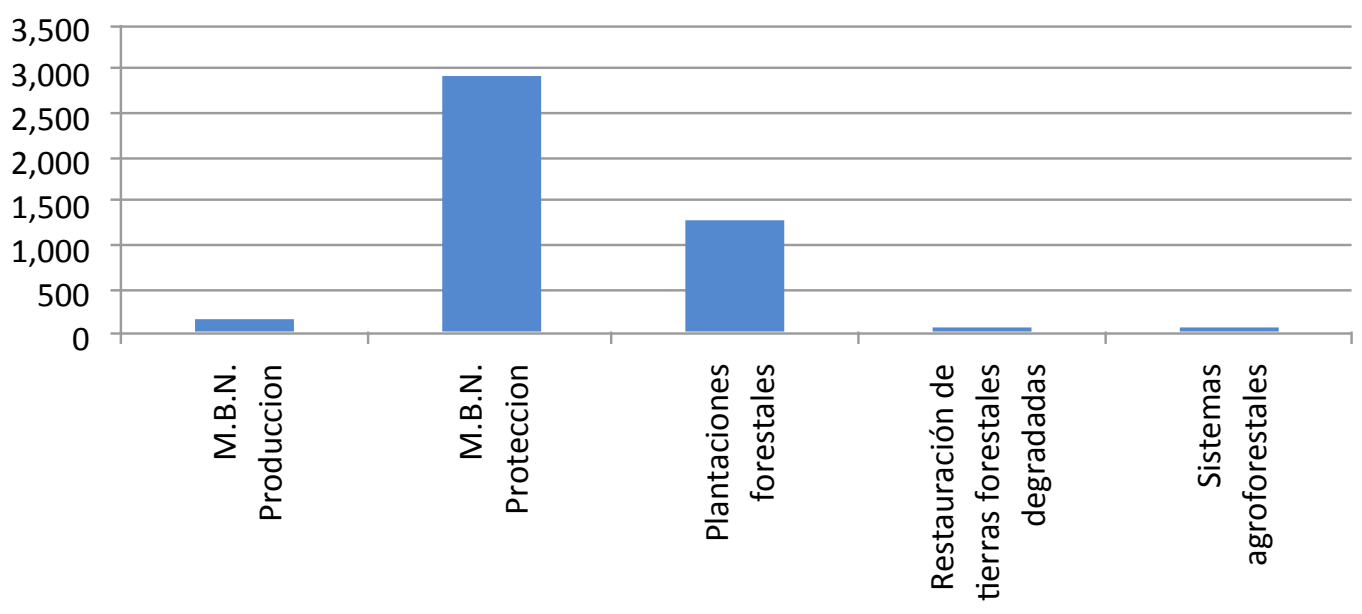

MONTO (Q.)

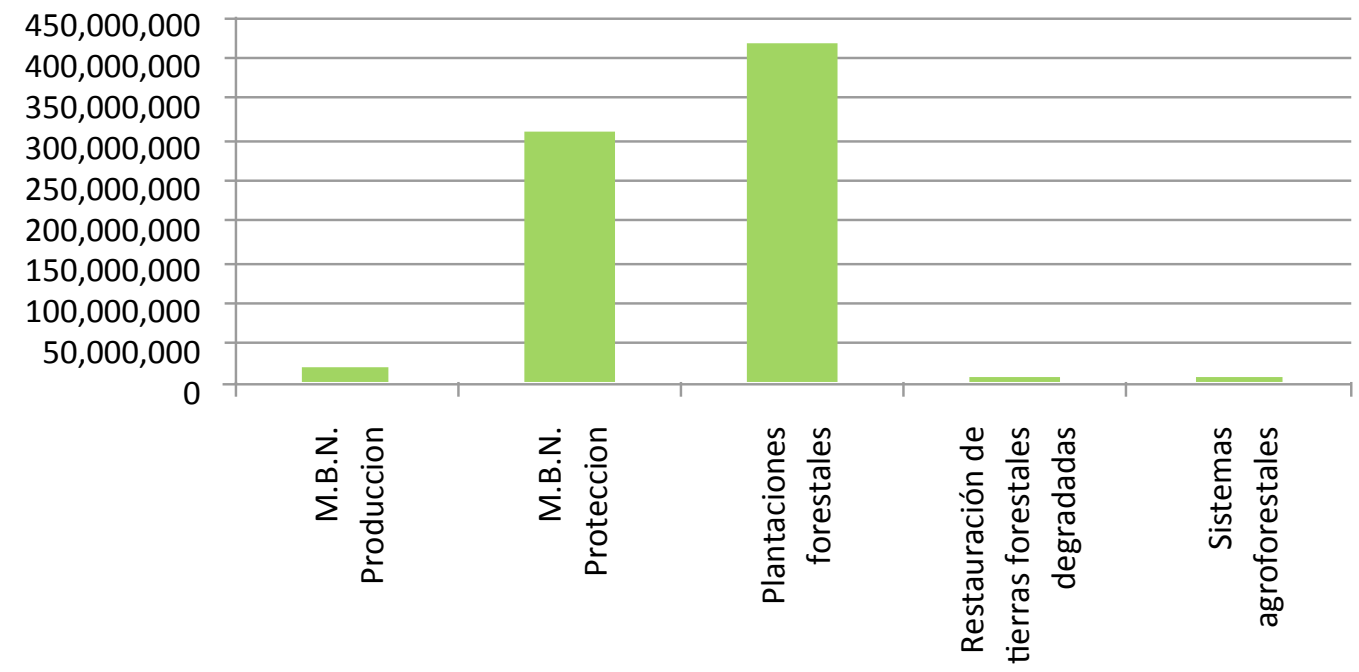

Figura 10. Area y monto de inversión de incentivos forestales PINFOR-PROBOSQUE M.B.N. Manejo de Bosque Natural.

Sumando este monto al obtenido por las actividades productivas maderables en áreas protegidas US\$ 7.29 millones/año, se puede concluir que la industria forestal en Petén genera ingresos brutos por US\$ 15.39 millones/año. Este aporte de los bosques a la economía regional se desdibuja por la falta de disponibilidad de datos a la escala departamental y por la escasa información consolidada que existe respecto a las fuentes de ingresos en áreas protegidas cuyo manejo forestal es supervisado bajo CONAP y aquellas áreas privadas y públicas fuera de áreas protegidas supervisadas bajo el INAB. Por otro lado, estos montos dejan fuera algunos datos relevantes, la generación de ingresos por productos no maderables, los volúmenes, y aún más importante el proceso de gestión y manejo que está detrás. A nivel del manejo forestal en áreas protegidas, estudios especializados al igual que los informes anuales de certificación han demostrado que la producción maderable puede realizarse de manera sostenible (ver Grogan et al. 2016 y Tobler et al. 2018). En su conjunto el potencial de desarrollar economías basadas en la gestión de los bosques es un reto aún por resolver, sin embargo, los datos muestran un avance importante (Ver Stoian et al, 2019). 


\subsubsection{Industria maderera}

La actividad forestal, y en particular la actividad de extracción maderera tiene una historia propia, inclusive previo al establecimiento del FYDEP. La RBM se establece en el área anteriormente destinada como reserva forestal (FYDEP 1971). Esta zona se manejaba bajo escasos lineamientos técnicos y se enfocaba en la extracción de maderas duras con alto valor comercial - beneficiando en particular a la industria maderera local constituida por los aserraderos: Del Norte, San Nicolás, Gibor, Baren, Maingua, Petexbatún, El Rondón, Buenos Aires, Santa Elena, La Constancia y San Francisco. Estos aserraderos manejaban áreas grandes (Ver Figura 11), por medio de concesiones forestales de corto plazo (5 años) en todo lo que hoy es la RBM (incluidas las áreas de parques nacionales Schwartz, 1995). Tras la liquidación del FYDEP, los aserraderos se constituyeron en la Asociación de Industrializadores de la Madera de Petén (AIMPE), para tratar de mantener presencia con sus operaciones forestales, posterior a la cancelación del FYDEP, pero no tuvieron éxito (manejaban como lema: "La Reserva de la Biosfera Maya es hoy, lo que la industria maderera conservó ayer"). ${ }^{14}$ Sólo dos empresas industriales lograron acceder a concesiones industriales dentro de la Zona de Usos Múltiples, incluyendo las empresas Gibor y Baren - ambas manejaron concesiones con el FYDEP.
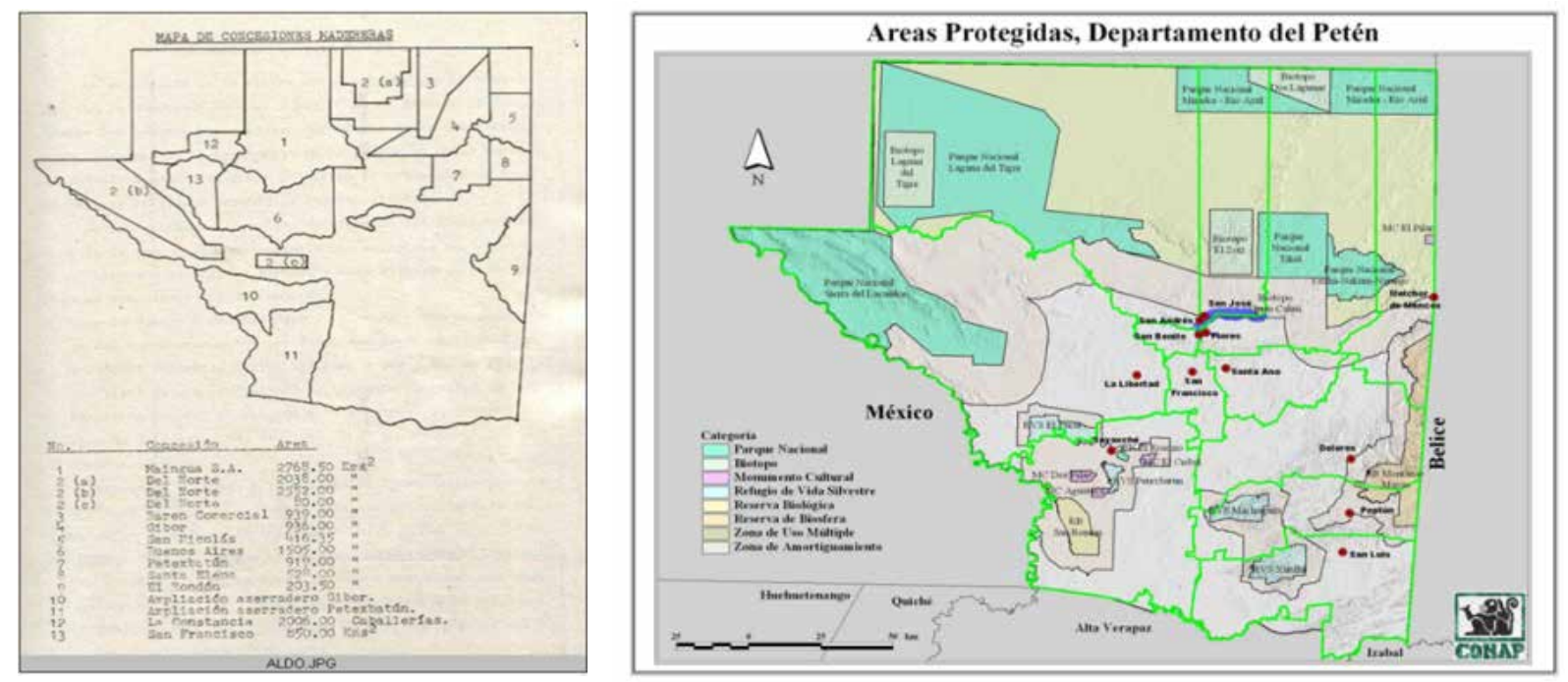

Figura 11. Mapa de adjudicación de concesiones industriales del FYDEP (1980) y actual zonificación de las áreas protegida de Petén (1990)

Según el Diagnóstico Territorial (SEGEPLAN 2013b) entre el 2000 y el 2008 se vendieron madera aserrada y otros productos madereros de Petén a un valor promedio de US\$ 4.99 millones/año. No existe un desglose detallado, pero este dato seguramente abarca a concesiones comunitarias, industriales y otras empresas forestales de Petén, que se abastecían de madera de afuera de la RBM (es el caso del aserradero San Nicolás). El Departamento de Manejo Forestal del CONAP (2014) estimaba un promedio de venta anual de madera (todas las concesiones) de US\$ 5.59 millones/año, mientras que el análisis desarrollado por Stoian et al. (2018) refleja una venta anual de US\$ 4.99 millones/año en 9 concesiones forestales comunitarias activas para el período 2012-2016. Una aproximación para el año 2019 (Cuadro 4) reflejaría una comercialización no menor a US\$ 2.3 millones/año entre las dos concesiones industriales (Gibor-Baren), con lo cual el ingreso bruto de todas las concesiones activas sería de aproximadamente US\$ 7.29 millones/año.

14 Entrevista al Sr. Carlos Rodas, quien laboró para el FYDEP durante 29 años. 
Cuadro 4. Dinámica de la venta de madera en distintos períodos de tiempo

\begin{tabular}{lcll}
\hline Período & $\begin{array}{c}\text { Promedio de venta anual } \\
\text { (Millones de US\$) }\end{array}$ & Fuente & Observaciones \\
\hline $2000-2008$ & 4.99 & SEGEPLAN & $\begin{array}{l}\text { Abarca todas las exportaciones de } \\
\text { todas las empresas forestales de Petén }\end{array}$ \\
\hline $2010-2014$ & 5.59 & $\begin{array}{l}\text { Departamento de Manejo } \\
\text { Forestal CONAP }\end{array}$ & $\begin{array}{l}\text { Abarca a todas las concesiones } \\
\text { de la RBM }\end{array}$ \\
\hline $2012-2016$ & 4.99 & Bioversity International & $\begin{array}{l}\text { Abarca ventas totales de las Empresas } \\
\text { Forestales Comunitarias }\end{array}$ \\
\hline 2019 & 7.29 & Aldo Rodas & $\begin{array}{l}\text { Abarca a todas las concesiones de la } \\
\text { RBM (comunitarias e industriales) }\end{array}$ \\
\hline
\end{tabular}

\subsection{Industria de turismo}

Existe muy poca información sobre la situación de empresas en el sector de servicios en Petén (SEGEPLAN, 2013a). A nivel del departamento, la RBM es el área de mayor concentración arqueológica del país, algunas, como Tikal, de gran importancia dentro del área considerada como territorio cultural Maya (Chan 2007; 2009). A nivel de la RBM se han identificado cerca de 188 sitios arqueológicos, de los cuales 166 se encuentran aún sin clasificar. El 30\% de los sitios se encuentran en la ZUM y el 44\% en las Zonas Núcleo. Según datos al 2002, dentro de la RBM se calculan cerca de 300,000 visitantes al año distribuidos en 16 sitios arqueológicos, hacia el 2019 los datos del Instituto Guatemalteco de Turismo INGUAT mostraban que la visitación al departamento se ha duplicado. Sin embargo, la actividad turística se concentra en Tikal, área que registra más de 250,000 turistas al año. Esto significa que Tikal concentra cerca del 90\% de los visitantes que ingresan a la RBM (Monterroso 2010).

A pesar de ser uno de los destinos turísticos más importantes del país, la visitación del departamento se encuentra por debajo de otras regiones. Por ejemplo, para el año 2018 se reportaron un total de 284,202 turistas en Petén (debajo de Sololá con 387,163; Sacatepéquez con 639,571 y ciudad de Guatemala con $747,763)^{15}$. Por otro lado, si bien entre 2014 y 2019, la visitación había estado en aumento de hasta el $20 \%$ anual, la pandemia de COVID 19 a inicios de 2020 disminuyó la visitación de ambos - turistas y excursionistas al departamento - debido a las restricciones establecidas, reduciéndose a 594,000 a nivel del país. En Petén la situación fue similar - afectando de forma significativa la actividad. ${ }^{16}$ Según reportes del INGUAT de un promedio previo de alrededor de 700,000 visitantes al año 2019, en 2020, la visitación cayó de forma abrupta a 21,492 visitantes, reportes de visitación de 0 personas entre los meses de abril a agosto ${ }^{17}$. Los impactos de la pandémia representaron retos importantes para la conservación del patrimonio cultural y natural, especialmente en materia económica y social, no sólo para sitios emblemáticos como Tikal, sino para el considerable número de sitios menores - en visitación - resaltando los desafíos institucionales que enfrenta el sector para aprovechar al máximo el potencial de la industria a nivel del país (Chan 2020). Según estos informes oficiales, el 73\% de los visitantes registran visitas a sitios arqueológicos y el 59\% visitas a espacios naturales (lago, lagunas, paisajes).

Según el presidente de la cámara de turismo de Petén ${ }^{18}$, en el departamento existen cerca de 100 entidades turísticas (hoteles, tour operadoras, restaurantes, entre otros), que generan un ingreso bruto de US\$ 25 millones/año. El orden de importancia económica se da así: hoteles, touroperadores, restaurantes,

\footnotetext{
15 https://www.guatemala.com/desarrollo/economia/departamentos-guatemala-mas-visitados-turistas-2018.html

$16 \mathrm{https} / /$ inguat.gob.gt/prensa/noticias-recientes/17-noticias-2019/215-inguat-comparte-plan-para-la-reactivacion-de-laeconomia-del-sector-turistico

17 Estadísticas de visitación oficiales obtenidas de INGUAT en https://inguat.gob.gt/estadistica/category/127-2020 (Informes 2018 y 2020).

18 Entrevista con el Ing. Billy Cruz, actual presidente de la Cámara de Turismo de Petén.
} 
transportistas, guías, artesanos y lancheros. El dato más relevante está proyectado en base a la cantidad de turistas que ingresan a Petén. Según estimaciones generadas por INGUAT promediando 10 días de visita, con un gasto aproximado de USD100/día, los ingresos generados durante el 2020 estarían alrededor de los USD15 millones/anuales, este es una disminución significativa, si tomamos en cuenta que el mismo informe para el Departamento de Petén, en 2018 reportaba 360,885 visitantes dejando ingresos del sector de alrededor de USD139 millones durante ese año (a nivel nacional hubo 2,405 mil visitantes y el sector superó los USD 1,200 millones en ingresos), lo cual muestra el potencial de continuar desarrollando el sector, en particular frente a la reciente Política Nacional para el Desarrollo Turístico Sostenible de Guatemala 2012-2022 (INGUAT 2012). En los últimos 20 años, se han planteado diversas propuestas que evidencian el creciente interés en el turismo a través de planes y propuestas de inversión para desarrollar el patrimonio cultural (Monterroso et al. 2018). Las iniciativas tienen como elemento común el interés por desarrollar la actividad turística con énfasis en el sitio El Mirador al norte de la RBM (Ver Cuadro 1 y 2). En el 2002 el presidente Portillo aprueba un Sistema Especial de protección para el patrimonio cultural que se encuentra en el Parque Nacional Mirador, en el 2006 se establece la Mesa Multisectorial para la Conservación y Manejo de la Zona Natural y Cultural MiradorRío Azul (Devine 2018). En el 2008 se lanza la iniciativa 4-Balam, que toma en cuenta todo Petén, pero incluye el Mirador como uno de sus ejes centrales. En el 2018 se establece una Mesa de Alto Nivel para el Turismo y Desarrollo de Petén.

El turismo se ha planteado como propuesta para articular los intereses de conservación con la posibilidad de promover la inversión económica y generar ingresos. Sin embargo, los escasos espacios para articular las diversas posiciones de los actores sobre el tema y la falta de claridad sobre el modelo han resultado en conflictos (Devine 2018). La reciente propuesta S3131 presentada al Congreso del Gobierno de los Estados Unidos ${ }^{19}$ de promover respaldo del país para la definición de áreas de conservación que permitan el desarrollo económico basado en el turismo. En Guatemala, posterior a la presentación de esta propuesta, se formaron dos mesas redondas en respuesta a la iniciativa legislativa, pero el interés de los congresistas ha disminuido con el cambio de gobierno de Estados Unidos en 2020. Aunque la iniciativa S.3131 no logró el respaldo necesario, el debate promovido es una muestra de que el turismo sigue siendo un tema de interés de la agenda política.

\subsection{Industria de fruticultura}

La papaya es una de las cinco principales frutas tropicales a nivel mundial la tercera en importancia después del mango (52\%), la piña (28\%), la papaya (14\%) (FAO 2018) ${ }^{20}$. Según análisis de producción generados entre el 2009 y 2018 Guatemala se convierte en el tercer productor principal después de México y Brasil, superando en volúmenes de producción a Malasia y Brasil desde el 2017 (Ibid.) Desde 2013, de acuerdo a un informe reciente del MAGA Guatemala ocupaba el 10 lugar en países productores de papaya, siendo los mercados nacionales y regionales (Centraomérica) los más importantes a nivel del país $^{21}$. De acuerdo a datos de SIECA (Escobedo 2018) Guatemala generó alrededor de USD8 mil millones por la exportación en la región, siendo Petén el departamento donde más se ha extendido su cultivo. A nivel de Petén según el Sr. Selvin Ramírez ${ }^{22}$ presidente de la Asociación de Papaya de Petén, actualmente existen 1,700 Ha establecidas, de las cuales 900 están en producción (generando 1,080 empleos permanentes). Las $900 \mathrm{Ha}$ en producción general 456 cajas/mes/Ha. El precio promedio comercial de la caja de exportación está a Q. 48 y esto genera un ingreso bruto mensual de US\$ 2.63 millones, con lo cual se puede generar una proyección de ingresos brutos de US\$31.52 millones /año, un monto superior a cifras oficiales.

19 https://www.congress.gov/bill/116th-congress/senate-bill/3131

20 FAO 2018. Análisis de mercado de las principales frutas tropicales. https://www.fao.org/3/ca5692es/CA5692ES.pdf

21 Perfil Comercial de la Papaya en Guatemala, MAGA 2013 https://precios.maga.gob.gt/archivos/perfiles/Perfil\%20 Papaya.pdf

22 Entrevista con presidente de la Asociación de Productores de Papaya de Petén 
Otro producto frutícola de importancia es la piña, según datos del MAGA para el 2016 la producción de piña en Petén representaba el $8.3 \%$ de la superficie cosechada y el $6.5 \%$ de la producción nacional, ubicándose en el quinto departamento en importancia de producción de esta fruta (MAGA 2016) ${ }^{23}$. En una entrevista al gerente de fincas de la empresa con mayor área productiva en Petén ${ }^{24}$ (empresa Popoyan) indica que en el área de Santa Ana se han establecido 200 Ha de este producto (generando 600 empleos permanentes). Cada Ha produce 80 toneladas (1,760 quintales) y el precio de venta por quintal es de Q. 85. Esta producción anual refleja que se están produciendo un total de 352,000 quintales anuales en Petén y genera un ingreso bruto de US\$ 3.99 millones/año. La suma de estos dos productos genera un total de US\$ 35.51 millones / año. Esto sin considerar otros cultivos frutícolas de importancia como limón y el melón.

\subsection{Industria de granos básicos}

Petén ha sido considerado el Granero de Guatemala, según datos del Ministerio de Agricultura (2016), es el máximo productor de maíz blanco del país (un 18\% de la producción nacional, seguido únicamente por Alta Verapaz donde se cultiva el 10\%). La producción de este grano se ha incrementado, ya que los datos oficiales registraban en 2011 una producción nacional de más de 36 millones de qq mientras que para el 2018 la producción de la cosecha 2016/2017 superaba los 46 millones de qq (cerca de 5 millones de qq a nivel de Petén), pese a que el precio por qq sufrió una disminución desde 2016. También es el mayor productor de frijol de Guatemala (un $27 \%$ de la producción nacional). Esta producción estaba representada por 609,785 quintales/año. La producción de maíz blanco reportado en el año 2018 (MAGA $\left.2018^{25}\right)$ se había incrementado a cerca de 8 millones de qq en el año $(5,075,043$ en primera cosecha y $2,884,401$ en segunda cosecha). Con esto aportaba un 20.6\% de la producción nacional. Del 2014 al 2018 el precio promedio mensual más bajo se presentó en febrero de 2018, llegando a Q.104.72 por quintal (MAGA 2018). Tomando este dato como referencia los ingresos brutos por la comercialización de maíz blanco sería de US\$ 111.13 millones/año. En cuanto a la producción de frijol el PDI-Diagnóstico refleja (SEGEPLAN, 2013a) reportaba una producción anual de 609,785 quintales en el año 2011, mientras el Agro en Cifras (MAGA, 2016) ${ }^{26}$, refleja una producción de 1,474,308 quintales al año. Considerando el precio promedio por quintal para ese mismo año (Q. 405.46/qq), se tendría un ingreso bruto anual de US\$. 79.70 millones/año. Solamente sumando el ingreso bruto anual en materia de los dos productos agrícolas más importantes de Petén (maíz blanco y frijol), se estima un movimiento anual de US\$ 190.83 millones / año.

\subsection{Industria ganadera}

En los últimos 20 años, Petén paso de ser un departamento no relevante para el tema ganadero, a ser el departamento con el hato de ganado más grande del país (Ver Cuadro 5). En 2021, Dolores (12\%), La Libertad (13\%), San Luis (11\%) Poptún (12\%) y el Chal (25\%) registraron la mayor proporción de cabezas de ganado en su conjunto representan el $73 \%$ del hato ganadero a nivel del departamento. Según datos del MAGA (2013) el 29\% de la superficie del departamento se encuentra cubierto de pastos.

\footnotetext{
23 El Agro en Cifras https://www.maga.gob.gt/sitios/diplan/download/El-Agro-En-Cifras-2016.pdf

24 Ing. Abel López/gerente de fincas Popoyan Petén (entrevista).

25 https://www.maga.gob.gt/wpfb-file/informe_situacion_maiz_blanco-pdf-2/

26 https:/www.maga.gob.gt/sitios/diplan/agro-en-cifras-2016/
} 
Cuadro 5. Dinámica de crecimiento en ganadería para el periodo 2000 - 2020 de Petén

\begin{tabular}{lccc}
\hline Municipio & $\mathbf{2 0 0 3}$ & $\mathbf{2 0 1 4}$ & $\mathbf{2 0 2 1}$ \\
\hline Flores & 17907 & 26523 & 39522 \\
\hline San José & 1050 & 10628 & 15837 \\
\hline San Benito & 1785 & 4348 & 6479 \\
\hline San Andrés & 20412 & 33948 & 50585 \\
\hline La Libertad & 62777 & 130617 & 194631 \\
\hline San Francisco & 7140 & 7876 & 11736 \\
\hline Santa Ana & 14561 & 14985 & 22329 \\
\hline Sayaxché & 50744 & 64604 & 96266 \\
\hline Melchor de Mencos & 23484 & 72509 & 108045 \\
\hline Dolores & 65970 & 122916 & 183155 \\
\hline San Luis & 34290 & 119834 & 178563 \\
\hline Poptún & 15699 & 124632 & 185712 \\
\hline Las Cruces & & 41618 & 62014 \\
\hline El Chal & $\mathbf{3 1 5 8 1 9}$ & 256254 & 381841 \\
\hline TOTAL & & $\mathbf{1 0 3 1 2 9 2}$ & $\mathbf{1 5 3 6 7 1 4}$ \\
\hline
\end{tabular}

El Cuadro 5, muestra la evolución entre 2003 a 2021, los datos del año 2003 son provenientes del último censo agropecuario, mientras los datos del año 2014 es un directorio creado entre el MAGA y la INE para hacer una estimación de la cantidad de ganado en Petén. Por su parte el dato del año 2021 es una proyección de crecimiento que implica: parición, extracción y mortalidad realizada por un equipo técnico del MAGA.

Los datos muestran que el hato ganadero se ha quintuplicado entre el periodo 2000 - 2020 (Figura 12), pasando a ser el departamento más importante en cuanto a la cantidad de ganado con que cuenta. Situación que se agrava dado que en Petén se ha documentado la existencia de trasiego (contrabando) de ganado que se origina desde Nicaragua y Honduras (WCS, 2018).
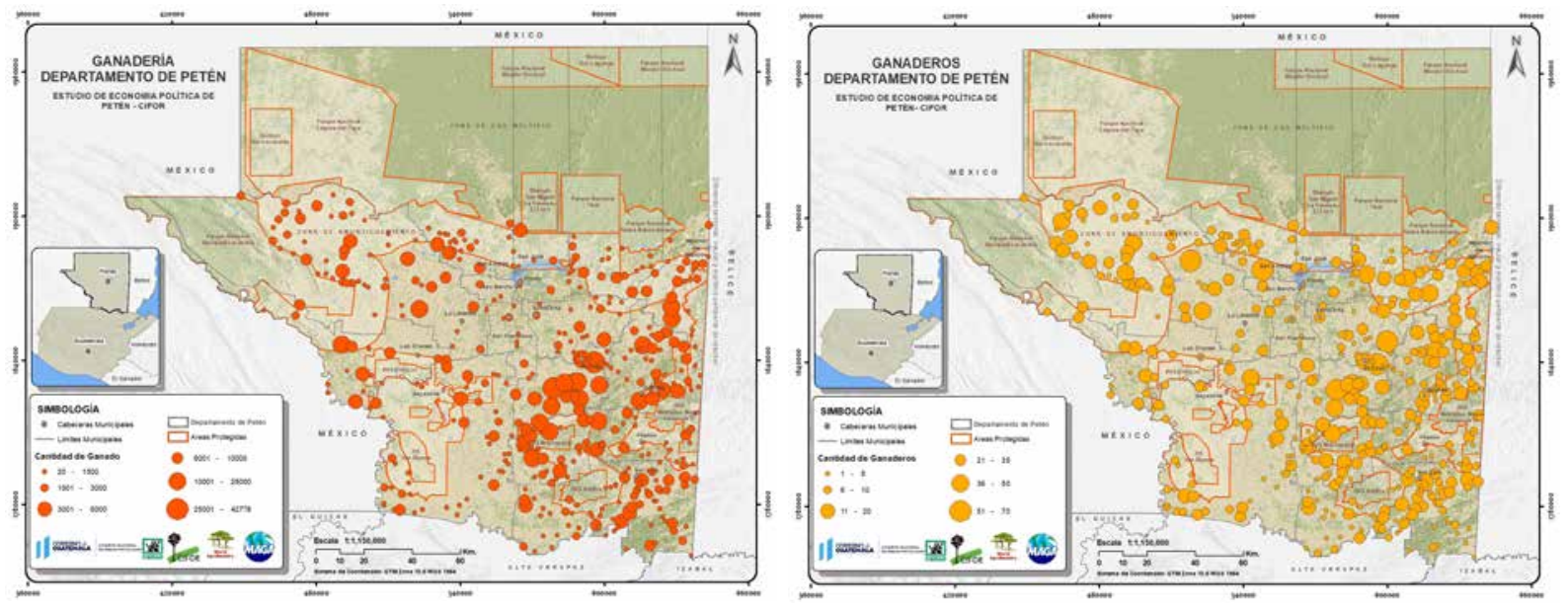

Figura 12. Distribución de ganaderos y ganadería de Petén fuera de areas protegidas 2021 
Petén es el departamento con el mayor hato ganadero de Guatemala $(1,031,412$ cabezas de ganado reportadas para el año 2013) MAGA Petén-INE (Directorio ganadero de Petén). Según El Agro en Cifras (MAGA 2016) ${ }^{27}$, Petén aporta el 19\% de la producción anual de carne bovina que se produce en Guatemala. Aporta del 6\% de la producción de lecha a nivel nacional (MAGA, 2016). Para el año 2015 el hato nacional se ubicaba en 3,768,400 de los cuales el 19\% se encontraba en Petén; mientras La Huella Humana Mesoamericana 2000-2015 (WCS) reportaba el hato nacional nacional de 3,458,600 millones de cabezas de ganado hacia el año 2014. Esta misma fuente afirma que el hato ganadero para el 2007 era de 2,856,009 cabezas a nivel nacional (con lo cual entre 2007 y 2014 creció 602,591 - crecimiento de un 17.4\% en 7 años). Según El Agro en Cifras MAGA 2016 se destazan un total de 1,004,900 cabezas de ganado al año y si de este dato el 19\% son de Petén, se destazarían 190,931 de este departamento. Poniendo un precio de referencia de Q. 5,000 por cabeza (compraventa de chivos, vacas, toros) el negocio generaría un ingreso bruto de US\$ 127.29 millones/año. Los datos del promedio anual de venta de ganado en Petén fueron corroborados por dos fuentes (mediante entrevistas) y ambas coincidieron con el dato reportado (unas 200,000 cabezas anuales). Un alto porcentaje de esta venta se va hacia México, por medio de contrabando, haciendo sumamente difícil tener estadísticas confiables. Según el directorio MAGA-INE del 2013 en Petén existían 4,909 fincas ganaderas. Otro aspecto que dificulta el seguimiento a los datos de producción del ganado es la falta de registros y el pago de impuestos, además que los productores ganaderos no están debidamente registrados (como productores o como comercializadores). En la actualidad el programa de trazabilidad impulsado por el MAGA podría reflejar información más confiable. Aun así, una proyección confiable es que el negocio del ganado genera un ingreso bruto anual de US\$ 127.29 millones/año.

\subsection{Industria de palma africana}

En los últimos 20 años, el cultivo de palma africana se ha incrementado exponencialmente en Petén. La Figura 13 permite visualizar el crecimiento que inició en el año 2000 con 320 Ha y ha llegado en el 2020 a 78,921.02 Ha (46.03\% del área establecida a nivel nacional). La tasa de crecimiento a nivel nacional entre 2005 y 2010 fue del 20\%, en Petén (192.4\%). De las 20 plantas de beneficio que existen a nivel nacional, 7 se encuentran en Petén. En 2017, Guatemala ocupó el quinto lugar en la producción de la palma a nivel mundial, el segundo en América Latina (GREPALMA, 2017). El 85\% de la producción se exporta. La actividad palmera contribuye al PIB nacional en un $1.2 \%$. Según la Gremial Nacional de Palma Africana, GREPALMA (2019) la producción de palma representa el 80\% del PIB en Sayaxché, $20 \%$ de PIB en el Chal y $12 \%$ del PIB en San Luis (generando alrededor de 13,000 empleos directos).

Considerando los datos de origen del año 2020 y la situación actual, se ha dado un ritmo de establecimiento (plantación) de 3,930 Ha/año en Petén. Un dato comparativo podría ser el ritmo de establecimiento (reforestación) del programa de incentivos forestales (modalidad de plantaciones forestales) que se ha dado con 1,716 Ha/año (PINFOR-PROBOSQUE ha establecido 37,007.85 Ha en el periodo 1998-2020 y PINPEP ha establecido 267.2 Ha en el periodo 2013-2020).

La distribución por municipio se muestra en el Cuadro 6, la producción de palma en el municipio de Sayaxché representa el 87\% de la producción a nivel del departamento según datos para 2018-2019 generados por la Gremial de Palma ${ }^{28}$. El crecimiento en área del cultivo de palma ha implicado la adquisición de fincas (lotes) y para el año 2017 se habían adquirido 1,480 lotes y para el año 2019 creció a 1,779 fincas.

27 https://www.maga.gob.gt/sitios/diplan/agro-en-cifras-2016/

28 https://www.grepalma.org/wp-content/uploads/2020/04/Anuario_estadistico_2018_2019.pdf 

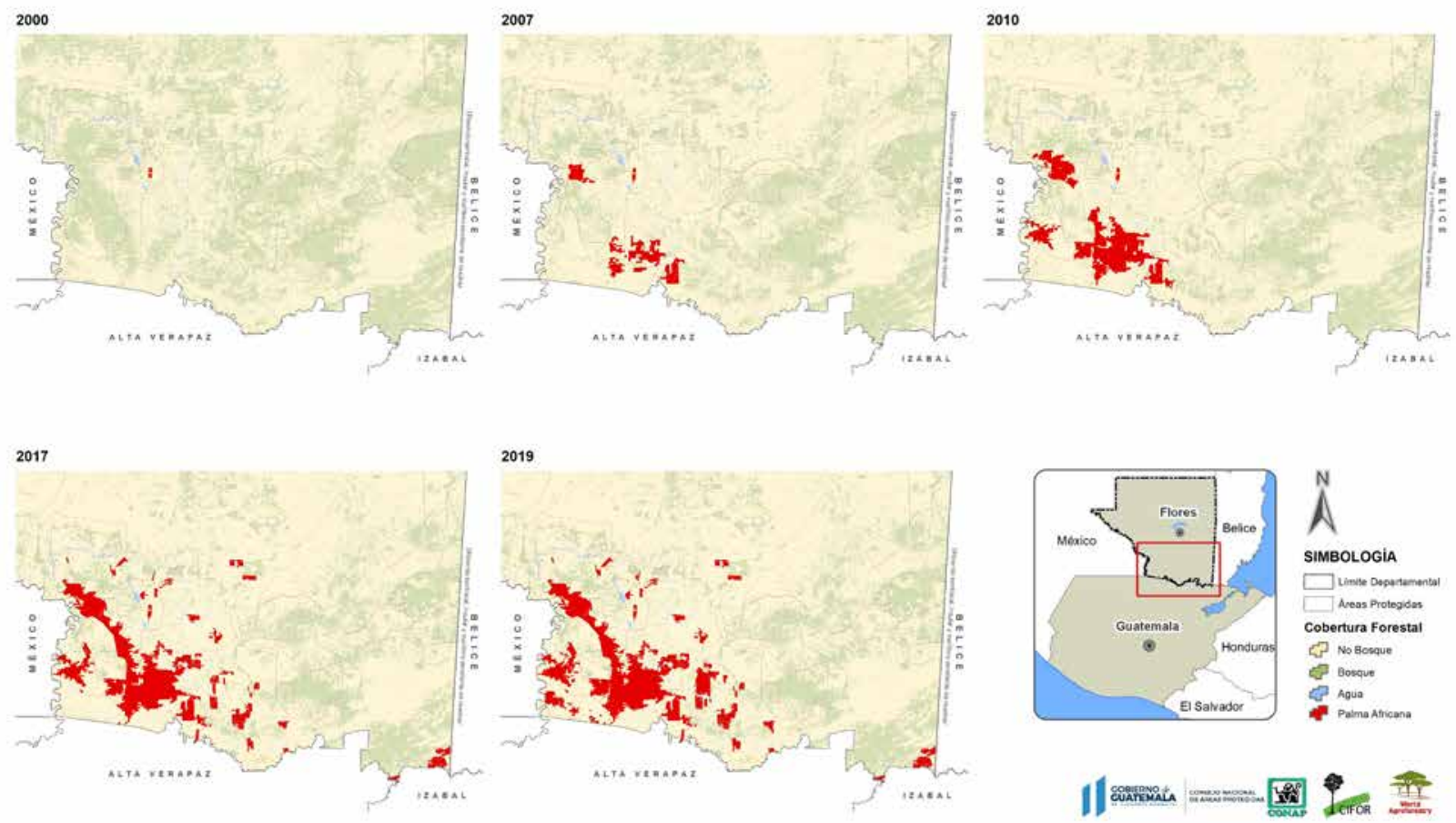

Figura 13. Dinámica de crecimiento del cultivo de palma africana en Petén 2000 - 2020 en la región sur de Petén

Cuadro 6. Distribución de plantaciones de palma africada en municipios de Petén

\begin{tabular}{lc}
\hline Municipio & $\begin{array}{c}\text { Area } \\
\text { (Hectareas) }\end{array}$ \\
\hline Sayaxché & 68,740 \\
\hline San Luis & 6,598 \\
\hline El Chal & 1,307 \\
\hline Poptún & 1,300 \\
\hline San Francisco & 462 \\
\hline San Andrés & 513 \\
\hline TOTAL & $\mathbf{7 8 , 9 2 1}$ \\
\hline
\end{tabular}

Fuente: GREPALMA (2019)

La expansión de la palma ha generado un proceso de venta y compra de tierra, a través de contratos de arrendamientos de tierra, compra directa, o a través de terceros, para el establecimiento de plantaciones. La compra de tierra también busca asegurar accesos a caminos y zonas donde hay nacimientos o fuentes de agua, en algunos casos afecta el acceso y resulta en la privatización de zonas de acceso a carreteras y/o fuentes de agua. La Figura 14 muestra la dinámica de la adquisición de fincas por parte de las empresas palmeras en la zona sur de Petén entre el 2017 al 2019. 

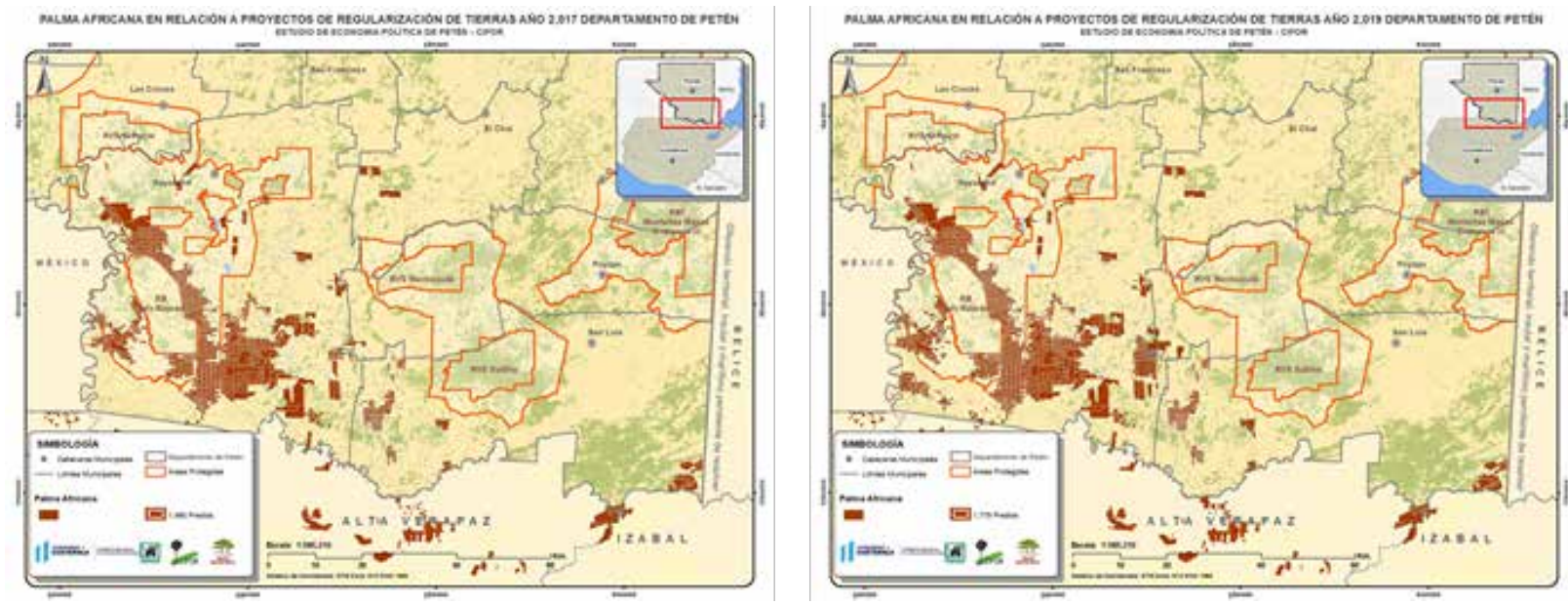

Figura 14. Dinámica de la adquisición de fincas por parte de las empresas palmeras en la región sur de Petén (2017-2019)

En la actualidad según GREPALMA en Petén existen 78,921.02 Ha de palma africana establecidas $(68,740.18$ Ha en Sayaxché; 6,598.46 Ha en San Luis; 1,307.38 Ha en El Chal, 1,300 Ha en Poptún, 462 Ha en San Francisco, 513 Ha en San Andrés).

Según el Estudio Socioeconómico del Cultivo de Palma de Aceite en Guatemala ${ }^{29}$ los costos aproximados de adquisición de tierras y establecimiento de cultivos son alrededor de USD3,500/Ha, mientras que la inversión de tierra depende de la necesidad de riego (USD6,250) o no riego (USD5000) por lo que el costo de establecimiento es mucho más alto al costo de la tierra (CABI 2015:2). Partiendo de los datos producidos por este estudio y considerando que en Petén se ubica el $46.03 \%$ del área establecida a nivel nacional se puede deducir que los costos de producción - vinculados con los costos de producción de palma ascienden a US\$ $1,410,000,000^{30}$, que en Petén sería alrededor de US\$ 649,023,000 y US\$ 157,724,671.9 en Plantas Industriales (datos para el año en que existían 160,000 Ha plantadas).

En materia de ingresos brutos por ventas, se estima que Guatemala ha exportado del 2015 al 2019 un promedio de venta de US\$ 389,207.6 millones/año a nivel nacional (2015-2019). Considerando el porcentaje de las plantaciones que se ubican en Petén (46.03\%), esto daría un ingreso bruto anual de US\$ 179.15 millones/año.

\subsection{Impactos de las dinámicas económicas sobre los bosques}

Los cambios en las dinámicas socio-productivas en Petén han tenido impactos claros en la cobertura forestal. La Figura 15 muestra la evolución de la pérdida de la misma, el departamento pasó de una cobertura forestal del $61 \%$ en el año 2000 a $45 \%$ en el año 2016, perdiéndose en este período un total de 565,008 ha (35,313 ha/año). La pérdida de bosque es directamente proporcional con la expansión del área para uso agropecuario.

29 Página 2. http://grupohame.com/wp-content/uploads/2017/02/Estudio-PALMA-CABI-Guatemala.pdf

30 Para corroborar se tomó el dato del costo de la tierra por Ha y su inversión para el establecimiento sin riego (US\$ $3,500+5,000$ ) y se multiplicó por las 78,921.02, danto como resultado una inversión de US\$ 670,828,670. 

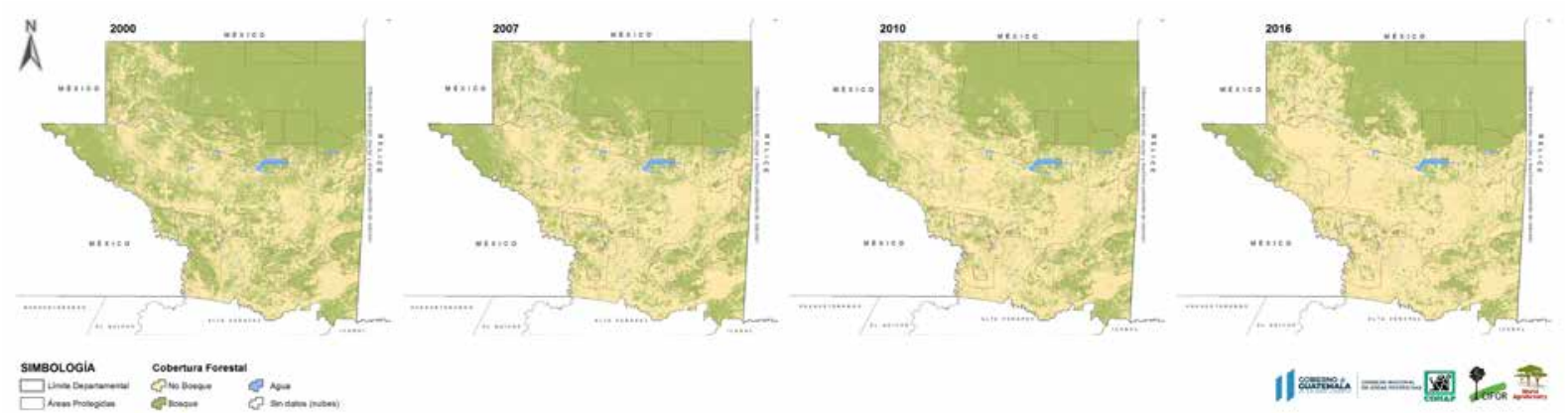

Figura 15. Cobertura forestal de Petén 2000 - 2016

El Cuadro 7 y la Figura 16 muestra los cambios a nivel del tipo de uso de suelo - específicamente entre el uso agropecuario - no bosque incluyendo guamiles y el bosque entre el período 2000 - 2016.

Cuadro 7. Cobertura forestal de Petén (2000 - 2016)

\begin{tabular}{lcrrr}
\hline Cobertura/Año & $\mathbf{2 0 0 0}$ & \multicolumn{1}{c}{$\mathbf{2 0 0 7}$} & \multicolumn{1}{c}{$\mathbf{2 0 1 0}$} & \multicolumn{1}{c}{$\mathbf{2 0 1 6}$} \\
\hline Agropecuario - No bosque - Guamiles & $1,184,022$ & $1,435,991$ & $1,514,000$ & $1,921,198$ \\
\hline Bosque & $2,194,320$ & $1,927,930$ & $1,820,271$ & $1,629,312$ \\
\hline Agua & 39,779 & 39,779 & 39,799 & 34,163 \\
\hline
\end{tabular}

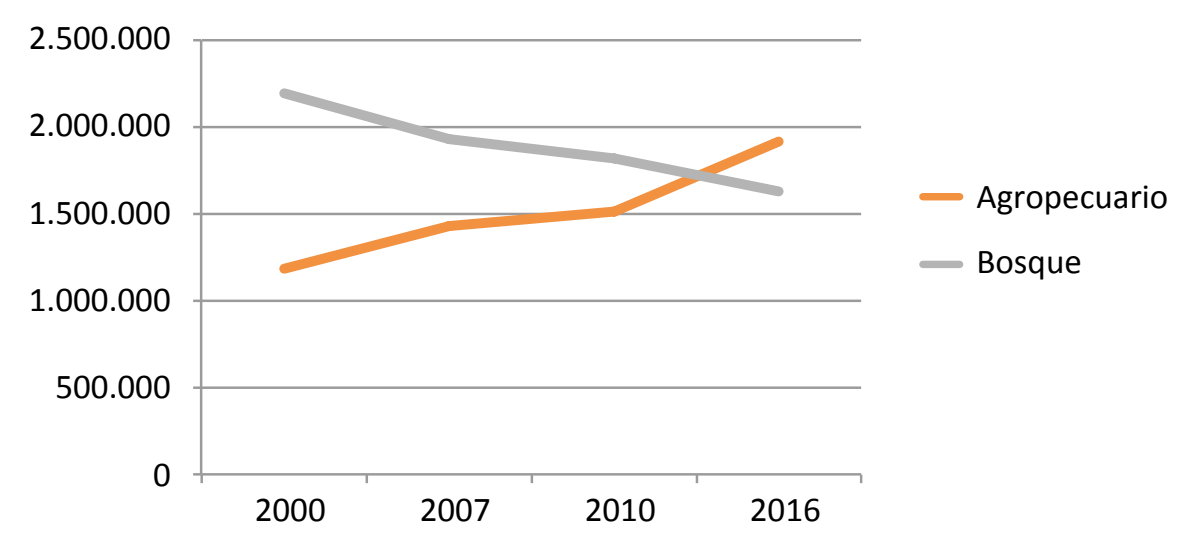

Figura 16. Área de pérdida de bosque y crecimiento agropecuario en el período 2000-2016

Por otro lado, el Cuadro 8 proporciona una síntesis de los datos anteriormente mencionados, indicando un fuerte incremento en el área dedicada a actividades agropecuarias, con dos ejemplos en el área dedicada al cultivo de palma africana, al mismo que un aumento significativo del número de cabezas de ganado vacuno en la región. De igual manera, los datos muestran un aumento de población aunado a un incremento significativo de las carreteras en el departamento. Esto permite ver, por ejemplo, que por cada kilómetro de carretera que se habilita aumenta 172 cabezas de ganado. Por otro lado, también evidencian una fuerte inversión generada por ciertas actividades, por ejemplo, la importancia de las actividades como los incentivos forestales con una inversión de Q6,310 pagados en incentivos por cada hectárea forestal incentivada. Además los datos reflejan que en Petén por cada Q. 3 que invierte el Consejo de Desarrollo, el INAB invierte Q.1 en materia de incentivos forestales (analizando como referencia los datos para el período 2005-2020). 
Cuadro 8. Parámetros de origen (2000-2003) y situación actual (2016-2020) para los principales usos de la tierra en Petén

\begin{tabular}{|c|c|c|c|c|c|c|c|c|}
\hline Parametro/Año & 2000 & 2002 & 2003 & 2016 & 2018 & 2020 & $\begin{array}{l}\text { Pérdida/ } \\
\text { Aumento }\end{array}$ & Cambio \\
\hline Bosque (Ha) & $2,194,320$ & & & $1,629,312$ & & & 565,008 & Pérdida \\
\hline $\begin{array}{l}\text { Agropecuario } \\
(\mathrm{Ha})\end{array}$ & $1,184,022$ & & & $1,921,198$ & & & 737,176 & Incremento \\
\hline $\begin{array}{l}\text { Población } \\
\text { (No. Habitantes) }\end{array}$ & & 366,735 & & & 545,600 & & 178,865 & Incremento \\
\hline Carreteras $(\mathrm{Km})$ & 4,890 & & & & & 12,007 & 7,117 & Incremento \\
\hline $\begin{array}{l}\text { Ganadería } \\
\text { (No. Cabezas) }\end{array}$ & & & 315,819 & & & $1,536,714$ & $1,220,895$ & Incremento \\
\hline $\begin{array}{l}\text { Palma Africana } \\
(\mathrm{Ha})\end{array}$ & 320 & & & & & 78,921 & 78,601 & Incremento \\
\hline $\begin{array}{l}\text { Incentivos } \\
\text { Forestales (Ha) }\end{array}$ & 5,865 & & & & & 158,396 & 152,531 & Incremento \\
\hline
\end{tabular}

Dado que este análisis buscaba generar datos a nivel del departamento, la escala no profundiza sobre las diferencias existentes. A manera de identificar algunas de estas diferencias a lo interno del departamento, se hizo un análisis de cuadrantes partiendo de la identificación de 5 áreas diferentes (Ver Figura 17) a nivel de todo el departamento. Las áreas seleccionadas traslapan con diversas zonas de manejo de la RBM incluyendo su Zona Núcleo, la Zona de Usos Múltiples y la Zona de Amortiguamiento, así como las Áreas Protegidas del Sur y áreas del departamento que se encuentran fuera de áreas protegidas. Estas áreas se identifican en las figuras siguientes (Ver Figuras 18, 19, 20 y 21) si bien requieren un análisis más detenido - que queda fuera de este estudio - si permiten identificar trayectorias diferentes. Para identificar los cambios más importantes a nivel del uso de suelo, cada cuadrante presenta dos imágenes una correspondiente al área en el año 2000 y otro correspondiente en el año 2020, el análisis de los mapas se realiza de forma cualitativa, a partir de los cambios significativos que muestran la imagen.

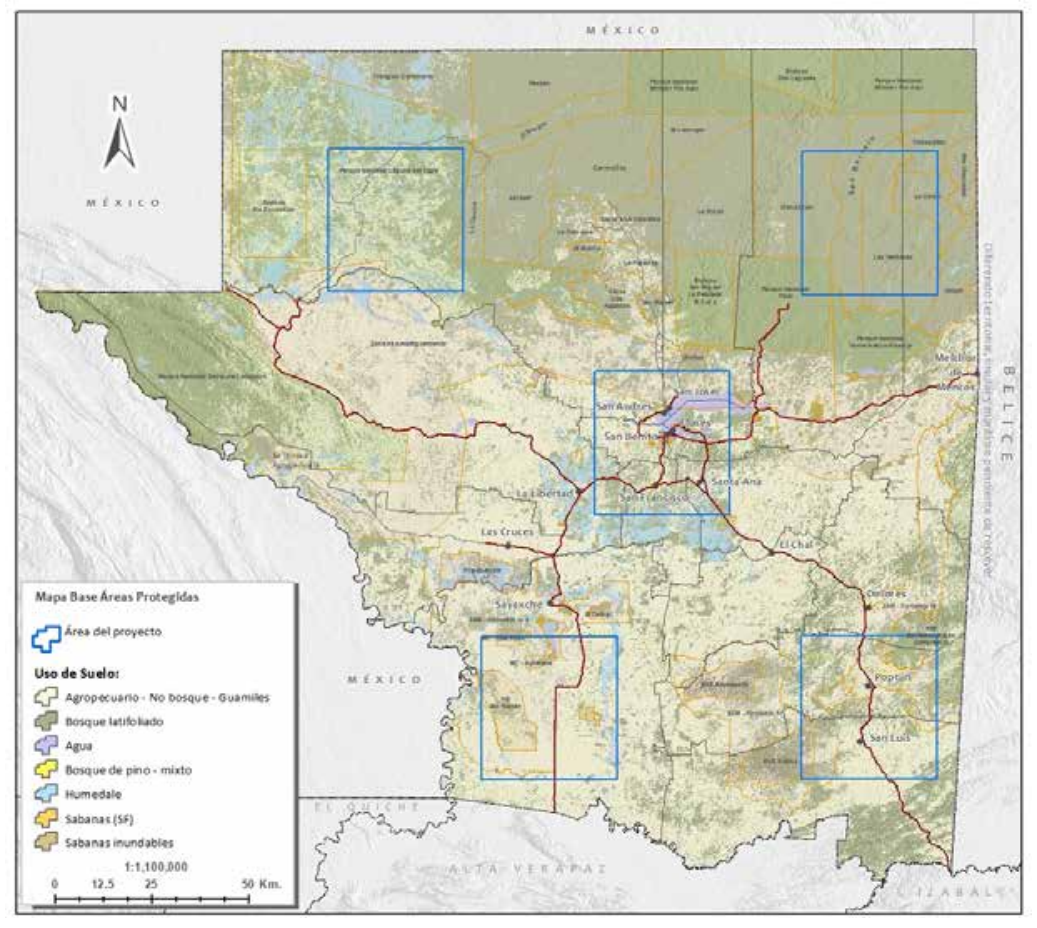

Figura 17. Análisis de cambios a nivel de cuadrantes 

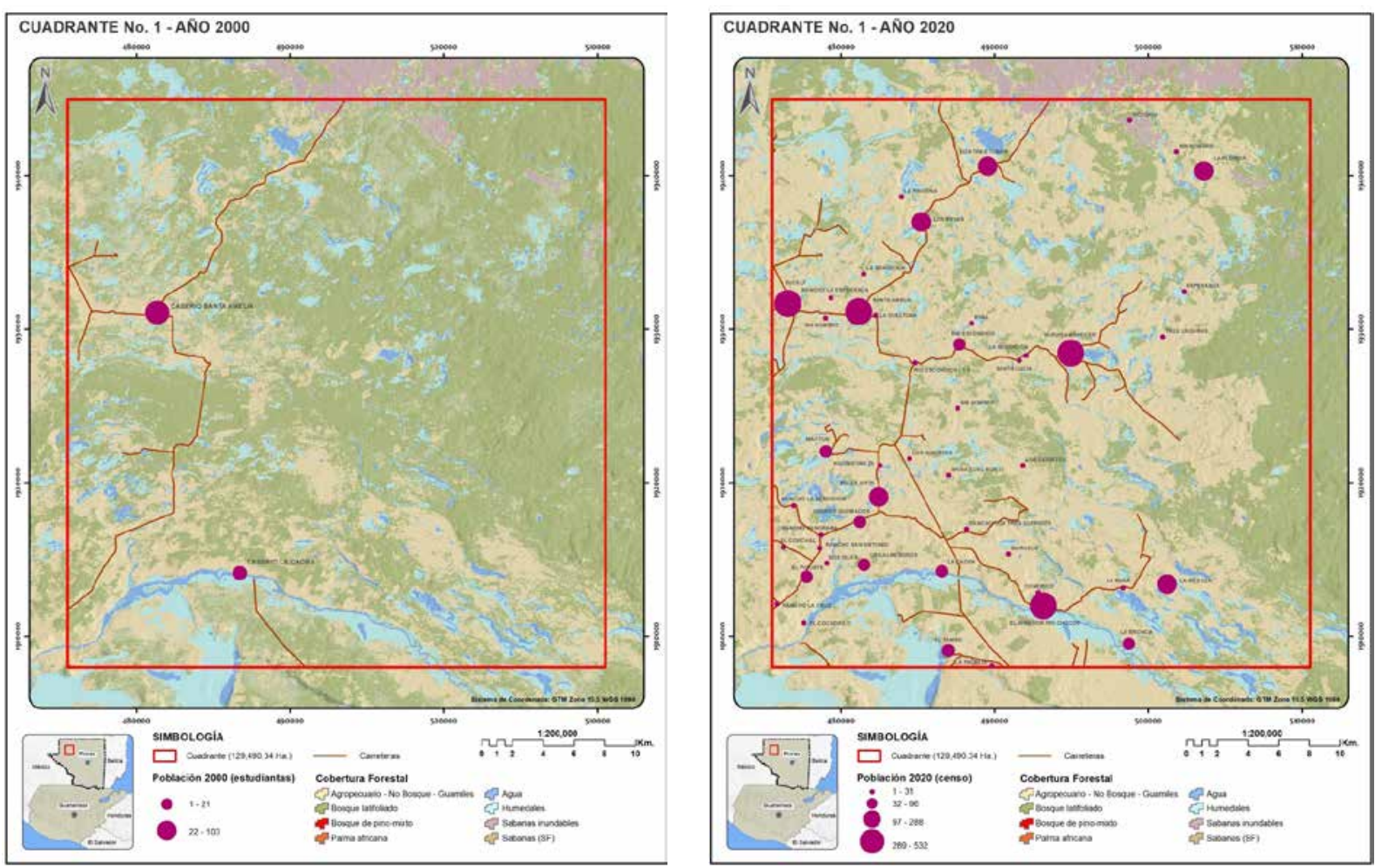

Figura 18. Cuadrante 1 principales cambios de uso de la tierra 2000-2020
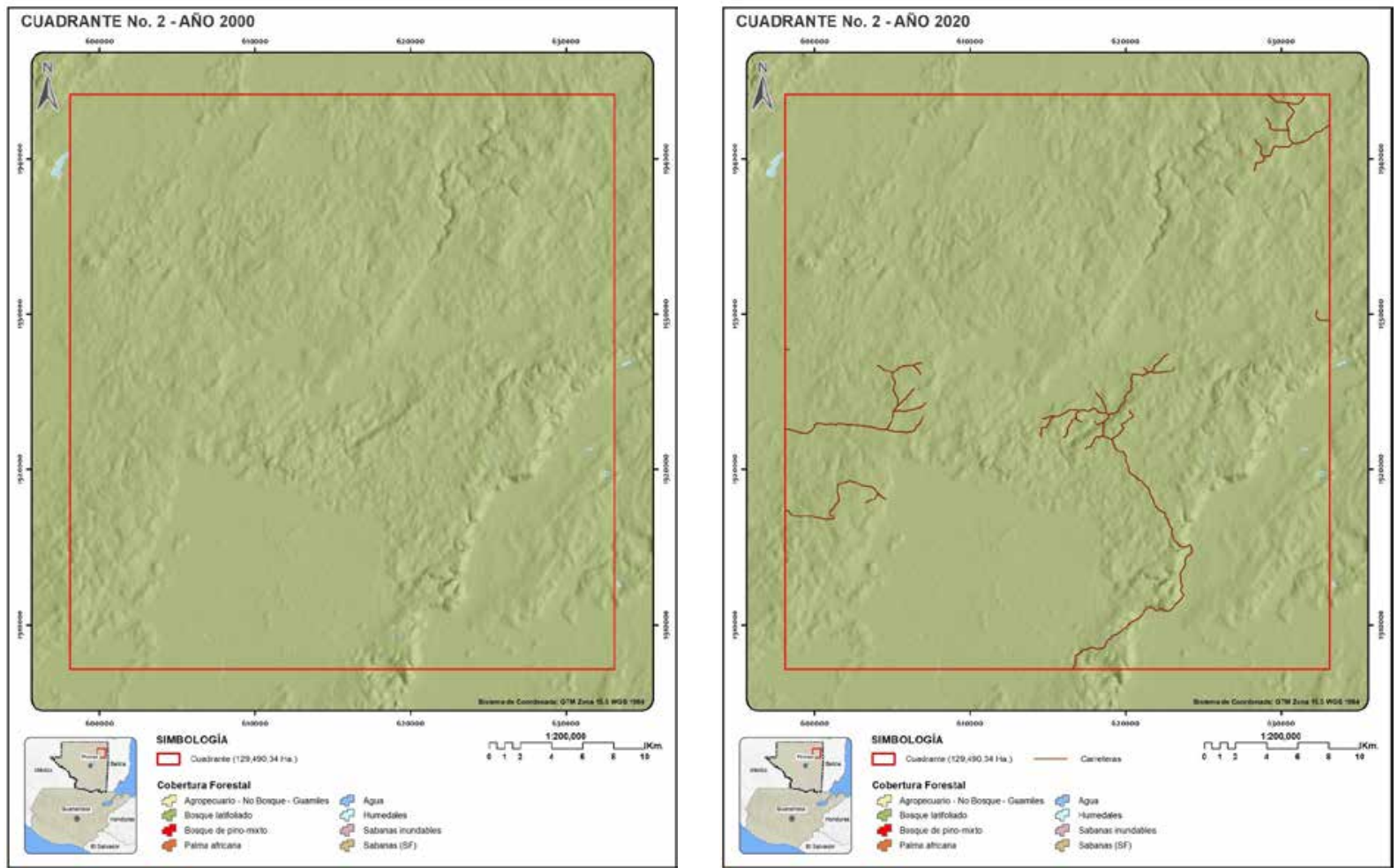

Figura 19. Cuadrante 2 principales cambios de uso de la tierra 2000-2020 

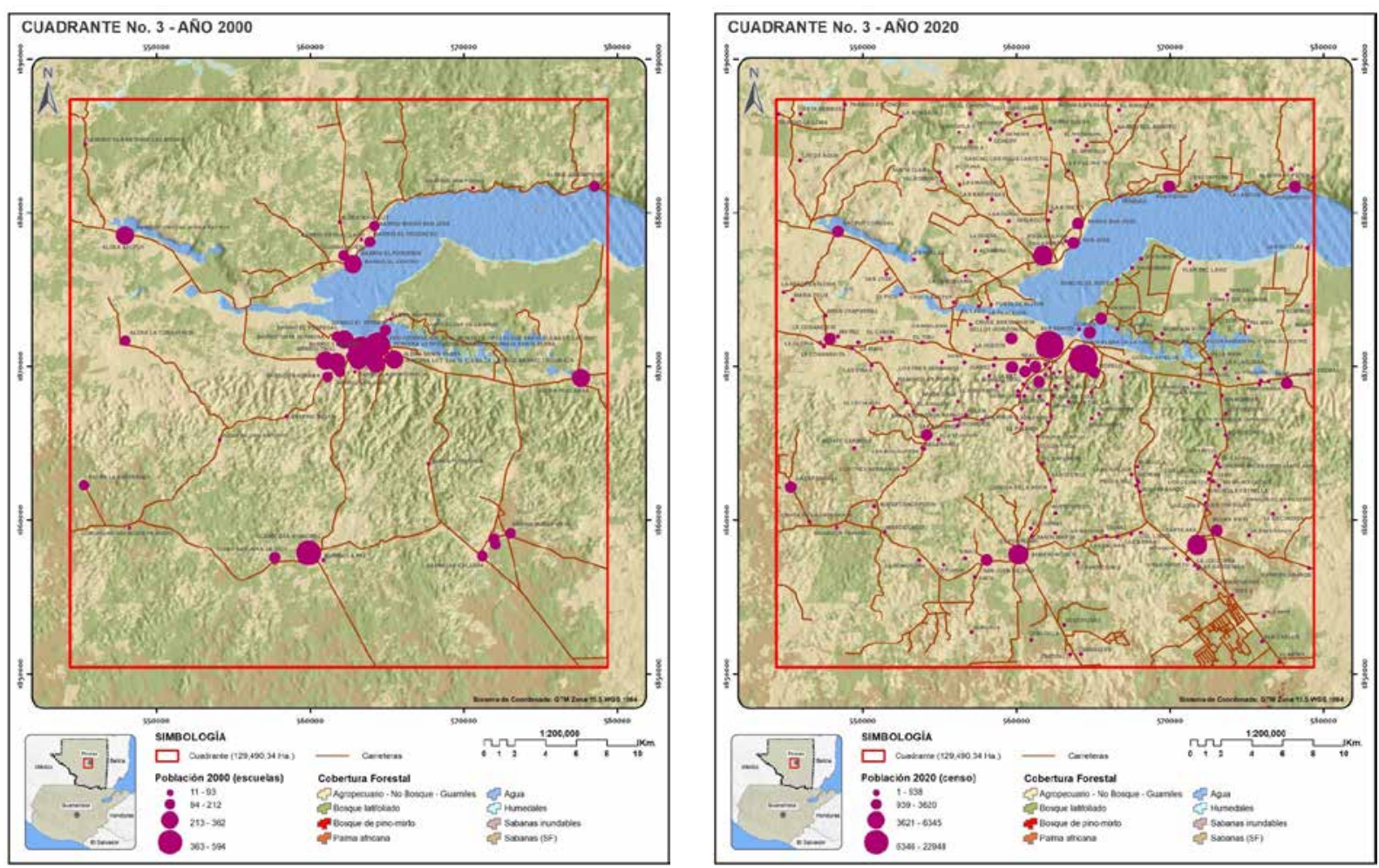

Figura 20. Cuadrante 3 principales cambios de uso de la tierra 2000-2020

Por ejemplo, los cuadrantes 1 y 2 se encuentran dentro de la RMB (Figura 17 y 18), incluyendo áreas que se ubican dentro del Parque Nacional Laguna de Tigre (Cuadrante 1) y la Zona de Usos Multiples (Cuadrante 2) traslapándose ésta, con zonas de manejo bajo contrato de concesión comunitaria. Si bien el Cuadrante 1 se encuentra en un área cuya categoría de manejo en área protegida es Parque Nacional y restringe la actividad humana, la comparación entre el mapa del año 2000 al 2020 - muestra dos cambios significativos a simple vista: un aumento en la población - que apunta a la ampliación de sitios poblados, comunidades y la red vial, si bien el mapa no establece el tipo de vía dado que incluye caminos de terracería, senderos y trocapaces, los cambios en la cobertura de bosque a no bosque entre el año 2000 a 2020 son claros. Por otro lado, el cuadrante 2, muestra un área bajo contrato de concesión comunitaria, que si bien evidencian un aumento de las vías, por su ubcación permiten deducir que son trocopases derivados de la actividad de manejo forestal, sin embargo, el mapa no evidencia cambios significativos en la cobertura en los ultimos 20 años. Así mismo, el cuadrante 3 muestra los cambios a nivel del área central, una desconcentración del área poblada de San Benito y Santa Elena y un aumento de los sitios poblados y las carreteras alrededor del área del Lago con una disminución del área de cobertura de bosque (Figura 19).

Al mismo tiempo, los cuadrantes 4 y 5 se encuentran ambos en el Sur de Petén, el cuadrante 4 se traslapa con areas que forman parte del Complejo 4 de Areas Protegidas del Sur en Sayaxché (Figura 21 y 22). A pesar de la categoría de manejo, en la comparación de los años 2000 a 2020 este cuadrante muestra uno de los cambios más drásticos de los cinco analizados. No solo en terminos del aumento de población y la red de carreteras incluyendo una de las ultimas carreteras asfaltadas que van del tramo de Alta Verapaz vía Sayaxche, este cuadrante muestra el aumento de áreas dedicadas a cultivos de palma africana y un cambio de uso de suelo significativo. Por otro lado, el cuadrante 5 es interesante, en tanto que si bien es cierto hay cambios en aumento de pobalción y carretera, también muestra un aumento significativo de las áreas bajo el programa de incentivos forestales. En su conjunto, los cinco cuadrantes muestran que diversas trayectorias tienen impactos importantes en el uso de suelos a nivel del departamento. 

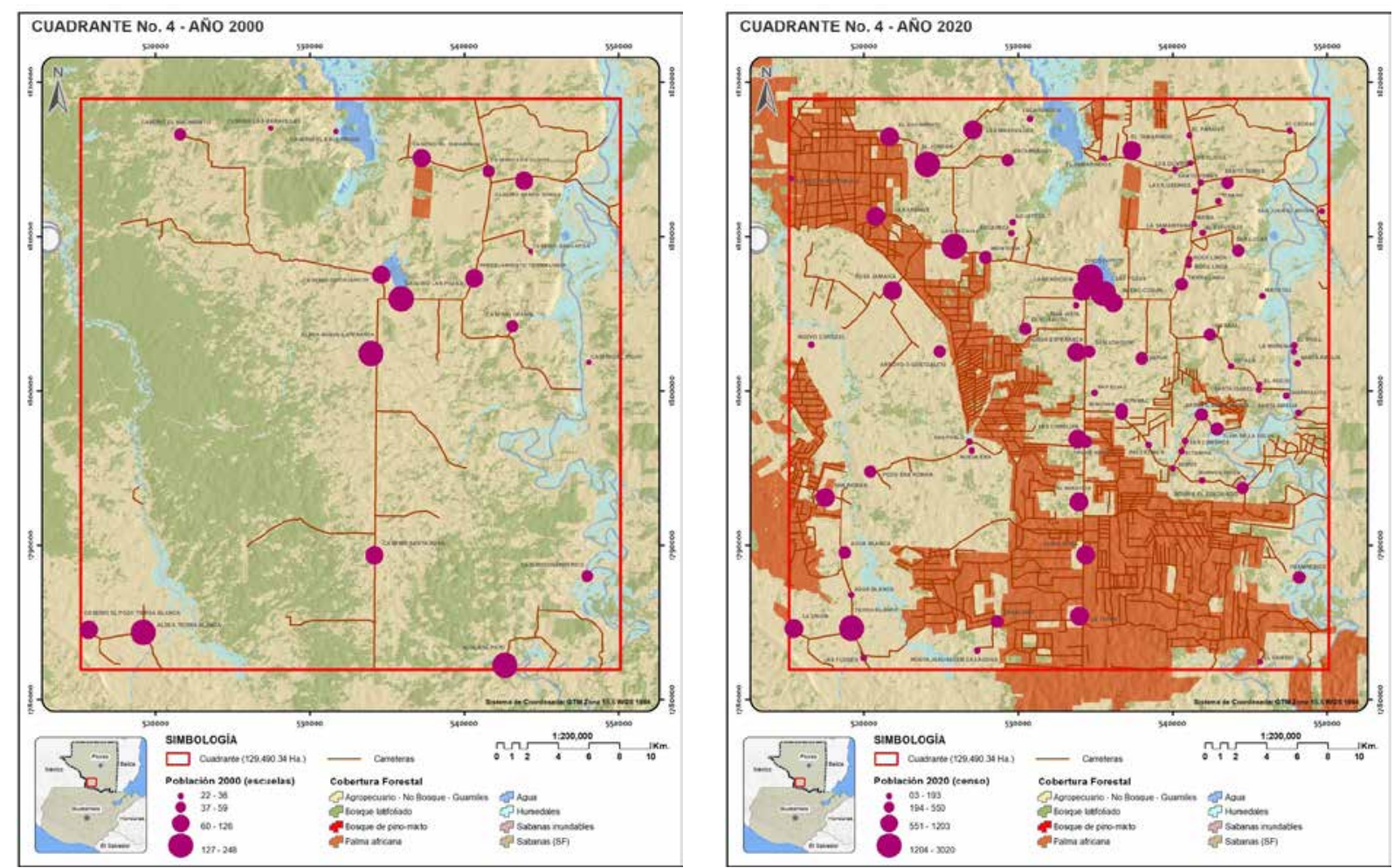

Figura 21. Cuadrante 4 principales cambios de uso de la tierra 2000-2020
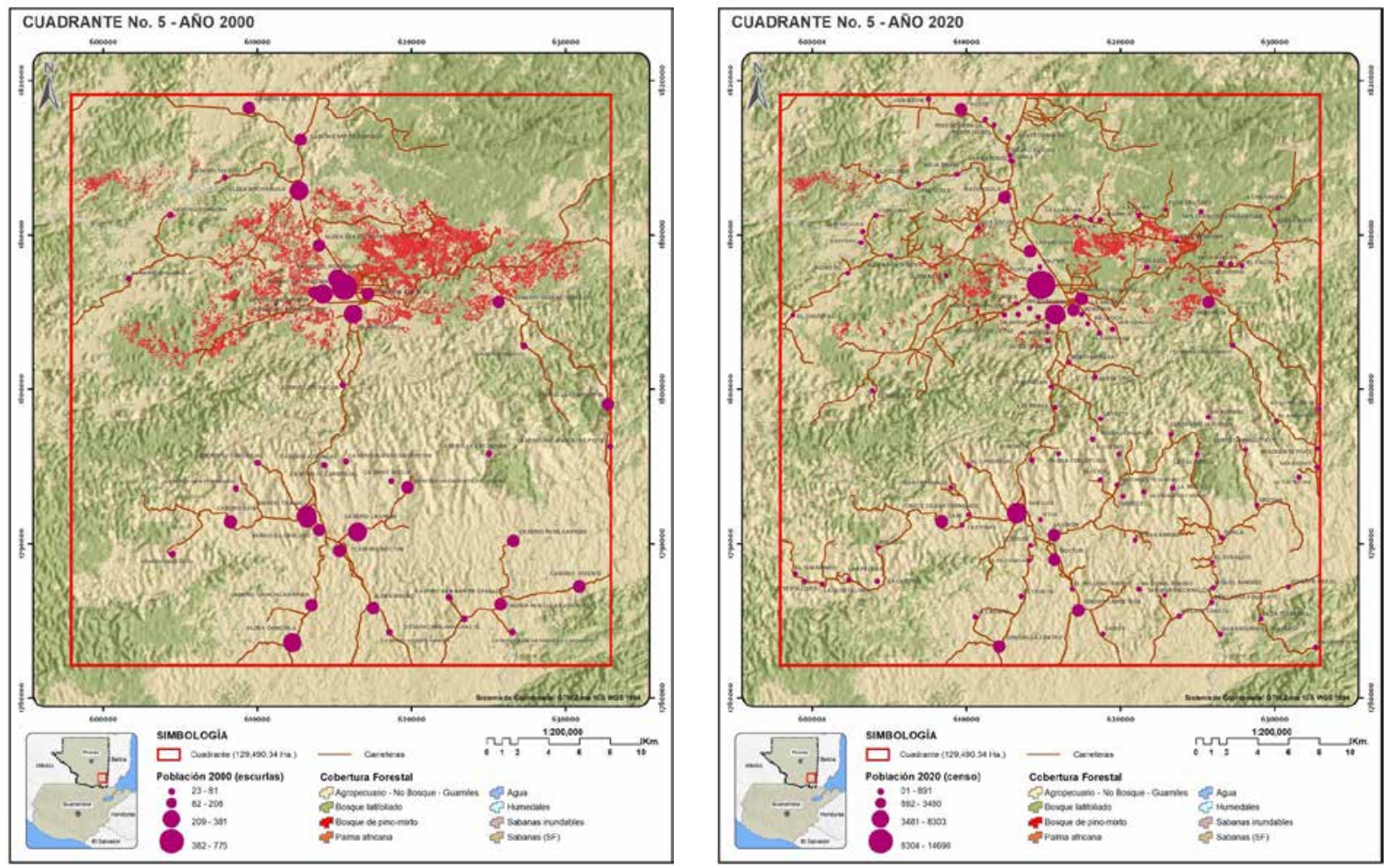

Figura 22. Cuadrante 5 principales cambios de uso de la tierra 2000-2020 
La red de carreteras se ha ampliado también dentro de las áreas protegidas. Solo en el Parque Nacional Laguna del Tigre subió de $272 \mathrm{~km}$ en 2015 (asfalto, terracería y trocopaces) a 1,188 km en 2020 (aumentando $915 \mathrm{Km}$, que equivale al viaje por tierra ida y vuelta de Flores Petén a ciudad de Guatemala). En el PN Sierra del Lacandón las carreteras incluso más que se duplicaron, de $135 \mathrm{~km}$ en 2015 (asfalto, terracería y trocopaces) a $413 \mathrm{~km}$ en 2020 (Figura 23).
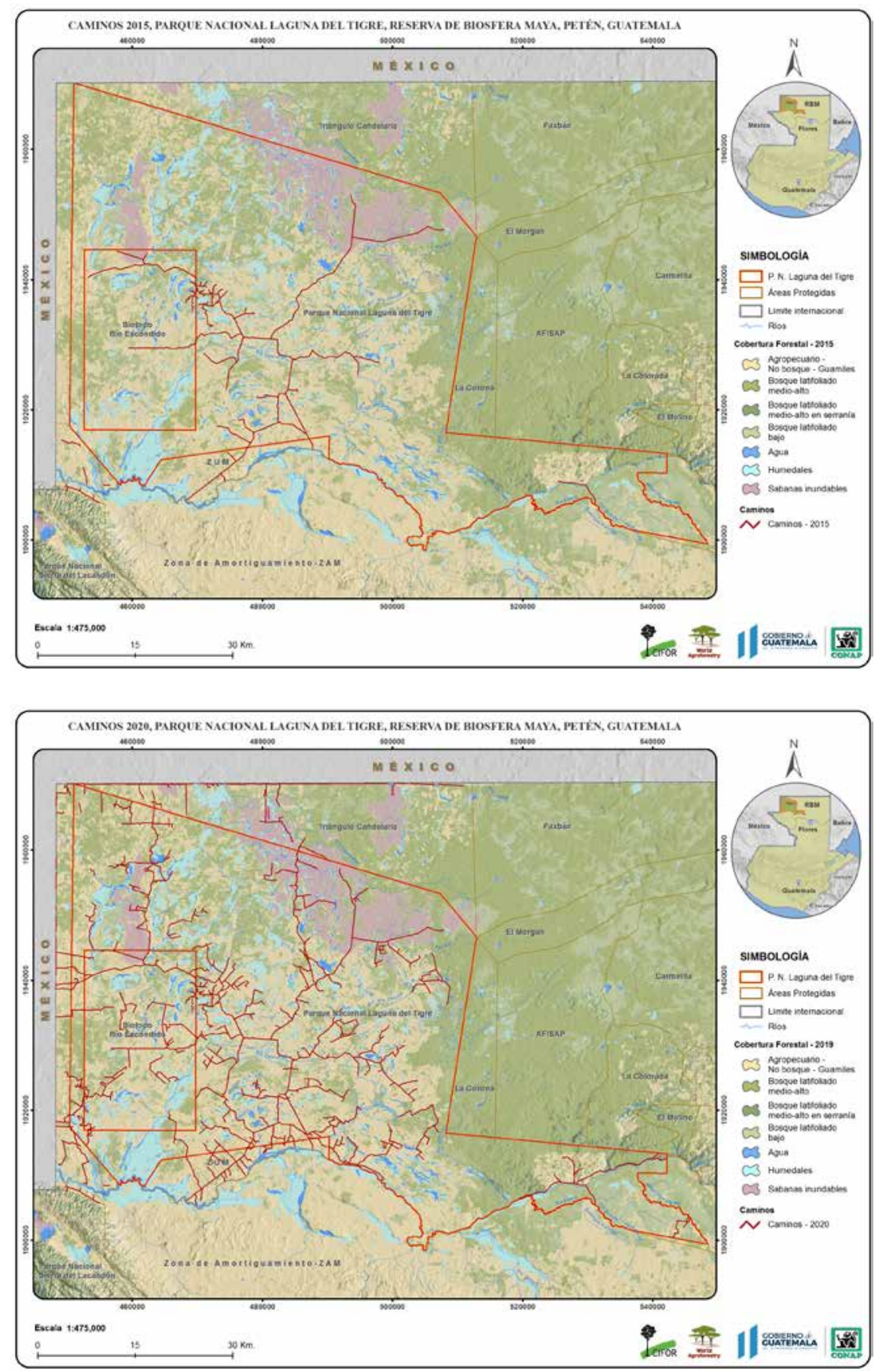

Figura 23. Incremento de la red de carreteras dentro del PNLT Parque Nacional Laguna de Tigre (2000-2020)

No se cuenta con un estudio detallado que refleje la dinámica posterior al proceso de venta de tierras para el cultivo de Palma Africana, al momento se sabe que muchas de las familias que venden se quedan trabajando en el mismo cultivo, pero otras emigran internamente dentro de Petén. 


\section{La inversión pública en Petén}

El Cuadro 9 muestra una síntesis de los datos presentados en la Sección 2, mostrando el volumen de ingresos brutos anuales generados por las principales industrias en el Petén propuestas a fortalecerse por el PDI se presenta en el Cuadro 9 Plan de Desarrollo Integrado (SEGEPLAN, 2013b).

Cuadro 9. Resumen de los valores brutos anuales (US\$) generados por las principales industrias del Petén, 2010-2020

\begin{tabular}{lc}
\hline Industria & Ingreso bruto anual (US\$ millones/año) \\
\hline Forestal & 15.39 \\
\hline Turismo & 28.42 \\
\hline Fruticultura & 35.55 \\
\hline Ganadera & 127.29 \\
\hline Palma Africana & 179.13 \\
\hline Total & $\mathbf{5 7 6 . 6 3}$ \\
\hline
\end{tabular}

Por otro lado, el aporte del Consejo de Desarrollo es de US\$ 17.5 millones/año (promedio 2005-2020), constituyéndose en un 3\% de lo que generan las industrias analizadas. Estos datos no muestran en sí la relación entre los valores brutos, la generación de empleo y la reinversión a nivel del departamento pero si dan una idea del papel que las industrias basadas en los recursos naturales y culturales juegan para la economía de la región. Sin embargo, estos no reflejan la pérdida de ingresos por el cambio de uso de suelo, la degradación de recursos y/o la perdida de los servicios ecosistémicos.

Esta sección parte del análisis realizado por Tillit (2020) que buscaba entender los flujos de inversión pública en el departamento. Estos varían de acuerdo con los fondos que manejan los Consejos Departamentales de Desarrollo, bajo tres fuentes principales: a) Aporte presupuestario a Consejos de Desarrollo (asignaciones del presupuesto nacional que han sido constantes y han ido en aumento), b) Aporte extraordinario a los Consejos de Desarrollo y c) FONPETROL (a partir del año 2009).

\subsection{Inversión por tipo de fondo}

Nuestros resultados muestran que en el período comprendido entre el año 2005 - 2020 se han invertido más de US\$261 millones de dólares, distribuidos en los 14 municipios que forman parte del departamento (Ver Cuadro 10). La evolución de estos fondos se describe en las secciones siguientes.

Cuadro 10. Inversión pública en función del tipo de aporte

\begin{tabular}{lcc}
\hline Rubro & Monto en Q & Monto en US\$ \\
\hline Aporte a Consejos de Desarrollo & $916,014,161$ & $122,135,221$ \\
\hline Aporte Extraordinario a Consejos de Desarrollo & $126,787,056$ & $16,904,940$ \\
\hline Aporte FONPETROL & $921,685,258$ & $122,891,368$ \\
\hline Total Aportes de Fuentes & $1,964,486,475$ & $261,931,530$ \\
\hline
\end{tabular}




\subsubsection{Aporte a Consejos de Desarrollo (ACDD)}

De acuerdo con el Reglamento para la Administración del Aporte a los Consejos de Desarrollo (Acuerdo 2007), el aporte se constituye a partir del 1\% de los ingresos obtenidos por la recaudación del Impuesto al Valor Agregado, el cual se asigna con el objetivo de apoyar "programas y proyectos de infraestructura de los Consejos Departamentales de Desarrollo." El Punto Resolutivo 04-2019 del Reglamento de CONADUR se definen como proyectos de infraestructura todos aquellos proyectos o programas que son necesarios para generar bienes y servicios para la población que permitan el crecimiento económico y el desarrollo social (Artículo 2). Los programas y proyectos a financiar deben estar contemplados en los Planes de Desarrollo de acuerdo al Plan Nacional de Desarrollo pudiendo ser en temas de educación, salud e infraestructura ya sea vial, para la producción o para el saneamiento (Capítulo III). El aporte al Consejo Departamental de Desarrollo de Petén ha ido en aumento, con excepción de los años 2013 y 2015 (Figura 24). El aporte más importante se dio recientemente en el año 2019 (Q. 95,345,620.56). Mientras el año con menor aporte fue el año 2005 (Q. 16,987,130.15).

\section{Aporte a consejos de desarrollo}

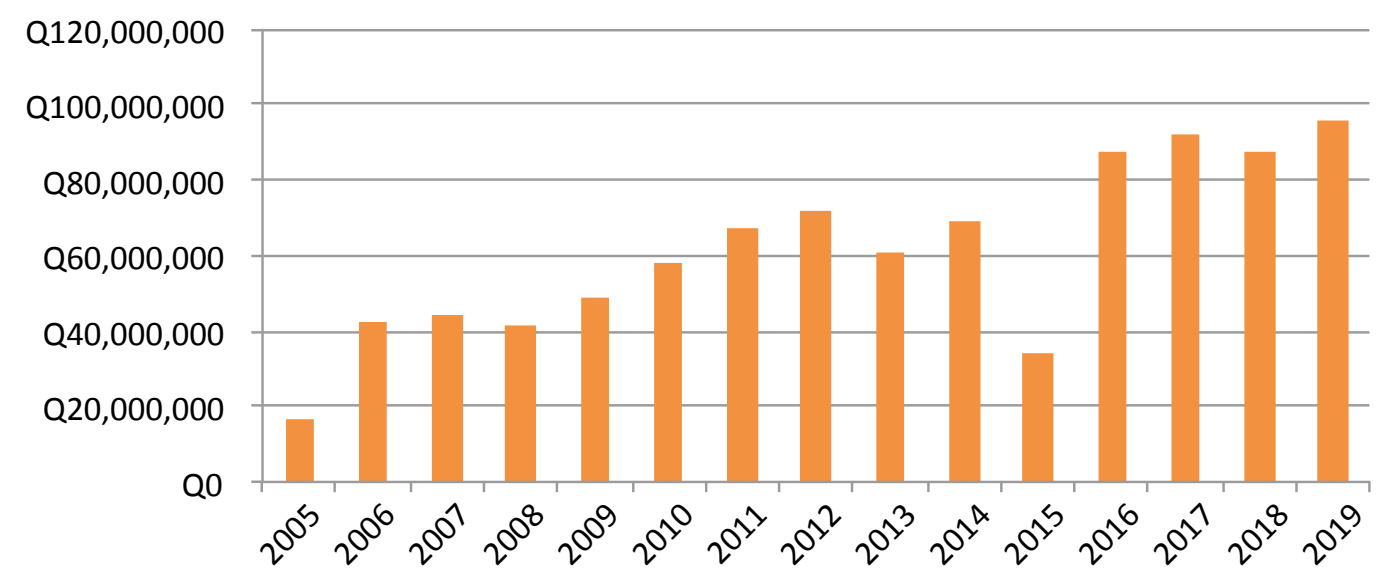

Figura 24. Inversión en el periodo 2005-2019 a través del aporte a consejos de desarrollo Fuente Tillit (2020)

\subsubsection{Aporte Extraordinario a Consejos de Desarrollo}

La aprobación de asignación y distribución del aporte extraordinario a consejos de desarrollo se encuentran registrados en el sistema de Consejo de Desarrollo SISCODE, variando de acuerdo al requerimiento de las autoridades de los gobiernos locales. Distribución del fondo Aporte Extraordinario a los Consejos de Desarrollo -AEOCDD- desde 2010 a 2019 (único período del financiamiento). No existe mucha claridad sobre los criterios que se utilizan tanto para solicitar como para asignar estos fondos. En el caso del departamento de Petén los montos registrados se muestran en el Cuadro 11.

Cuadro 11. Análisis comparativo para diferentes parámetros estudiados y su relación con los cambios ocurridos en el periodo $2000-2020$

\begin{tabular}{lcccc}
\hline Año & AEOCDD F11 & AEOCDD F41 & AEOCDD F52 & Total general \\
\hline $2009-2012$ & $26,993,372$ & & $32,505,395$ & $59,498,767$ \\
\hline $2010-2012$ & & $58,988,288$ & & $58,988,288$ \\
\hline $2011-2019$ & $8,300,000$ & & & $8,300,000$ \\
\hline Total general & $\mathbf{3 5 , 2 9 3 , 3 7 2}$ & $\mathbf{5 8 , 9 8 8 , 2 8 8}$ & $\mathbf{3 2 , 5 0 5 , 3 9 5}$ & $\mathbf{1 2 6 , 7 8 7 , 0 5 6}$ \\
\hline
\end{tabular}

Fuente: Tillit (2020) 


\subsubsection{Aporte de FONPETROL}

El Fondo Económico de la Nación FONPETROL (Decreto 71-2008) es producto de las regalías que goza del Estado de Guatemala, producto de la explotación petrolera. Se distribuye directamente a departamentos productores - distribuido de la siguiente manera: 20\% dedicado al CODEDE; 5\% dedicado a los Consejos Municipales de Desarrollo COMUDE; un 3\% adicional es asignado a actividades de vigilancia del CONAP. Como se puede observar en la Figura 25 el año 2011 es el de mayor ejecución. Dicha dinámica ha respondido a los informes del Ministerio de Energía y Minas y Ministerio de Finanzas respecto de la cantidad de petróleo contabilizado y los precios del barril del crudo en el mercado internacional.

\section{FONPETROL}

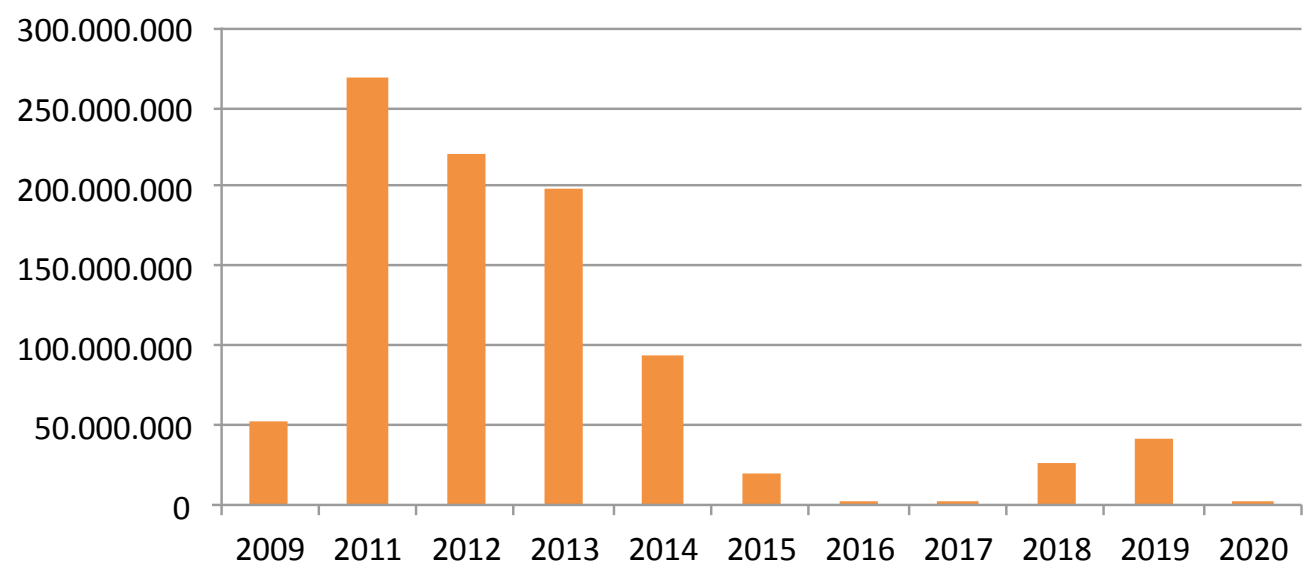

Figura 25. Inversión en el periodo 2009-2020 a través del FONPETROL

Fuente Tillit (2020)

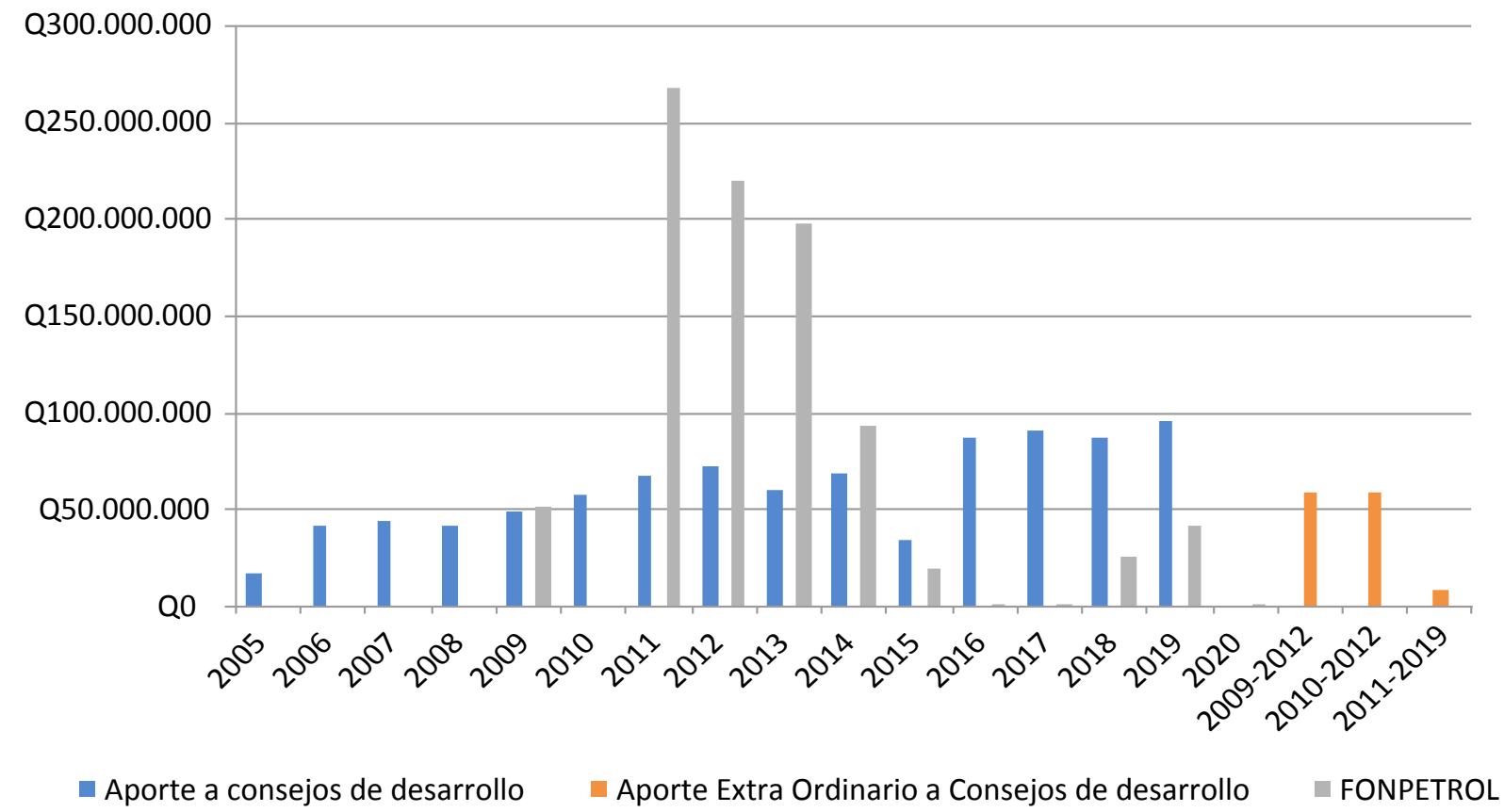

Figura 26. Inversión en el periodo 2005-2020 a través del Consejo de Desarrollo de Petén (tres fuentes) Fuente Tillit (2020) 
La Figura 26 muestra una síntesis de la inversión a través del Consejo de Desarrollo de Petén a través de sus tres fuetnes identificadas en el período 2005-2020. El impacto más fuerte de inversión proviene de FONPETROL y el aporte principal se dio mayormente en el periodo 2011-2020, coincidiendo con el periodo de mayor establecimiento de nuevas carreteras de terracería en Petén (cuando incrementó en 11,265 nuevos kilómetros), con lo cual se dio un incremento de $2.4 \mathrm{Km}$ en relación a toda la red carretera de éste tipo creada desde 1960 al $2000(4,662 \mathrm{Km})$.

\subsection{Inversión por sector}

\subsubsection{Sectores priorizados para la inversión pública}

De los fondos manejados por los consejos departamentales y municipales, los principales sectores de inversión están relacionados con la infraestructura y el transporte. Esto se puede observar en el análisis (Ver Figura 27), que plantea que el sector con mayor inversión es el de transporte por carretera, y el de menor inversión son los de transporte por agua y seguridad.

\section{Sectores de inversion CODEDE Peten - Monto Total 2005-2019}

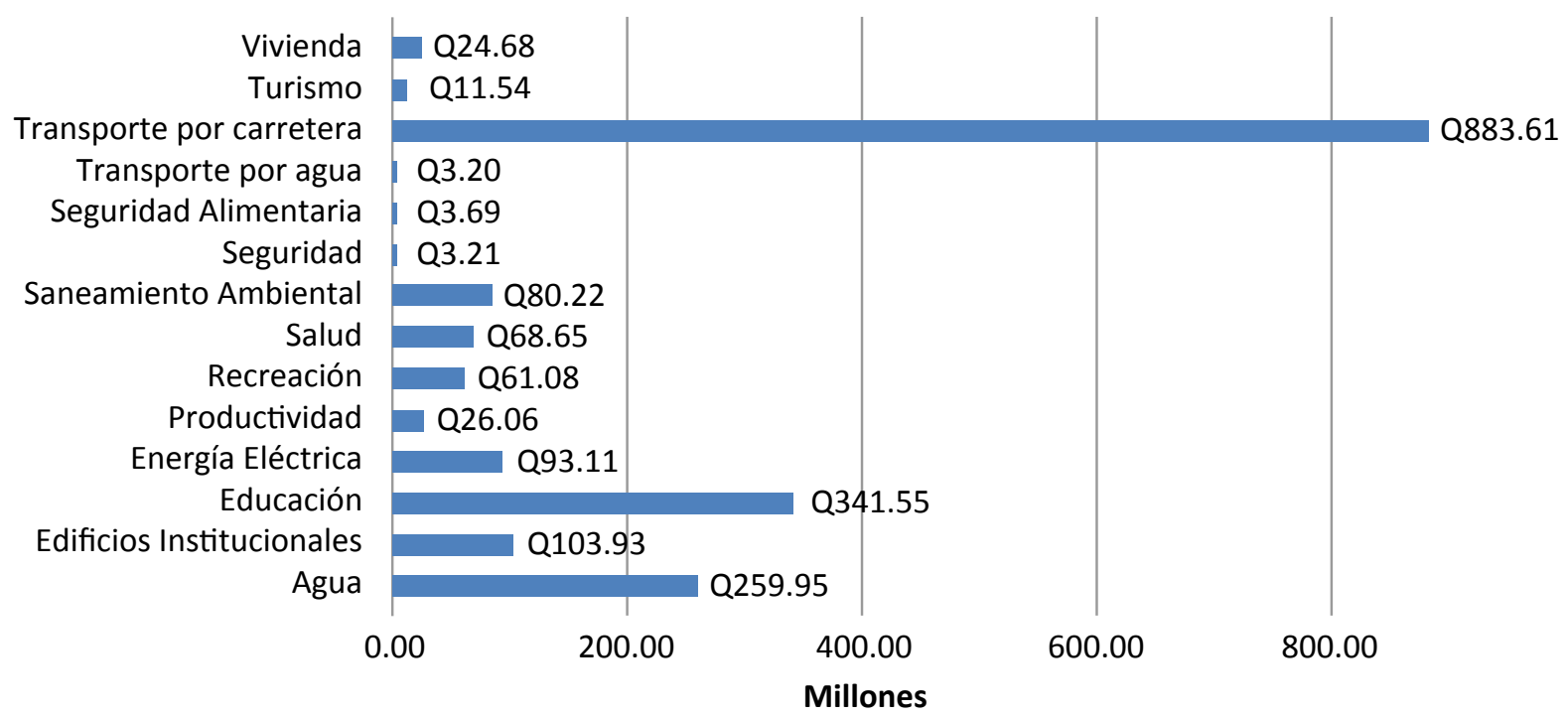

Figura 27. Sectores de inversión de CODEDE (tres fuentes) para el periodo 2005-2019

Fuente Tillit (2020)

\subsubsection{Inversión pública de fondos de CODEDE a municipios}

Anivel de los gobiernos locales, los fondos manejados por el Consejo Departamental de Desarrollo generan fondos para manejarse a nivel de los Consejos Municipales de Desarrollo, en las 14 municipalidades que forman parte del Departamento de Petén (Figura 28).

Al analizar la inversión hecha por CODEDE en el periodo 2005-2020, la cual varía de acuerdo al número de habitantes reportados, resulta que el municipio de San José es el que tiene una asignación individual más grande, seguido por San Francisco y Santa Ana. Nuevamente los municipios recién creados reportan los aportes individuales más bajos (dado a que el monto recibido inicia con la creación del municipio. 


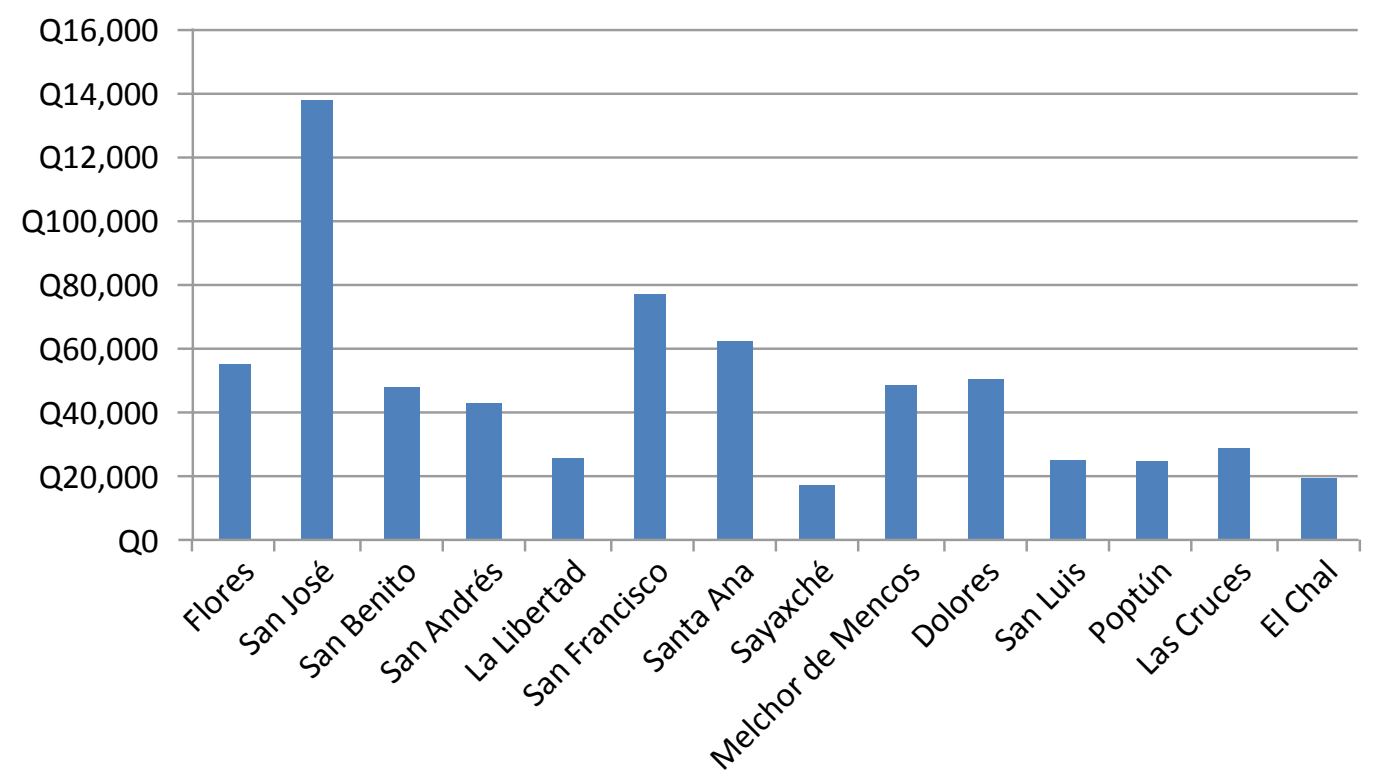

Figura 28. Inversión municipal en relación con el número de habitantes

Los municipios con mayor inversión son los ubicados en el área central de Petén (Flores, en su calidad de cabecera departamental y San Benito). Los municipios con menor inversión son lo creados más recientemente (El Chal, San José y Las Cruces).

Monto invertido, total por Municipio 2005-2019

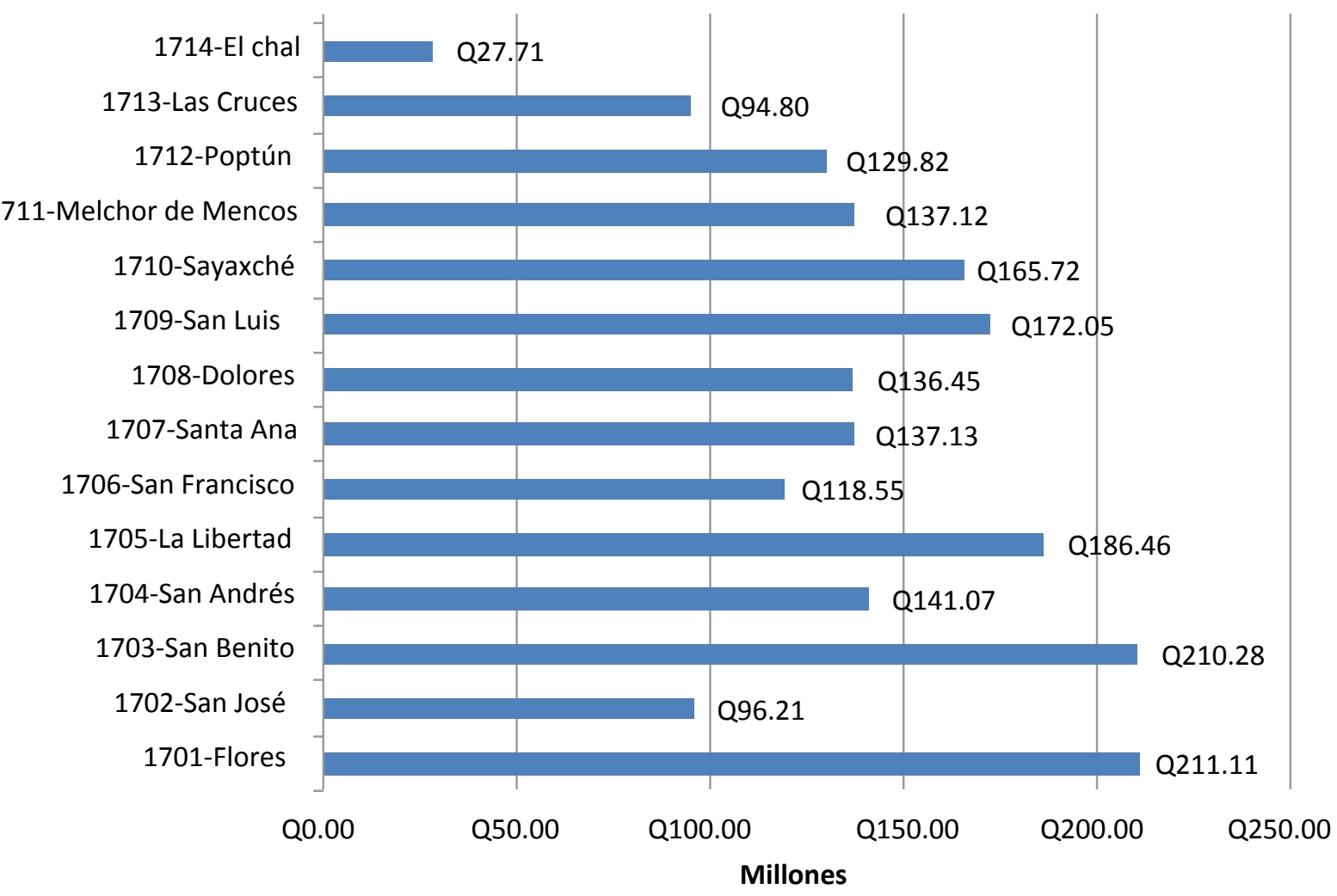

Figura 29. Análisis de la inversión pública con distintos Fondos del CODEDE (tres fuentes) de Petén, distribución a municipios 


\section{Discusión: Implicaciones para la gestión de recursos y la RBM}

Los resultados muestran que las intervenciones gubernamentales en la región del Petén han pasado por diferentes etapas, con diferentes impactos sobre los bosques. Este estudio se ha concentrado en aportar datos para entender los procesos de política pública y otros cambios socio-productivos que influyen desde principios de la década de 2000. Este período está marcado por el surgimiento de nuevas iniciativas y un renovado interés en los bosques y los recursos naturales como espacio para el desarrollo económico basado en la agroindustria, como lo podemos ver con el surgimiento del cultivo de palma aceitera, la producción frutícola y la expansión de la ganadería. Estas propuestas de gestión de recursos han dejado su huella en el paisaje regional, en particular en el sur de Petén, con la conversión a gran escala del bosque al uso agrícola. En la RBM, por otro lado, una segunda trayectoria en algunos espacios de protección - el caso particular de los Parques nacionales Laguna de Tigre y en áreas de Sierra de Lacandón implica un enfoque de conservación incompleto, marcado por la ausencia de acuerdos operativos para el control efectivo de los bosques, lo que abre la puerta a la deforestación local y al surgimiento de redes ilícitas. Estas trayectorias se vuelven más evidentes en la visualización de los cambios en los cinco cuadrantes estudiados. Finalmente, una alternativa construida a partir de una tercera trayectoria, que combina la conservación de los bosques con el desarrollo de los medios de vida, implica la coordinación y consolidación de los intereses territoriales, en la que las concesiones comunitarias y el programa de incentivos forestales muestran los aportes que el manejo de los bosques puede tener a la economía local.

Una buena comprensión de estas etapas y las trayectorias de política y sus implicaciones en los cambios de uso de la tierra resultantes permite situar el proceso de gestión de la RBM en un contexto más amplio de reivindicaciones sobre derechos y recursos. Estas dinámicas muestran los riesgos de las propuestas y políticas que no concilian intereses y actores en torno a un modelo de gestión forestal sostenible. Por ejemplo, proponer el desarrollo del turismo en áreas actualmente gestionadas por las comunidades, junto con la pretensión de suspender la gestión comunitaria de los bosques, ignora sin tapujos que esa "protección total" ha fracasado en gran medida en la zona central de la RBM. De hecho, estas propuestas socavarían los acuerdos de gobernanza estables y eficaces que han garantizado la conservación de los bosques y el desarrollo de los medios de vida durante más de dos décadas.

Los escenarios en los que la degradación de los bosques, el conflicto social y la ingobernabilidad se refuerzan mutuamente han afectado durante mucho tiempo al sur de Petén y a la zona central de la RBM, incluidos dos parques nacionales. Los responsables de la toma de decisiones políticas tendrán que tener en cuenta esto, y la alternativa que supone el apoyo a una economía basada en la gestión de recursos y la gestión comunitaria de los bosques en la ZUM, a la hora de deliberar las propuestas para desarrollar la RBM, en busca de los mismos objetivos para los que se ha creado la RBM, incluida la preservación de los sitios del Patrimonio Mundial de la región.

Esta última sección busca reflexionar sobre trayectorias de política que continúan en la actualidad, en particular en relación a la tenencia de la tierra y el ordenamiento del territorio, especialmente en el sur, así como las propuestas de territorialización en todo el Departamento. 
El FYDEP definió seis áreas de colonización inducida para el departamento, siendo éstas: (1) Proyecto Santa Elena-La Libertad, con 3,000 $\mathrm{km}^{2}$. Sus tres frentes de trabajo eran La Libertad (529 fincas cooperativas), Mopán (60 fincas ganaderas) y la Sabana (153 fincas); (2) Proyecto Machaquilá, que comprende 3,000 km², entre Santa Elena y Poptún, para 1,400 fincas; (3) Proyecto San Luis, que comprende 3,000 km², entre Poptún y el Puerto Fluvial Modesto Méndez, para 1,400 fincas; (4) Proyecto Altar de Sacrificios, de $2,000 \mathrm{~km}^{2}$ en la bifurcación de los ríos Salinas y La Pasión, con grupos cooperativos; (5) Proyecto Sayaxché, con 3,000 km² para el asentamiento de cooperativas en orillas del río La Pasión; y (6) Proyecto San Fernando, en las márgenes del Alto Usumacinta, para asentar 9 cooperativas (Hurtado, 2010)

El proceso catastral siguió adelante posterior a la culminación del FYDEP y las regiones prioritarias fueron tomadas en cuenta.
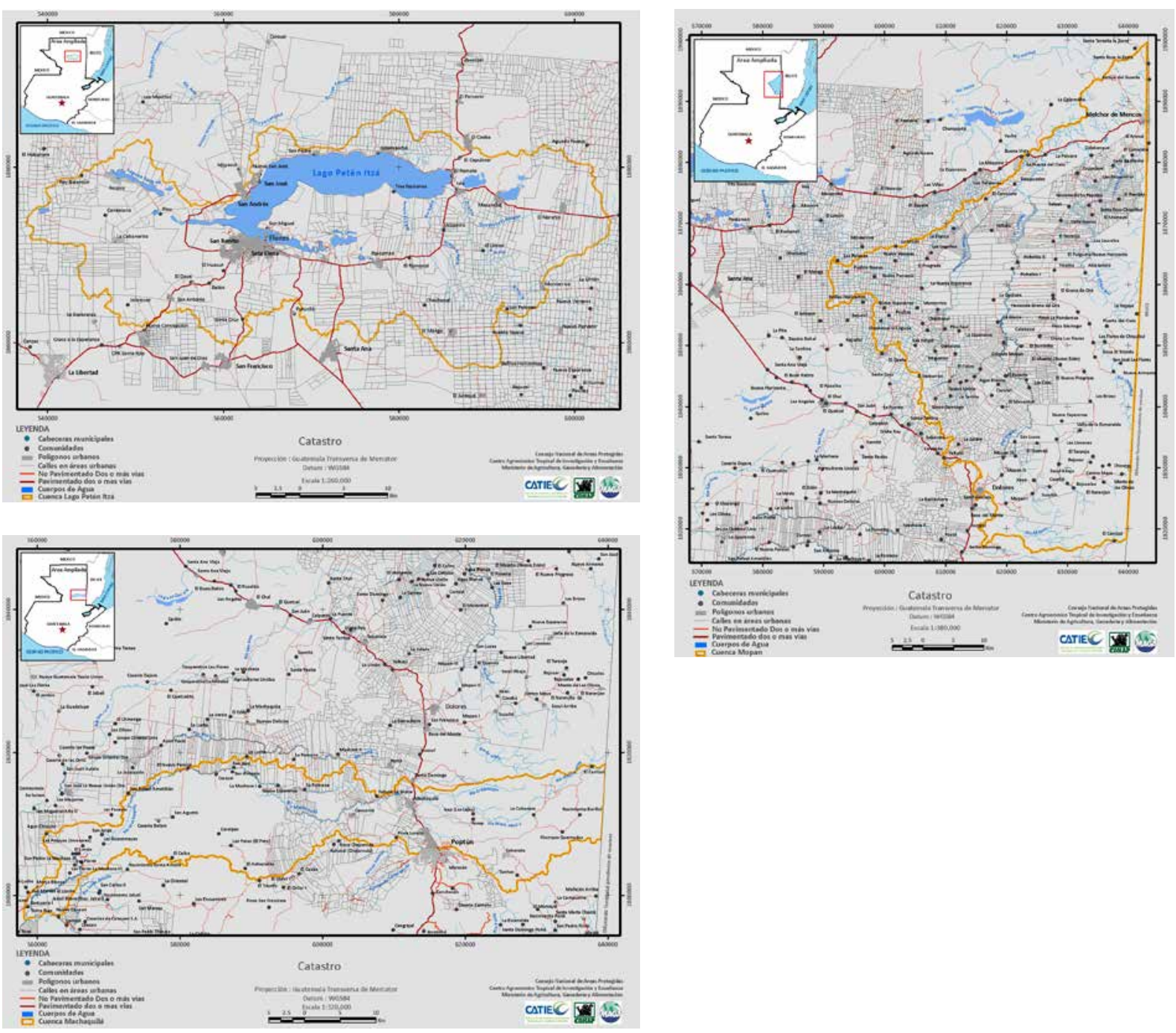

Figura 30. Continuidad del proceso catastral del FYDEP en regiones prioritarias de Petén

De izquierda a derecha cuenca del lago Petén Itzá, cuenca del río Machaquilá y cuenca del lago Mopán. 
Un ejemplo de seguimiento al tema catastral es el de ZAM-RBM:
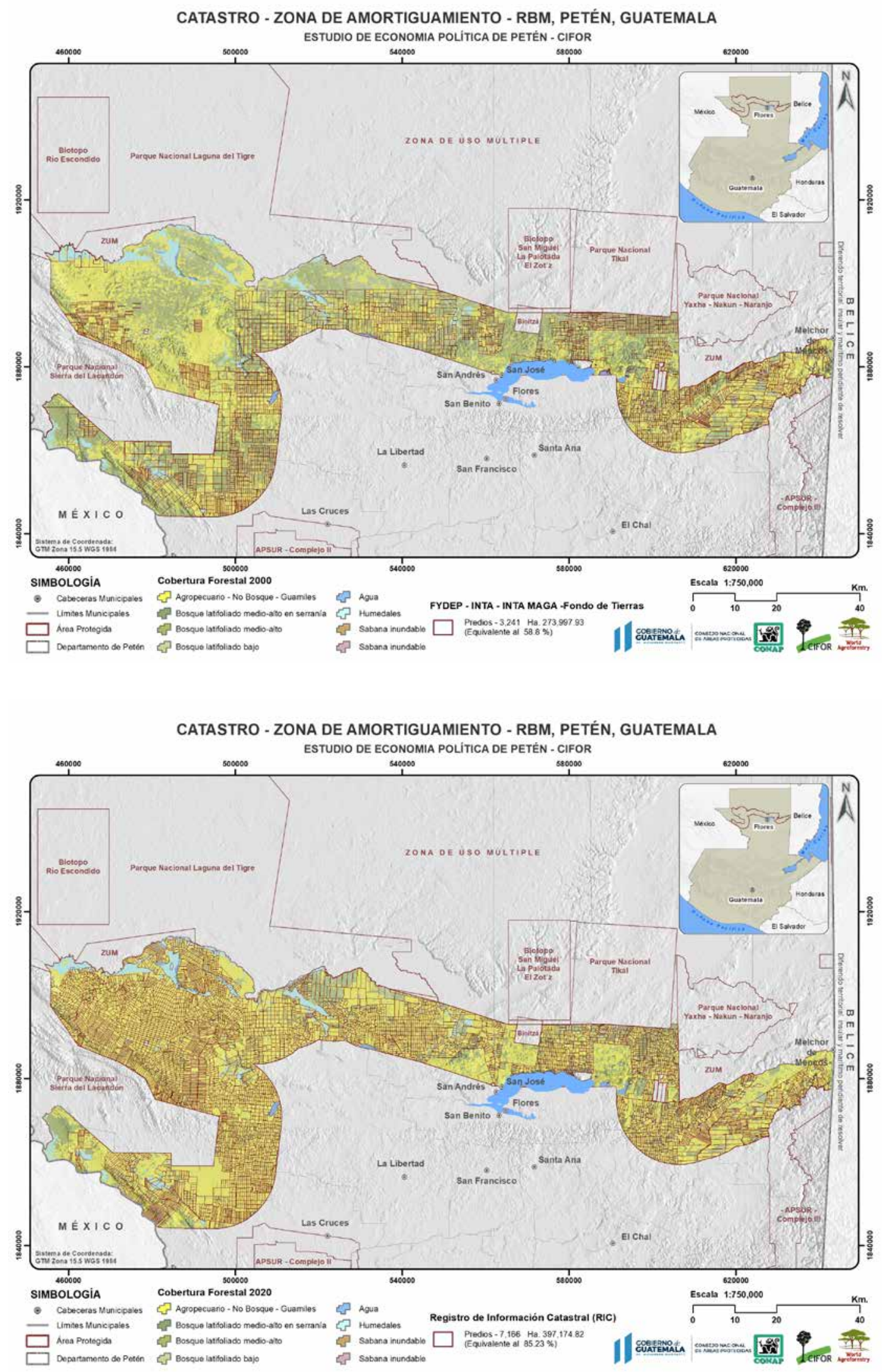

Figura 31. Continuidad del proceso catastral del FYDEP e INTA y culminación por parte del RIC en la ZAM-RBM 
Se considera que este proceso catastral iniciado por FYDEP y continuado por el Registro de Información Catastral (RIC) ha dado cierta estabilidad, bajo la premisa que el acceso a la tierra disminuiría la presión hacia el requerimiento de más tierras dentro de las áreas protegidas dentro de la RBM. Sin embargo, el comercio de tierras en Petén sigue activo y más bien como lo reportan algunos estudios, las dinámicas de tenencia han seguido un proceso de concentración de la tierra que es nuevo para la región pero que es común en otras regiones del país (Grunberg et al., 2013).

La región ha jugado objetivos diferentes en materia de desarrollo, y quizá es la región que mejor refleja los desafíos de coordinación a nivel sectorial, así como las prioridades del Estado. En el caso de Petén, el papel que mantiene como región productora de alimentos (por ej. maíz blanco, frijol, ganado) mantiene firme los objetivos de la política de colonización, aún más de treinta años de promover una agenda ambiental. Petén es el departamento con el mayor hato ganadero de Guatemala $(1,031,412$ cabezas de ganado reportadas para el año 2013) MAGA Petén-INE (Directorio ganadero de Petén) y es considerado el granero de Guatemala, ya que es el máximo productor de maíz blanco del país (un 18\% de la producción nacional). También es el mayor productor de Frijol de Guatemala (un 27\% de la producción nacional).

La territorialización prevista por el proyecto de colonización destinaba el sur de Petén como una zona ganadera y la mayor productora de granos básicos (maíz y frijol) para el consumo nacional (Hurtado, 2010).

Fue justificada en el mismo Decreto Ley por la necesidad de cubrir la creciente demanda de producción de alimentos, planteando que las tierras en la cuenca del río Usumacinta y sus afluentes "por sus condiciones ecológicas son las indicadas para este propósito", considerándolas "zona de reserva de producción de alimentos" (Hurtado, 2010).

Las políticas recientes, buscan promover un papel central de los gobiernos locales; por ejemplo, a través de la dotación de recursos a los consejos de desarrollo y las municipalidades, a través de FONPETROL. La asignación de recursos, entre otras razones ha promovido que surjan nuevos municipios. Esta región (actual municipio de La Cruces y la Libertad) es considerada una de las zonas de mayor producción de granos básicos. Su producción industrial y artesanal, establecida sobre algunos de los mejores suelos de Petén, es una de las más altas (unida a algunas zonas de San Luis y Sayaxché). 


\section{Conclusiones}

Este estudio busca promover una discusión sobre los principales cambios económicos-productivos a nivel de Petén. Los resultados muestran como intervenciones de política pública influyen en trayectorias diferentes de uso de la tierra con implicaciones diversas para la gestión de recursos y específicamente a nivel de la RBM.

Analizando acontecimientos de política claves, los cambios en las intervenciones del Estado y las respuestas de los actores en el territorio generan trayectorias diferentes con implicaciones para la gestión de los recursos y el manejo de la RBM. El análisis de estas trayectorias evidencia algunos de los desafíos de articular las necesidades de desarrollo con la gestión de recursos - con implicaciones para el uso de la tierra diferentes. Una primera trayectoria que plantea la conservación estricta a través de la categoría de parques nacionales ha tenido resultados diversos, para la gestión de recursos en zonas como los Parques Nacionales de Laguna de Tigre y Sierra de Lacandón, con serias dificultades: incremento de centros poblados, aumento de caminos y otras vías, así como la pérdida del bosque. Esta trayectoria es similar en las áreas que forman parte de los Complejos del Sistema de Areas protegidas del Sur de Petén, con una pérdida de cobertura de bosque y un aumento significativo de las áreas dedicadas a la agroindustria como por ejemplo de cultivos de palma africana o la papaya, así como la ampliación de ganadería. Finalmente, un tercer modelo a partir del programa de incentivos forestales y el sistema de concesiones forestales en la Zona de Usos Múltiples que buscan no sólo ampliar la participación de organizaciones de base comunitaria, el surgimiento de Empresas Forestales Comunitarias y suponen una articulación con la industria local.

El papel que las dinámicas socio-económicas tiene a nivel de los recursos y de la población se puede ver en la diversidad de industrias incluidas en el análisis que promueven sistemas de gestión de uso de suelo y los recursos diversos-la industria turística, la industria forestal, la agroindustria tienen implicaciones en la gestión de recursos diferentes - especialmente si tomamos en cuenta que tres cuartas partes del departamento se encuentran bajo alguna categoría de protección. Los resultados muestran la importancia que tienen estas industrias en la generación de ingresos, en algunos casos - apuntando también a la generación de empleos y la importancia de ciertos sectores para la inversión a nivel de hogar y comunidad. De igual manera es interesante resaltar que los aportes que estos ingresos generan a nivel de inversiones son significativamente mayores en comparación con los ingresos que se obtienen a nivel de los gobiernos locales -inclusive tomando en cuenta las tres fuentes de fondos analizadas. Esto apunta a la necesidad de profundizar las vías para promover una mayor coordinación sectorial y territorial. En este caso, este análisis busca aportar información a escala departamental que es clave para entender mejor las presiones y propuestas de desarrollo a nivel de Petén y la RBM. Este estudio apunta a la necesidad de profundizar en estos hallazgos para promover alternativas de desarrollo que concilien las necesidades de desarrollo con la conservación - de manera que articule la participación de las comunidades, la generación de oportunidades de desarrollo que incorporen de manera más clara el rol de la gestión de recursos a escala regional. 


\section{Bibliografía}

Bocci C, Fortmann L, Sohngen B, y Milian B. 2018. The impact of community forest concessions on income: an analysis of communities in the Maya Biosphere Reserve. World Development, 107, 10-21.

Bovarnick A, Fernandez-Baca J, Galindo J, y Negret H. 2010. Financial sustainability of pro- tected areas in Latin America and the Caribbean. Investment policy guideline. New York: UNDP (United Nations Development Programme); Ballston, Virginia: TNC (The Nature Conservancy).

[Central American Business Intelligence] CABI 2015. Estudio Socioeconómico del Cultivo de Palma de Aceite en Guatemala http://grupohame.com/wp-content/uploads/2017/02/Estudio-PALMACABI-Guatemala.pdf

Casasola O. 1968. Grandezas y Miserias del Petén. Ediciones Indiana. Guatemala.

Carr DL, Murtinho F, Pan WK, Barbieri A, Bilsborrow RE, Suchindran C, y Whitmore TM. 2008. A multilevel analysis of population and deforestation in the Sierra de Lacandon National Park, Peten, Guatemala. Documents D'analisi Geografica, 52, 49-67.

Chan RM, 2007. Informe final de la consultoría análisis de la situación del patrimonio cultural en la Reserva de la Biósfera Maya, Guatemala. Consejo Nacional de Áreas Protegidas, Direc- ción General de patrimonio cultural y natural- Instituto de Antropología e Historia, Asociación Tercer Milenio, Instituto de Agricultura, Recursos Naturales y Ambiente de la Universidad Rafael Landívar, International Resources Group Ltd. Guatemala.

Chan RM. 2009. Análisis de la situación del patrimonio cultural en la reserva de la biosfera Maya, Petén. En XXII Simposio de Investigaciones Arqueológicas en Guatemala, 2008 (editado por J.P. Laporte, B. Arroyo y H. Mejía), pp.235-244. Museo Nacional de Arqueología y Etnología, Guatemala (versión digital).

Chan RM. 2020. Retos en la conservación del patrimonio mundial en la pandemia: Experiencia de Guatemala. En Herbert, L. Quizoz, E. Vidargas, F. (Coord. Ed.) Patrimonio en emergencia: Alternativas locales a problemáticas globales. Secretaría de Cultura, Instituto Nacional de Antropología e Historia. Gobierno de México.

[CONAP] Consejo Nacional de Áreas Protegidas. 2001. Plan Maestro de la Reserva de Biósfera Maya. CONAP. Guatemala.

CONAP. 2015. Plan Maestro Reserva de la Biósfera Maya: Segunda Actualización. Tomo I. Consejo Nacional de Áreas Protegidas, Gobierno de Guatemala. 373p.

CONAP y WCS. 2015. Monitoreo de Gobernabilidad en la Reserva de la Biosfera Maya: Actualización a 2014 de la versión de Septiembre 2013. Petén, Guatemala.

CONAP y WCS. 2018. Monitoreo de la Gobernabilidad en la Reserva de la Biosfera Maya, actualización al año 2017. Con el apoyo de USAID y el USDOI/ITAP. 56 p.

Clark C. 2000. Land tenure delegitimation and social mobility in tropical Petén, Guatemala. Human organization, 59(4), 419-427.

Devine J. 2018. Community forest concessionaires: resisting green grabs and producing political subjects in Guatemala. The Journal of Peasant Studies, 45:3, 565-584.

Devine JA, Currit N, Reygadas Y, Liller LI, y Allen, G. 2020. Drug trafficking, cattle ranching and Land use and Land cover change in Guatemala's Maya Biosphere Reserve. Land Use Policy, 95, 104578. https://doi.org/https://doi.org/10.1016/j.landusepol.2020.104578

FAO. 2018. Análisis de mercado de las principales frutas tropicales. https://www.fao.org/3/ca5692es/ CA5692ES.pdf

FYDEP 1971. Memoria de Labores 1960 - 1970. Empresa Nacional de Fomento y Desarrollo de Petén. FYDEP: Santa Elena, Petén, Guatemala.

Grandia L, Schwartz, NB, Corzo A, Obando O, y Ochoa L. 2001. Salud, migración y recursos 
naturales en Petén: Resultados del módulo ambiental en la encuesta de salud materno infantil 1999. Guatemala: Instituto Nacional de Estadística y United States Agency for International Developmenty Measure/DHS.

Gnych S, Lawry S, McLain R, Monterroso I, y Adhikary A. 2020. Is community tenure facilitating investment in the commons for inclusive and sustainable development? Forest Policy and Economics, 111, 102088.

[GREPALMA] Gremial de Palmicultores de Guatemala. 2017. GREPALMA, 2016-2017. Anuario Estadístico https://www.grepalma.org/wp-content/uploads/2018/07/GREPALMA_Ints_Anuario_ Estadistico.pdf.

GREPALMA 2019. GREPALMA, 2018-2019. Anuario estadístico 72 p.

https://www.grepalma.org/wp-content/uploads/2020/04/Anuario_estadistico_2018_2019.pdf.

Grogan J, Free C, Pinelo G, Johnson A y Alegría R. 2016. Estado de Conservación de las Poblaciones de Cinco Especies Maderables en Concesiones Forestales de la Reserva de la Biósfera Maya. Ciudad de Guatemala: CATIE.

Herrera Arango, J. 2017. La tenencia de tierras colectivas en Colombia: Datos y tendencias (Vol. 203). CIFOR.

Herlilhy PH y Tappan TA. 2019. Recognizing indigenous miskitu territory in Honduras. Geographical Review, 109(1), 67-86.

Hodgdon B, Hughell D, Ramos V y Balas R. 2015. Deforestation trends in the Mayan Biosphere Reserve, Guatemala: 2000-2013. Washington, DC: Rainforest Alliance, World Conservation Society y Consejo Nacional de Áreas Protegidas.

Hurtado Paz y Paz M. 2010. Petén: ¿La última frontera?. Ciudad de Guatemala, Guatemala: Editorial de Ciencias Sociales

[IBC] Instituto del Bien Común. 2016. Tierras comunales: Más que preservar el pasado es asegurar el futuro. El estado de las comunidades indígenas en el Perú. Informe 2016. Lima: Instituto del Bien Común.

[Instituto Nacional de Estadística de Guatemala] INE. 2002. XI Censo Nacional de Población y VI de Habitación 2002. Gobierno de Guatemala.

INE. 2014. Encuesta Nacional de Condiciones de Vida. Gobierno de Guatemala.

INE 2018 XII Censo Nacional de Población y VII de Habitación 2018. Gobierno de Guatemala.

[Instituto Guatemalteco de Turismo] INGUAT 2012. Política Nacional para el Desarrollo Turístico Sostenible de Guatemala 2012-2022. Gobierno de Guatemala.

Larson AM, Barry D y Dahal GR. 2010. New rights for forest-based communities? Understanding processes of forest tenure reform. International Forestry Review, 12(1), 78-96.

Larson AM, Cronkleton PJ, y Pulhin JM. 2015. Formalizing indigenous commons: The role of 'authority'in the formation of territories in Nicaragua, Bolivia, and the Philippines. World Development, 70, 228-238.

[Ministerio de Agricultura y Ganadería] MAGA 2013. Perfil Comercial de la Papaya en Guatemala. Ministerio de Agricultura y Ganadería. Gobierno de Guatemala. https://precios.maga.gob.gt/ archivos/perfiles/Perfil\%20Papaya.pdf

MAGA 2016. El Agro en Cifras. Ministerio de Agricultura y Ganadería. Gobierno de Guatemala. https://www.maga.gob.gt/sitios/diplan/download/El-Agro-En-Cifras-2016.pdf

Melville, T. and Melville, M. 1971. Guatemala: the politics of land ownership. Free Press: New York.

Millner, N., Peñagaricano, I., Fernandez, M., \& Snook, L. K. (2020). The politics of participation: negotiating relationships through community forestry in the Maya Biosphere Reserve, Guatemala. World Development, 127, 104743.

Monterroso 2010. ¿De qué clase de turismo estamos hablando? Una mirada a los conflictos asociados con la expansión turística dentro de la Reserva de la Biosfera Maya en Guatemala. En Cañadas, E (Editor)Turismo y Conflictos Socio-ambientales en Centroamérica. Fundación Luciérnaga.

Monterroso Ibarra IM. 2015. Forest tenure reforms and socio-environmental consequences: case studies on Guatemala and Nicaragua. PhD Thesis. Universitat Autònoma de Barcelona.

Monterroso I, Sauls L, Davis A and Martí M. 2018a. Deforestation and Public Policy. Fundación PRISMA. 
Monterroso I, Stoian D, Lawry S, and Rodas, A. 2018b. Investigación y política sobre concesiones forestales comunitarias en Petén, Guatemala: Lecciones aprendidas y desafíos pendientes (Vol. 236). CIFOR.

Monterroso I, Cronkleton P, and Larson AM. 2019. Commons, indigenous rights, and governance. In Routledge Handbook of the Study of the Commons (pp. 376-391). Routledge.

Paudel NS, Monterroso I, and Cronkleton P. 2013. Organizaciones de segundo nivel y la democratización de la gobernanza forestal: reconciling concerns on timber legality and forest-based livelihoods. CIFOR. Indonesia.

Pellecer Robles G. 2010. Petén, FYDEP y yo: Historia de Petén.

Tobler MW, Anleu RG, Carrillo-Percastegui SE, Santizo GP, Polisar J, Hartley AZ, and Goldstein I. 2018. Do responsibly managed logging concessions adequately protect jaguars and other large and medium-sized mammals? Two case studies from Guatemala and Peru. Biological Conservation, 220, 245-253.

Radachowsky J, Ramos VH, McNab R, Baur EH y Kazakov N. 2012. Forest concessions in the Maya Biosphere Reserve, Guatemala: A decade later. Forest Ecology and Management, 268, 18-28.

[Rights and Resources Initiative] RRI 2015. Who owns the world's land? A global baseline of formally recognized indigenous and community land rights. https://rightsandresources.org/wp-content/ uploads/GlobalBaseline_web.pdf

RRI 2020. Estimate of the area of land and territories of Indigenous Peoples, local communities, and Afro-descendants where their rights have not been recognized. Technical Report. Retrieved from RRI website: https://rightsandresources.org/publication/estimate-of-the-area-of-land-andterritories-of-indigenous-peoples-local communities-and-afro-descendants-where-their-rightshave-not-been-recognized/

Schwartz, N. (1995). Re-privatización y privación: sistemas tradicional y contemporáneo de tenencia de la tierra en el Petén, Guatemala. Mesoamérica, 16(29), 215-232.

Schwartz, N. (1990). Forest Society: A social history of Peten. Guatemala. Philadelphia.

[Secretaria General de Planificación] SEGEPLAN 2013a. Diagnóstico Territorial de Petén. Guatemala. Recuperado de https://www.segeplan.gob.gt/downloads/PDI\%20Petén\%202032\%20Diagnóstico.pdf

SEGEPLAN 2013b. Plan de Desarrollo Integral de Petén. Guatemala. Recuperado de https://www. segeplan.gob.gt/downloads/PDI\%20Petén\%202032\%20PLAN.pdf

Sesnie SE, Tellman B, Wrathall D, McSweeney K, Nielsen E, Benessaiah K, y Rey L. (2017). A spatiotemporal analysis of forest loss related to cocaine trafficking in Central America. Environmental Research Letters, 12(5), 054015.

Escobedo-Aguilar, A. (2018). Análisis de Cadenas de Valor multi-sectorial 'Conectando Centroamérica'. Secretaria de integración económica centroamericana. CBI,CATIE.

Stoian D, Rodas A, Butler M, Monterroso I, y Hodgdon B. (2018). Forest concessions in Petén, Guatemala: A systematic analysis of the socioeconomic performance of community enterprises in the Maya Biosphere Reserve. CIFOR

Stoian D, Monterroso I, \& Current D. 2019. SDG 8: Decent work and economic growth-potential impacts on forests and forest-dependent livelihoods. Sustainable Development Goals: Their Impact on Forests and People, 237-78.

Sylvander N. 2021. 'Territorial cleansing' for whom? Indigenous rights, conservation, and state territorialization in the Bosawas Biosphere Reserve, Nicaragua. Geoforum, 121, 23-32.

Tillit G. 2020. Informe sobre la inversión pública ejecutada en los últimos años en el departamento de Petén a través del Consejo Departamental de Desarrollo CODEDE - PETEN. SEGEPLAN

UNEPET Agrar-und Hydrotechnik (AHT) y Asesoría y Promoción Económica, S. A. APESA. 1992. Plan de Desarrollo Integrado de Petén: Diagnóstico General de Petén (UNEPET). Tomo I. SEGEPLAN (Secretaría General de Planificación Nacional): Santa Elena, Petén, Guatemala. PDI, 1992.

WCS. 2018. La Huella Humana Mesoamericana 2000 - 2015. Petén, Guatemala. 

Los Working Papers de CIFOR-ICRAF contienen resultados preliminares o avanzados de investigaciones relativas a problemas de los bosques tropicales, que deben ser publicados de manera oportuna. Son generados para informar y promover el debate. Su contenido ha sido revisado internamente pero no ha pasado el proceso más largo de la revisión externa por pares.

Este documento busca aportar información socio ambiental que permita contribuir a comprender el papel cambiante de los bosques en la historia reciente de Petén. Analiza las dinámicas de cambio de uso de suelo que muestran diferencias a nivel de los espacios de la región, especialmente durante los últimos 20 años que lleva establecida la Reserva de Biósfera Maya (RBM) en el Departamento de Petén, Guatemala. Tiene como objetivo comprender los factores que han incidido en las dinámicas diferenciadas de uso de suelo en Petén, enfocándose en analizar los principales cambios económicoproductivos que implican trayectorias diferentes de uso de la tierra, así como sus implicaciones para la gestión de los recursos naturales a nivel de la RBM. Partiendo de una combinación de métodos cualitativos y cuantitativos y análisis de información geográfica busca aportar datos e información a los diversos procesos sobre la toma de decisiones en materia de recursos naturales. Los resultados apuntan a cambios en las trayectorias de política que tienen impactos en la percepción de los bosques, el uso de la tierra y la relación entre las poblaciones locales y los recursos naturales.

\begin{tabular}{|c|c|c|}
\hline CGIAR & $\begin{array}{l}\text { RESEARCH } \\
\text { PROGRAM ON } \\
\text { Policies, } \\
\text { Institutions, } \\
\text { and Markets } \\
\quad \text { Led by IFPRI }\end{array}$ & $\begin{array}{l}\text { El Programa de Investigación del CGIAR sobre Políticas, Instituciones y Mercados (PIM) realiza } \\
\text { investigación orientada a la acción para dotar a los responsables de tomar decisiones con la } \\
\text { evidencia necesaria para desarrollar políticas alimentarias y agrícolas que sirvan mejor a los } \\
\text { intereses de los productores y consumidores pobres, tanto hombres como mujeres. El PIM emplea } \\
\text { los recursos de los centros CGIAR y de numerosos socios internacionales, regionales y nacionales. El } \\
\text { programa es liderado por el Instituto Internacional de Investigaciones sobre Políticas Alimentarias } \\
\text { (IFPRI, por sus siglas en inglés). www.pim.cgiar.org }\end{array}$ \\
\hline
\end{tabular}

\begin{tabular}{|c|c|c|}
\hline \multirow[t]{2}{*}{ CGIAR } & $\begin{array}{l}\text { PROGRAMA DE } \\
\text { INVESTIGACIÓN SOBRE } \\
\text { Bosques, Árboles y } \\
\text { Agroforestería }\end{array}$ & $\begin{array}{l}\text { El Programa de Investigación de CGIAR sobre Bosques, Árboles y Agroforestería (FTA) es el } \\
\text { programa de investigación para el desarrollo más grande del mundo dedicado a destacar el papel } \\
\text { de los bosques, los árboles y la agroforestería para el desarrollo sostenible, la seguridad alimentaria, } \\
\text { y frente al cambio climático. CIFOR dirige el programa FTA en asociación con ICRAF, la Alianza } \\
\text { Bioversity International-CIAT, CATIE, CIRAD, INBAR y TBI. }\end{array}$ \\
\hline & & $\begin{array}{l}\text { La investigación del Programa FTA cuenta con el apoyo del Fondo Fiduciario del CGIAR: } \\
\text { cgiar.org/funders }\end{array}$ \\
\hline
\end{tabular}

\section{cifor-icraf.org}

\section{CIFOR-ICRAF}

The Center for International Forestry Research (CIFOR) and World Agroforestry (ICRAF) envision a more equitable world where trees in all landscapes, from drylands to the humid tropics, enhance the environment and well-being for all. CIFOR and ICRAF are CGIAR Research Centers. 